
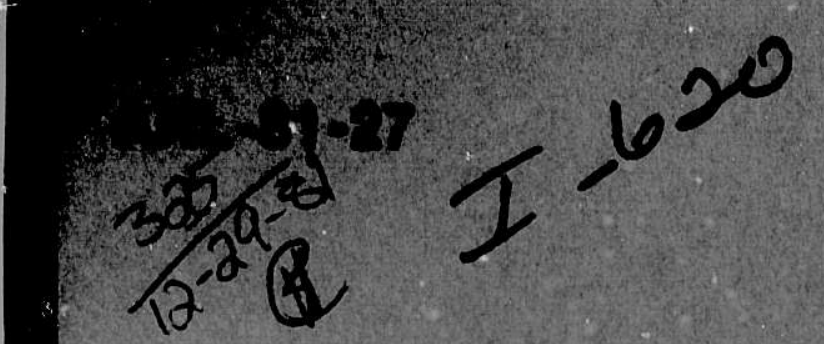

(1)

ANL-81-27

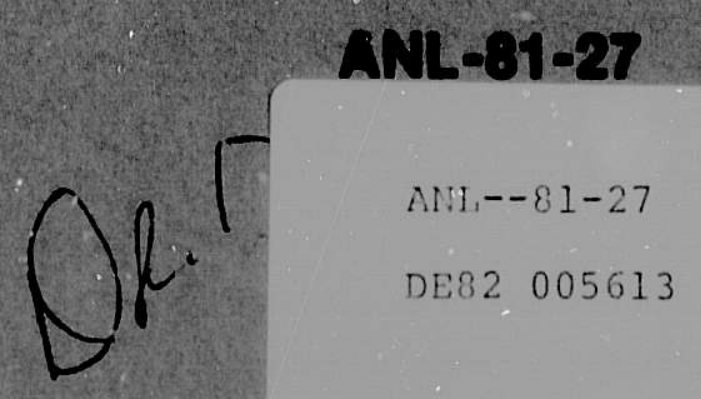

l

\title{
INTERIM REPORT OF BRITTLE-FRACTURE IMPACT STUDIES: DEVELOPMENT OF METHODOLOGY
}

by

Q. T. Reody, and M. J. Stoindlor

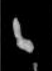

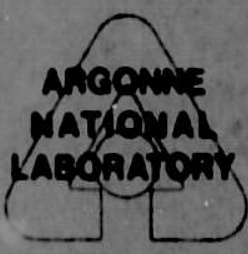

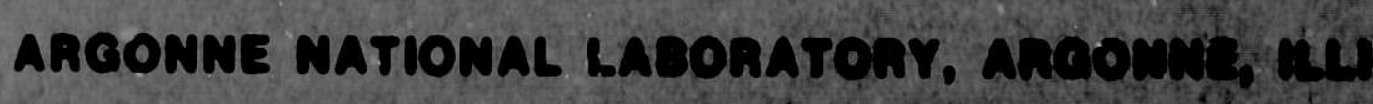
Proparod for tho?

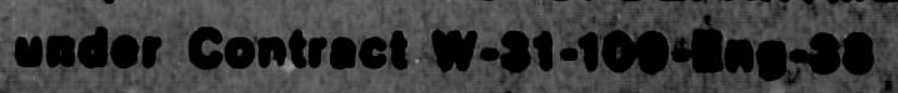



NOMENClATURE ............................. . . vii

ABSTRACT . . . . . . . . . . . . . . . . . . . . . . . . . . . . . . 1

SUMMARY . . . . . . . . . . . . . . . . . . . . . . . . . . 1

I. OBJECTIVES AND SCOPE . . . . . . . . . . . . . . . . . . . . . 2

II. BACKGROUND: SUMMARY OF TECHNICAL LITERATURE . . . . . . . . . . 3

A. Laboratory-Scale Tests . . . . . . . . . . . . . . 3

B. Large-Scale Tests on Canistered Waste Forms . . . . . . . . . 4

C. Fracture Mechanics . . . . . . . . . . . . . . . . 5

D. Surface-Energy Correlations . . . . . . . . . . . . . 8

E. Graphical Analysis on Lognormal Coordinates . . . . . . . . . 10

F. Modeling Impact Stresses . . . . . . . . . . . . . . 11

II . SUMMARY OF METHOdOLOGY . . . . . . . . . . . . . . . . . . . . 12

A. General Approach . . . . . . . . . . . . . . . . 12

B. Experimental Measurements . . . . . . . . . . . . . . 12

C. Correlation of Surface Area with Energy of Impact . . . . . . 13

D. Particle-Size Parameters . . . . . . . . . . . . . . 14

E. Materials Applicability . . . . . . . . . . . . . . 16

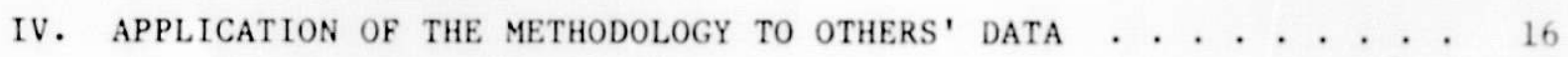

V. RESULTS AND DISCUSSION OF INITIAL ANL TESTS

ON VARIOUS MATERIALS . . . . . . . . . . . . . . . . . . . . . . 23

VI. ANL TESTS OF PYREX SPECIMENS UNDER

VARIOUS IMPACT CONDITIONS . . . . . . . . . . . . . . . 36

A. Description of Initial Experiments and Results . . . . . . . 36

B. Summary and Analysis of Data . . . . . . . . . . . . . . 40

VII. ENERGY, STRESS, ANJ TIME PARAMETERS . . . . . . . . . . . . . . . 47

APPENDIX A. STRESS, ENERGY, AND SURFACE AREA . . . . . . . . . . . . . 51

APPENDIX B. BINARY-CleAVAGE MOdEL PARAMETERS . . . . . . . . . . . . . 53

APPENDIX C. LOGNORMAL PARTICle Statistics . . . . . . . . . . . . . . 57

REFERENCES . . . . . . . . . . . . . . . . . . . . 63 


\section{LIST OF FIGURES}

No.

Title

Page

1. Summary of Fracture-Surface Energy Data from

Impact Tests and Slow-Compression Tests . . . . . . . . . . .

2. Frequency Curves of Measured New Surface Produced per Unit of Input Energy and Average Energy Concentration at Fracture for Single Particles in Slow-

Compression Tests . . . . . . . . . . . . . . . . . . . . . . . .

3. Data from [PNL-1975] on Increased Surface Area

for Canistered Glass Waste Form Plotted as a

Function of the Relative Kinetic Energy of Impact . . . . . .

4. Data from [PNL-1975] on Respirable Fraction for

Canistered Glass Waste Form Plotted as a Function

of the Relative Kinetic Encrgy of Impact . . . . . . . . . . .

5. Lognormal Analysis of Particle-Size Data Reported

by PNL for 0.61-m-dia Canister of Glass . . . . . . . . . . .

6. Lognormal Plot of Measured Particle-Size

Distributions for Various Impact Tests of

Simulated Waste Materials . . . . . . . . . . . . . . .

7. Lognormal Plots of Particle-Size Data for

for Three Impacted-Glass Compositions at

Four Impact-Energy Densities . . . . . . . . . . . . . . .

8. Lognormal Plot of Data Reported for Impacted-

Glass Specimens Receiving the Same Total Energy

But in a Varying Number of Impacts . . . . . . . . . . . . .

9. Lognormal Plots of Particle-Size Data for

Two Sizes of PNL Waste Glass ICM-11 . . . . . . . . . . . . . .

10. Bellows Chamber for Impacting Brittle Specimens . . . . . . .

11. Lognormal Plot of Particle-Size Data for Fracture

Particulates of Sevien Different Materials . . . . . . . . .

12. Size Data for Pyrex Cylinders Impacted at

$1.2 \mathrm{~J} / \mathrm{cm}^{3}$. . . . . . . . . . . . . . . . . .

13. Size Data for Fused Quartz Specimen No. 1

Impacted at $1.2 \mathrm{~J} / \mathrm{cm}^{3}$. . . . . . . . . . . . . .

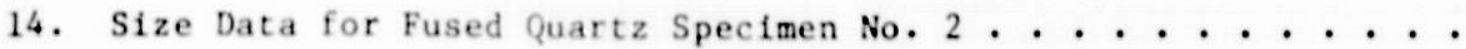

15. Size Data for Crystalline Quartz . . . . . . . . . . . 


\section{LIST OF FIGURES (contd)}

No.

16. Size Data for $\mathrm{UO}_{2}$ Specimen No. 1 . . . . . . . . . . . . . . . . 30

17. Data for $\mathrm{UO}_{2}$ Specimen No. 2, Including Mean Grain Size . . . . . 31

18. Size Data for Macor Specimen No. 1 . . . . . . . . . . . . . . . 32

19. Size Data for Two Macor Specimens Compared to Pyrex....... 32

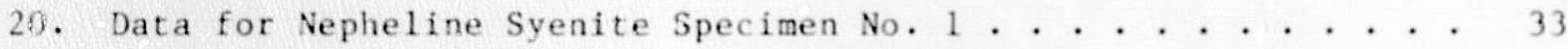

21. Size Data for Nepheline Syenite Specimen No. 2

Obtained by Core Drilling . . . . . . . . . . . . . . . . . . 34

22. Size Data for Sandstone Specimen Including

Size Distribution of Grains . . . . . . . . . . . . . . . . . . 35

23. Typical Pyrex Specimens Prepared for Impact Tests . . . . . . . 37

24. Internal Stress Patterns in Polarized Light for

Annealed, Unannealed, and Tempered Pyrex Specimeas . . . . . . 38

25. Size Distributions of Fracture Particulates from

Annealed, Unannealed, and Tempered Pyrex Cylinders . . . . . . 39

26. Particle-Size Distributions of Particulates

from Side Impacts of 38-mm-dia Pyrex Specimens

Impacted with $1.2-\mathrm{J} / \mathrm{cm}^{3}$ Energy Density to

Examine Test Reprodicibility . . . . . . . . . . . . . . . . . 40

27. Particle-Size Distributions of Particulates

from Side and End Impacts of Solid Pyrex

Cylinders at Energy Density $0.41 \mathrm{~J} / \mathrm{cm}^{3}$ to

Examine Test Reproducibility . . . . . . . . . . . . . . . 41

28. Pyrex Cone-Ended Cylinder . . . . . . . . . . . . . . . 42

29. Typical Pyrex Particles in Various Size Ranges

that Result from Impact Tests... . . . . . . . . . . . . . 46

30. High-Speed Motion Pictures of the Impact

Fracture of Pyrex Specimens . . . . . . . . . . . . . . . .

31. Some Glass and Canistered Specimens Proposed

for Future Free-Fall and Drop-Weight Tests . . . . . . . . . . 50

B-1. Binary-Cleavage Mode of Brittle Fracture

in Standard Strength Tests . . . . . . . . . . . . . . 53

B-2. Successive Stages of Binary Cleavage in a Cube . . . . . . . 54 
No.

B-3. Compressive Fracture of a Cube . . . . . . . . . . . . . 55

C-1. Lognormal Paraneters for Fractional Surface Area

$P_{S}(D)$ and Shape Factor $a(D)$ as a Function of

Particle-Size Parameter $u=\left(\ln D-\ln D_{g}\right) \div \ln \sigma_{g} \cdot . \cdot . \cdot . \cdot 62$

\section{LIST OF TABLES}

No.

Title

1. Lognormal Parameters of Impact Fracture

for Three Different Glass Compositions . . . . . . . . . . . . .

2. A Summary of Lognormal Parameters Derived by Graphical Analysis of the Particle-Size Distributions of Seven Materials Impacted at $1.2 \mathrm{~J} / \mathrm{cm}^{3}$. . . . . . . . .

3. Lognormal Paraneters of Impact Tests on 38-mm-dia Pyrex Cylinders with $\mathrm{V}_{0}$ Normalization . . . . . . . . . . . . . 43

4. Lognormal Parameters of Impact Tests on 38-mm-dia Pyrex Cylinders with the Aibitrary $2 \mathrm{~V}(8 \mathrm{~mm})$ Normalization . . . 44

5. Preliminary Correlatious of Lognormal Parameters with Energy Density for Diametral Impacts of 38-mm-dia Pyrex Cylinders . . . . . . . . . . . . . . . . 
NOMENCLATURE

v11 
NOMENCLATURE

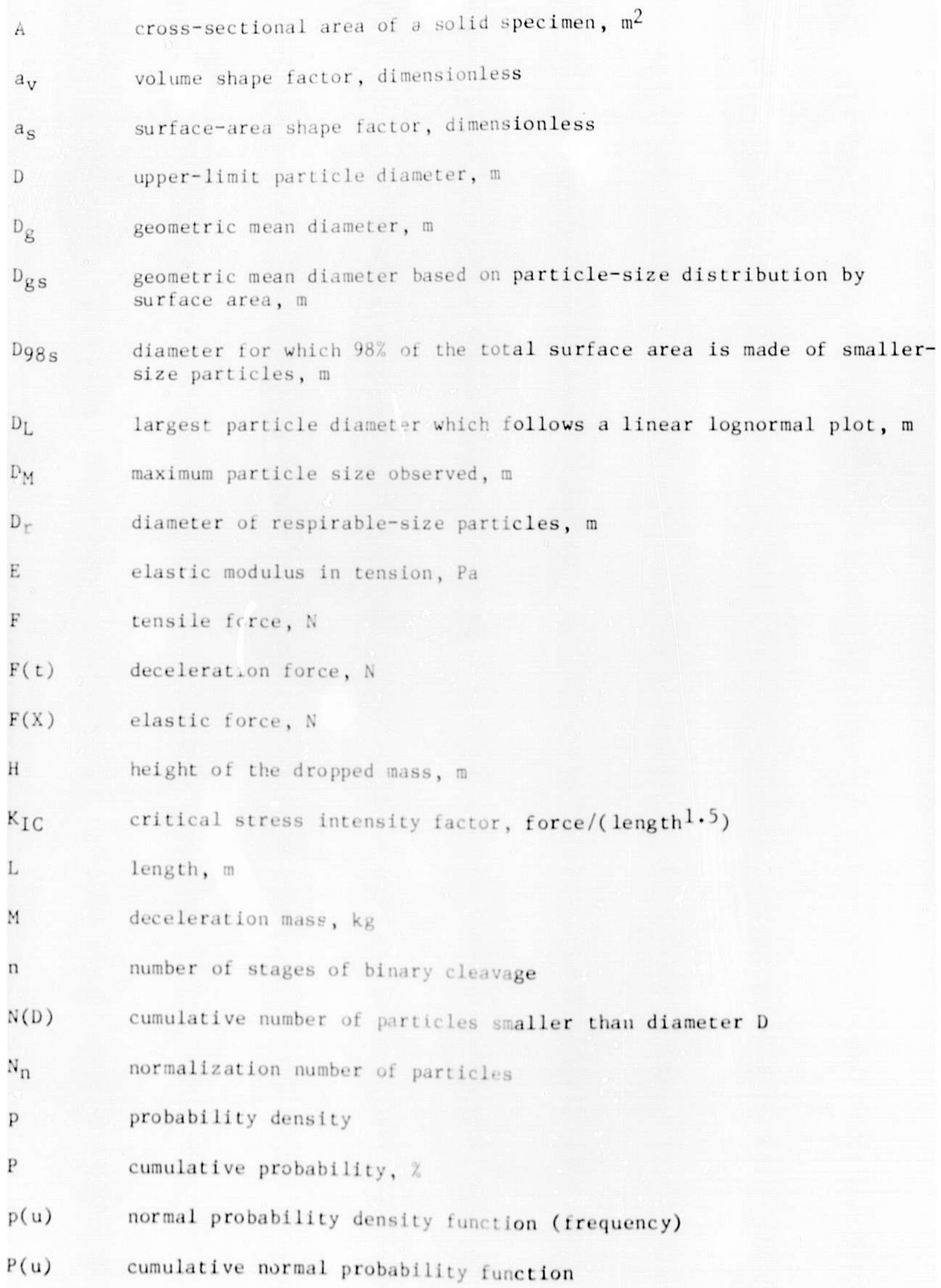


NOMENCLATURE. 


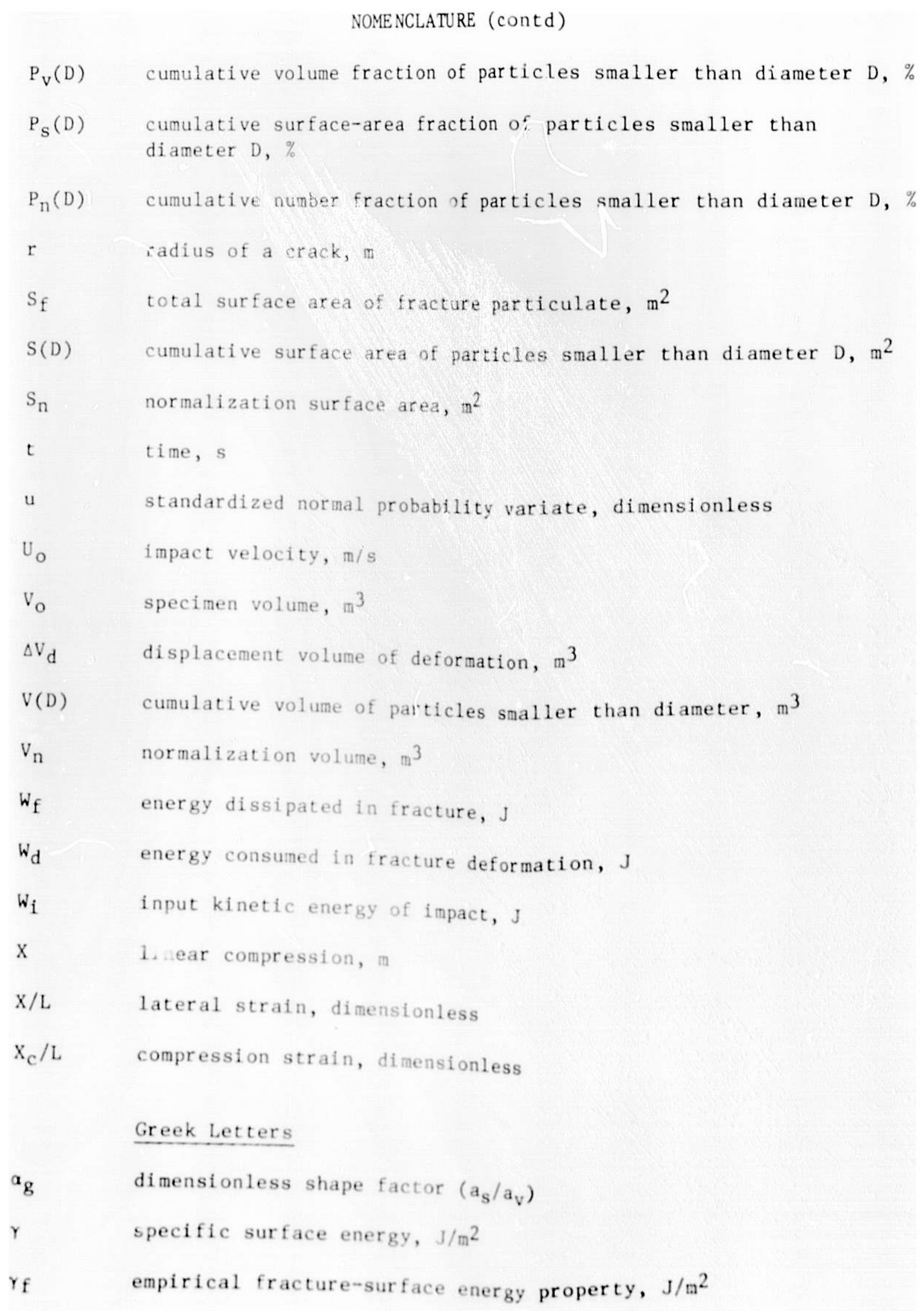




\section{NOMENCLATURE (cont d)}

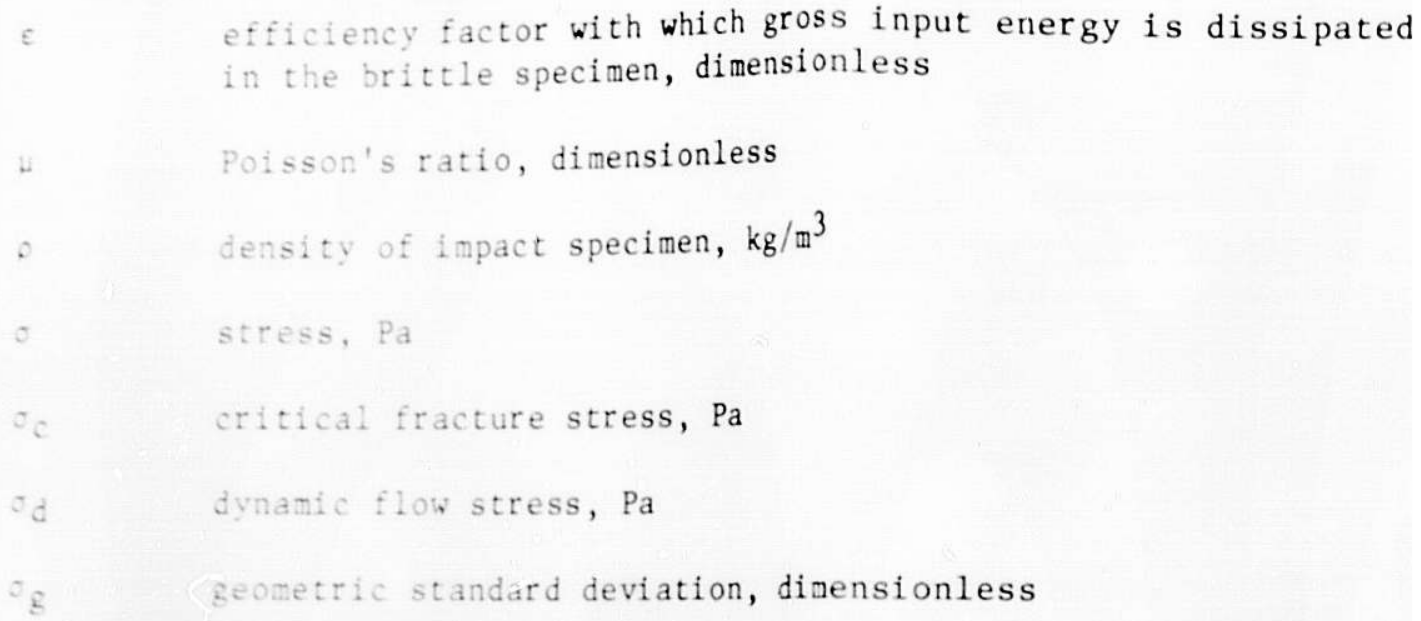


INTERIM REPORT OF BRITTLE-FRACTURE IMPACT STUDIES:
DEVELOPMENT OF METHODOLOGY

\author{
by \\ W. J. Mecham, L. J. Jardine, R. H. Pelto, \\ G. T. Reedy, and M. J. Steindler
}

ABSTRACT

\begin{abstract}
A comprehensive methodology for characterizing the results of impact fracture of brittle waste forms is presented, and its use illustrated by application to available particle-size data obtained in impact tests of various materials. The respirable-size fraction and the total surface area of the fracture particulates are the major criteria for characterization. Particle-size distributions were all found to be characterized approximately by the two parameters of the lognormal probability function (the geometric mean diameter $D_{g}$ and the geometric standard deviation $\left.v_{g}\right)$. These results are explained in terms of the brittle-fracture process as it is described in the technical literature. The methodology appears promising both for standardized evaluation of the impact strength of various solid-waste compositions, either vitreous or crystalline, and for studying the deformation of canistered waste forms in scale-model tests.
\end{abstract}

\title{
SUMMARY
}

The characterization of the fracture caused by mechanical impacts on vitrified or crystalline nuclear waste forms is likely to be a requirement for licensing these waste forms--a condition which has not been previously imposed on glass or ceramic technologies. The respirable fraction and the total surface area of the fracture particulate are the major criteria in this characterization.

From a review of the technical ilterature on fracture mechanics, it appears that brittle-fracture theories and data have been applied only to quasi-static loading, as used for tests of structural strength. However, important features of 1 mpact fracture must be dealt with by physical mechanics, elastic stress analyses, dimensional analyses, small-particle statistics, and engineering studies related to the crushing of minerals. After reviewing and combining these topics, a comprehensive brittle-fracture model was developed. The major elements are: (1) the lognormal particle-size distribution, (2) the relation between the surface area of the fracture particulate and the elastic energy dissipated in the brittle-fracture process, and (3) an approximate axisymmetric stress-distribution model for the solid body experiencing the application of deceleration force. This methodology was initially applied to others' data obtained for both small-scale laboratory tests and largescale waste impact tests. Further application was made to particle-size data obtained in ANL laboratory-scale tests on a range of different inaterials-vitreous, crystalline, and conglomerate. In all cases, the lognormal particlesize distribution was linear and provided a good approximation of experimental 
measurements of the fracture particulates, for all particle sizes below about 4000- $\mu \mathrm{m}$ dia. This size range includes, of course, the respirable size (about $10 \mu \mathrm{m})$ and typically more than $90 \%$ of the total fracture surface area. For conglomerates and for certain crystalline materials with large grains and well-defined grain boundaries, there is an influence of grain size on the size distribution of the fracture particulate; i.e., two lognormal distributions are observed, one for intergranular fracture and one for transgranular fracture.

Lognormal size analysis has been facilitated by computer assistance in determining the error estimates of the lognormal size parameter (the geometric mean diameter $D_{g}$ and the geometric standard deviation $\sigma_{g}$ ) by linear regression analysis of the lognormal straight-line plots made by computer graphics. Typical percent standard deviations are: $\mathrm{D}_{\mathrm{g}}, \pm 30 \% ; \sigma_{\mathrm{g}}, \pm 6 \%$; respirable fraction, $\pm 50 \%$. Similar computer assistance is planned in future tests to verify the effects of body size, velocity, and time dependence on the dynamic stress distributions. Such tests are required to establish the scaling laws for impacts under realistic accident conditions.

For the 11mited small-scale tests made thus far (prior to October 1980), the methodology described can characterize the relative resistance to fracture for various waste compositions under development. Reproducible fracture behavior is observed in impacts, but not in quasi-static tests, because the formation of large numbers of particles results in statistical averaging for the multiple stages of the binary cleavage mode of fracture in brittle materials. The effects of impact velocity and deceleration time are minor over a wide range of impact conditions of practical interest, principally because kinetic energy is apparently nearly completely converted into elastic strain energy stored in the material before extensive fracture has taken place. The methodology appears promising as a wasis tor experimental designs of standardized impact tests of materials and for scale-model tests of canistered waste forms.

This report summarizes our brittle fracture work done through the end of FY 1980. Further development of methodology and testing is being done in FY 1981 bur is not reported here.

\section{OBJECTIVES AND SCOPE}

Solid forms of radioactive waste from nuclear power applications may be subjected to mechanical impacts occurring normally or accidentally during process operations or during loading, interim storage, or transportation. It is important to understand the resistance of these brittle waste forms to dispersion caused by such impacts. This brittle-fracture study has the specific aim of characterizing dispersion resistance in terms of two observable quantities: (a) the in rease in total surface area avallable for leaching or dispersal and (b) the amount of respiratle-size particulate formed, i.e., less than about $10-\mu \mathrm{m}$ dia. This characterization must be reliable and useful for a practical range of waste forms and impact scenarios. Initial emphasis has been on vitrified or crystalline materials of a relatively small particle size that $\mathrm{might}$ be encapsulated in a metal-matrix waste form. Alternatively, such characterizations can be used for comparative evaluation of fracture resistance as a property of waste compositions under development. Laboratory-scale tests are being designed to establish the material properties 
and the scaling laws of brittle-impact behavior in an effort to reduce the number of expensive, large-scale 1 mpact tests needed for impact characterization.

A useful impact-characterization method must provide a sound basis for interpreting empirical measurements of material properties and impact-test data. It must be applicable to a wide range of impact conditions and alternative waste-form designs, including various waste compositions and composite waste-form packages. In addition, the method must establish impact-fracture resistance not only in terms of empirical data on developmental waste forms, but also more explicitly and generally in terms of the material properties which ultimately determine the resulting lognormal particle-size distribution, surface areas, and stresses in impact.

In this report, the comprehensiveness and potential applicability of the proposed general approach are illustrated by (1) an analysis of the particlesize distributions from a diverse set cf experimental impact tests, including literature data on realistic, full-scale tests of waste-glass canisters, (2) a summary of systematic test results showing the use of the proposed lognormal model of brittle fractures, and (3) an outline of a dynamic stress analysis and scaling laws. Appendices provide mathematical details of the modeling.

The results of our previous work on the impact fracture of brittle waste forms can be found in [MECHAM-1979, -1980] and in the Chemical Engineering Division (CEN) Fuel Cycle Programs Quarterly Progress Reports ANL-80-61, ANL-80-76, ANL-80-92, and ANL-80-114. This report summarizes the status of the methodology development through Sept mber 1980. Work done in FY 1981 is not reported here.

\section{BACKGROUND: SUMMARY OF TECHNICAL LITERATURE}

The prime objective of this study is to characterize how materials representative of solid forms of radioactive wastes (some of which are highly concentrated) from nuclear power applications and from the military production of plutonium respond to mechanical impacts. These materials are expected to be, in most cases, brittle oxide ceramics or glasses with physical properties similar to those of commercial laboratory glassware and refractories. The actual waste forms are expected to be large glass monoliths enclosed in steel canisters; the practical concern is not the structural strength of the glasslike material, but its potential for atmospheric dispersion and human contact. Therefore, the fracture surface area (avallable for water leaching) and the amount of small particles (of respirable size) generated on impact are the criteria for characterization. The approach presented here is based on the classical physical mechanics and engineering of brittle materials. The concerns of this study are related to current development of brittle waste forms at the Pacific Northwest Laboratory (PNL) and the Savannah River Laboratory (SRL) and the anticlpated future needs of the Nuclear Regulatory Commission in the technology assessment of :adioaclive waste fixation.

\section{A. Laboratory-Scale Tests}

Laboratory-scale 1mpact tests on small, unencapsulated monolithic specimens of simulated waste materials, both glass and Portland cement formulations, 
have been reported by SRL and PNL, as discussed in detail below and in Section IV. In these impact tests, cylindrical specimens of the order of $5-\mathrm{cm}^{3}$ volume are impacted in a drop-weight device between hardened steel surfaces. The particles fracture into irregular particles of a wide range of sizes, and empirical particle-size data are obtained by standard sieving methods down to a size of about $40 \mu \mathrm{m}$. Because sieving is not effective for particles of respirable size ( $(10-\mu m$ dia), other methods (for example, sedimentation) have been used to supplement sieve analysis [PNL-1979D]. Empirical measurements were made of total particle surface area, using the gas-adsorption BET technique. These results are usually plotted on linear coordinates as weight percent smaller than stated size vs. nominal sieve mesh size, or as surface area vs. gross input kinetic energy of impact. The principal results [PNL1979C, SRL-1976] are these:

1. Particle-size distributions by mass fractions are not linear, and mass fractions are smaller (for equal size ranges) for the particles of smaller size.

2. Eor a given energy input, different materials show different, but similarly shaped, plots of partici-size distributions, indicating a difference of impact resistance. Stronger materials show smaller mass fractions of particles throughout the neasured size range. The fraction of particles of respirable size increases as the input energy increases for a given naterial.

3. The total surface area of the fracture particulate increases with increasing impact energy. The increase in surface area is approximately directly proportional to energy input up to an impact energy of about $100 \mathrm{~J} / \mathrm{cm}^{3}$ of specimen, with less efficient surface formation at higher energies. The increase in surface area per unit of material is different for different types of glass. Soda-lime glass showed surface formation of about. $2.2 \times 10^{-3} \mathrm{~m}^{2} / \mathrm{J}$ within the proportional range of impact energy (up to about $100 \mathrm{~J} / \mathrm{cm}^{3}$ ) and about $1.1 \times 10^{-3} \mathrm{~m}^{2} / \mathrm{J}$ for higher impact energies (from 100 to about $\left.1400 \mathrm{~J} / \mathrm{cm}^{3}\right)$.

4. For a given total energy input, less fracture results when the energy is delivered in a single blow than when delivered in smaller energy increments. ihis is shown by the difference in particle-size distributions for the two cases. The plotted size distributions in these tests have similar slope, regardless of whether the impact was to a monolith or to a prefractured specimen, and regardless of the number of blows (up to 8 ).

Empirical data such as the above can be used to characterize dispersion resistance for particular materials and impact conditions. However, more extensive empirical studies of specific materials, sizes, shapes, energies, etc. are needed to formulate a more general model with which dispersionresistance can be quantified and predicted.

\section{B. Large-Scale Tests on Canistered Waste Forms}

One-half- and 1/6-scale model tests of canistered waste glasses were made [PNL-1975] for simulated waste glass in free-fall 1mpact tests at up to $129-\mathrm{km} \cdot \mathrm{h}^{-1}(80-\mathrm{mph})$ velocity. Empirical size data (including respirable size) and surface areas were measured. The principal results were: 
1. No significant effect of devitrification or of temperature (up to $425^{\circ} \mathrm{C}$ ) on particle-size distribution or surface area was found.

2. Canister failures occurred sometimes at impacts of $64 \mathrm{~km} \cdot \mathrm{h}^{-1}$ $(40 \mathrm{mph})$ but nearly always at $129 \mathrm{~km} \cdot \mathrm{h}^{-1}(80 \mathrm{mph})$, and these failures were only very fine cracks through which few, if any, glass particles escaped.

3. Impact on a corner produced the largest fraction of small particles.

4. The canistered specimens were not true monoliths because of cracking caused by thermal stresses upon cooling; however, the preimpact surface area was only a few percent larger than the geometric surface area of the monolithic form. At the 80-mph impact, fracture surface areas were on the order of 40 times the original surface area.

5. Particle-size distributions down to $5 \mu \mathrm{m}$ were obtained by sieving, but because sieving to such small size is difficult, it was not possible to evaluate the error in respirable size due to possible particle losses.

6. Because of insufficient test data, the scaling laws (the effects of size and shape) could not be determined. However, it was observed that the fraction of glass broken to particulate size correlated better with impact velocity than did the absolute amount of broken glass for cylinders of different volume.

7. A review of the literature (pre-1975) on brittle-fracture methodology showed conflicting theories and an absence of relevant data.

In a later test, a full-scale (about 2000-kg) canister of s:mulated waste glass was dropped $7.6 \mathrm{~m}$ on an essentially unyielding surface. Sieve andysis (down to $44 \mu \mathrm{m}$ ) was made of the resulting particles. Sedimentation analysis showed the respirable (less than $10 \mu \mathrm{m}$ ) fraction was $0.14 \%$ by welight [PNL1979B, -1979C, -1979D].

These results illustrate the type of empirical characterization that is required for waste canisters. However, the results could not be interpolated or extrapolated to other cases, since quantitative parameters and scaling laws were not available. In Section IV below, the empirical data reported in both the laboratory and the engineering-scale tests reviewed above are reanalyzed in terms of the parameters used in the characterization methodology presented in this report.

\section{Fracture Mechanics}

Fracture mechanics is the general application of the methods of physics and engineering to the fracture of brittle materials. Our concern is the class of solld materials that fracture only in the brittle mode; that is, they deform in the elastic mode right up to the point at which fracture cleavages occur in the body. Plastic deformation is insignificant for this type of material. Elastic theory and dimensional modeling are applicable, as are a number of methods used in determining the strength of materials. However, because of the nonequilibrium and time-dependent aspects of brittle 
fracture, certain properties (such as the energy of surface formation) defined by thermodynamic equilibrium cannot be used. Also, because of the cleavage discontinuities which occur in the body undergoing fracture, certain mathenatical formulations based on continuous media cannot be applied to crack propagation and the fracture process itself.

The leading concept of brittle fracture in fracture mechanics is the Griffith criterion for crack propagation and brittle fracture. This concept, which has been revised from its original, more ambiguous form, has been useful in relating stress, energy, and flaws in a brittle body to the conditions for fracture. In this concept, a monolithic brittle body fractures under applied force when microcracks (flaws, or gross discontinuities of the atomic lattice) propagate by plane cleavage. The cleavage occurs when the stress distribution is such that increase of crack surface area is accoinanied by a greater release of elastic strain energy (stored in the material) than the energy requirements to form the new fracture surface. Tensile cracking is a process that relieves stress and "gives up" the associated elastic energy, and it is also a process that "uses" energy (in particular, the energy to break atomic bonds). The geometry of this concept is 1llustrated in the diagram below for a three-dimensional body shown in two conditions of tensile loading ( $A, B$ ) under which a penny-shaped microcrack develops and propagates.

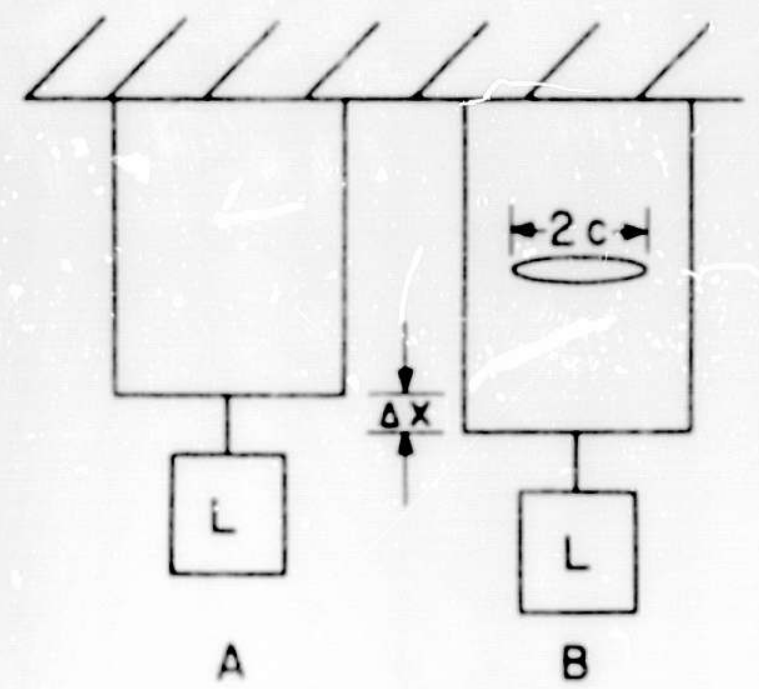

Condition A is obtained by placing the load $L$ on the uncracked body and allowing it to extend due to the force of the load. Condition A is defined in terns of rhe tensile stress within the body and its total energy. Condition B is obtained in a sinilar manner except an internal, penny-shaped crack of radius c is present prior to loading. Because the crack reduces the loadbearing area, it is observed that the load further extends the body by $\Delta X$ relative to condition $A$. The total free energies of states $A$ and $B$ are now compared. First, the crack introduces new surface energy, adding to the total energy. Second, fewer atomic bonds must support the same applied load, increasing the strain energy within the body. Third, the potential energy of the load is decreased since its position has changed by $\triangle X$ [1.ANGE]. The mathematical statement of the Griffith criterion for brittle fracture defines the critical fracture stress $o_{c}$ in terms of the assumed crack geometry, 
which may vary. For the above illustration of a circular plane crack normal to the tensile-force axis in an infinite body, the critical stress is given by

$$
\sigma_{c}=\left[\frac{\pi}{2\left(1-\mu^{2}\right)}\right]^{1 / 2}\left(\frac{\gamma E}{r}\right)^{1 / 2} \doteq\left(\frac{\gamma E}{r}\right)^{1 / 2}
$$

where $\mathrm{E}$ is the elastic modulus in tension $(\mathrm{Pa}), \mathrm{r}$ is the radius of the crack $(\mathrm{m}), \mu$ is Poisson's ratio (about 0.2 for glass), and $\gamma$ is the specific surface energy $\left(\mathrm{J} / \mathrm{m}^{2}\right)$ [LANGE]. The Griffith concept of brittle fracture is consistent with observations that 1 !) fracture occurs, in practice, at stresses far below those consistent with theoretical stress requirements for material cleavage. (2) practical strength depends on the flaws in the material, and (3) fracture is a catastrophic rate process that releases energy in a sort of chain reaction. Griffith originally associated yith the theoretical (thermodyramically reversible) surface tension of solids. The irreversible nature of brittle fracture makes the surface-energy quantity $r$, so defined, not measurable in the fracture process. ${ }^{\star}$ Therefore, the Griffith concept as expressed in Eq. 1 can be transformed to a form without $\gamma$ by defining an empirical "critical stress intensity factor" $K_{I C}$ [A. EVANS], where

$$
\gamma=K_{I C}^{2} / 2 E
$$

Therefore Eq. 1 is expressed as

$$
\sigma_{C}=K_{I C}\left(\frac{1}{2 r}\right)^{1 / 2}
$$

This factor $K_{I C}$ has dimensions of force/(length 1.5$)$. Althcugh it is difficult to perceive these dimensions for a basic parameter of a physical process, $K_{I C}$ is useful in enpirical tests of structural strength, which are appropriately concerned with initial crack prupagation, and not with the fracture process itself. For waste forms, however, the concern is not with structural strength, but with the extent of fracture as it affects dispersibility. The practical measures of dispersibility are surface area (presented to possible leaching) and particle sizes (amounts of respirable saterial). Thus, based on these criteria, the threshold conditions for fracture are the formation of negligible surface area and of a negligible amount of particles smaller than about $10 \mu \mathrm{m}$.

It is now generally understood [HASSELMAN] that the Griffith fracture criterion for critical stress, involving global energy instability (for the body as a whole), constitutes a necessary but not a sufficient condition for immediate fracture. The Griffith critical stress (based on the thermodynamically reversible surface specific energy $\gamma$ ) is the lowest stress level required for slow crack growth, i.e., the fatigue limit. There is, however, a higher critical stress level corresponding to the local stress sufficient for immediate crack propagation and f:acture.

\footnotetext{
ॠ A simple model 11lustrating this is shown in Appendix A.
} 
Fracture mechanics has been developed mainly for application to slow (or static) compression leading to brittle fracture of structural materials; however, it applies in more practical ways to impact fracture, i.e., dynamic loading. In static loading (slow compression), the applied force sufficient for fracture depends on flaws in the body, and the time of cleavage at a given loading is unpredictable, because of the slow rate of growth of small cracks. In impact compression, very high force loads can be applied by elastic compression in a very short time (the order of microseconds), and if fracture does not occur in that time, the body will rebound and the elastic stress will be relieved in an equally short time without fracture at all. For example, the velocity of propagation of fracture of soda-lime glass was measured at $600 \mathrm{~m} / \mathrm{s}$ when the crack reached a $2-\mathrm{mm}$ length, and about $1400 \mathrm{~m} / \mathrm{s}$ at the $25-\mathrm{mm}$ length; the maximun crack-propagation velocity was $1500 \mathrm{~m} / \mathrm{s}$, about $40 \%$ of the acoustic velocity [DOREMUS]. For a cylindrical body of diameter and length of $4 \mathrm{~cm}$, and an effective crack velocity of $1000 \mathrm{~m} / \mathrm{s}$, the cracking time required is $2 \times 10^{-5} \mathrm{~s}$ or $20 \mathrm{us}$. The compression or rebound time for a Pyrex cylinder of this size could be as short as 11 us, so it could escape fracture. Such time effects are discussed later; the point here is that impact loading, in contrast to slatic loading, can occur with very high elastic stresses throughout a brittle body before enough time has elapsed for fracture to occur by the "weakest link" process according to the Griffith fracture criterion.

Because of the very high impact stresses throughout the body, once a crack propagates, stress waves travel through the body and trigger fracture throughout the body, in an explosive chain reaction of successive binary cleavage stages. A simple geometrical model for this is shown in Appendix B.

With regard to the Griffith criterivn, however, there is elastic strain energy associated with the peak elastic stress in an imparted body undergoing fracture. This energy is stored throughout the body and is dissipated in the collisions of the particles produced by fracture. It is this strain energy which correlates so well as a simple proportionality to the total surface area of the fracture particulate. This empirical correlation does not seem to have been anticipated by the present. state of fracture mechanics; it is described below.

\section{Surtace-Energy Correlations}

E. L. Piret and associates at the University of Minnesota have conducted experiments on the crushing of Pyrex glass and crystalline quartz, with respect to correlating energy input with the fracture surface area produced.

Smal1-scale tests were made using (1) slow-compression crushing, (2) single-impact fracture (with a pendulum device), and (3) multiple impacts. An impact calorimeter was used to make an energy balance on the input kinetic energy actually dissipated in brittle fracture (and not otherwise). The results [PIRET-1950, -1961, -1962] are shown in Fig. 1. The data plotted are identified as follows: 


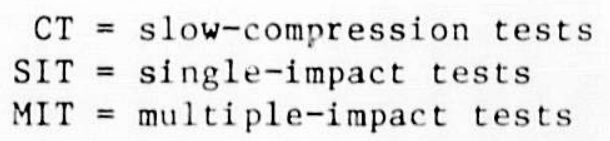

The empirical fracture-surface energy property, $\gamma_{f}$, is the ratio of (a) the energy $W_{f}$ actually dissipated in fracture of the brittle material to (b) the total surface area of the solid particulate formed by fractire. This surface area was measured by the BET gas adsorption technique. (Size distributions of the fracture particulate were not reported.)

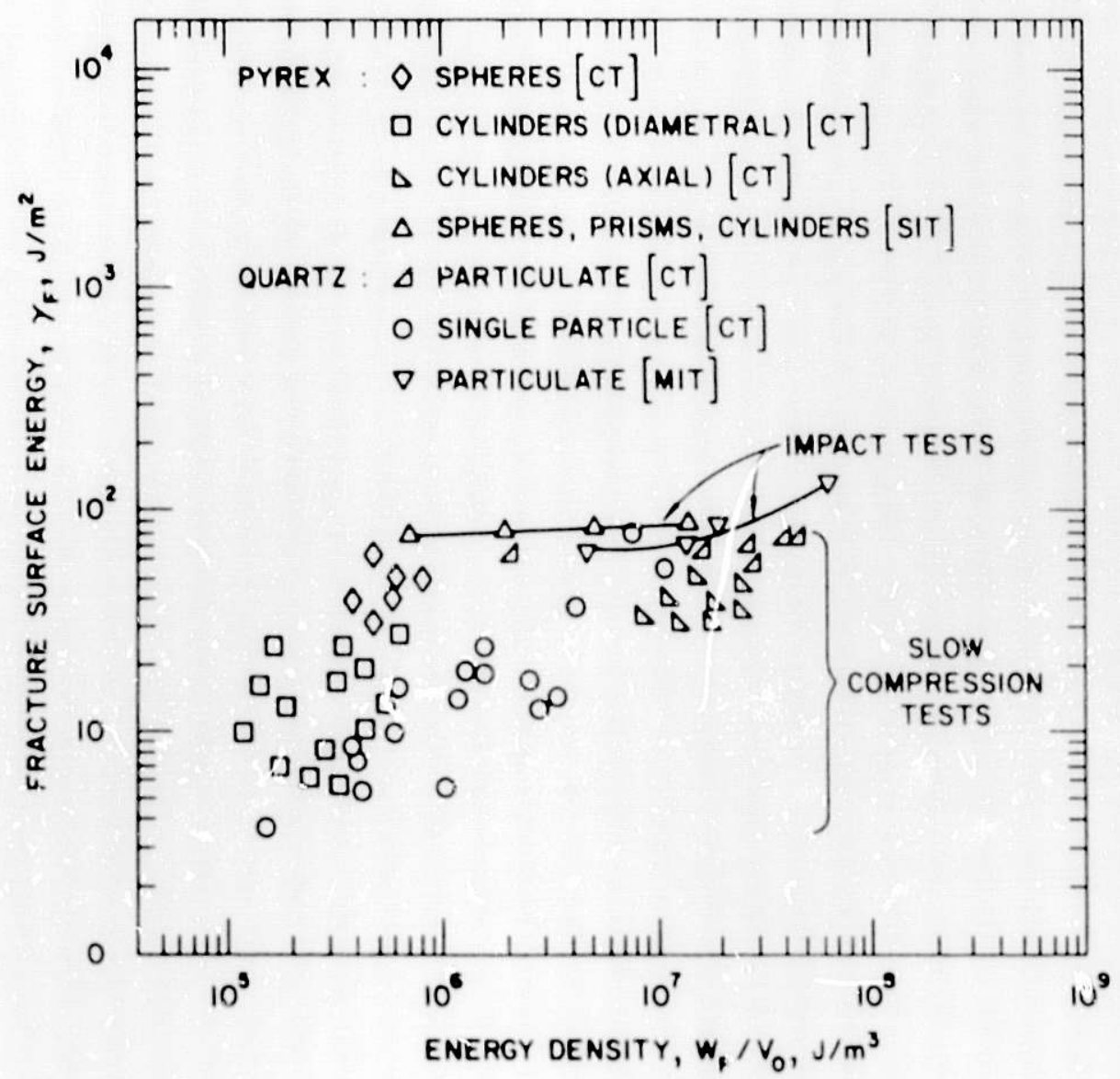

Fig. 1. Summary of Fracture-Surface Energy Data

from Impact Tests and Slow-Compression Tests [PIRET-1950, -1961, -1962].

$\left(W_{\mathrm{f}} / \mathrm{V}_{\mathrm{o}}\right.$ is equal to the energy absorbed per unit of brittle material.)

As shown in the figure, the values of $\gamma_{f}$ vary widely for slow-compression tests but are nearly constant at about $77 \mathrm{~J} / \mathrm{m}^{2}$ for impact over a $24-\mathrm{fold}$ range of energy density. For the calorimeter measurements, 0 to $50 \%$ of the input kinetic energy was dissipated in ways other than brittle fracture. At higher energies, some deformation of the metal components was observed. 
In these impact tests, no significant differences in $\gamma_{f}$ were found between Pyrex glass and crystalline quartz nor for different shapes of specimens having about the same size (about $1 \mathrm{~cm}^{3}$ ). Very little difference in the value of $\gamma_{f}$ was found between impact of inonoliths (in single impacts, SIT) and impact of prefractured specimens (particulates in multiple impact tests, MIT).

In the earlier work on slow compression, [PIRET-1950] made a number of tests on standard brittle specimens and reported variability of the values of stress causing fracture and variability of the observed value of $\gamma_{f}$. This is reflected in the probability frequency diagrams of the test results shown in Fig. 2, The frequencies of $\gamma_{f}$ values are shown in the upper diagram and the frequencies of average energy density vaiues (corresponding to average stress) in the lower diagram. These frequencies exhibit a "mode" and a "variance."
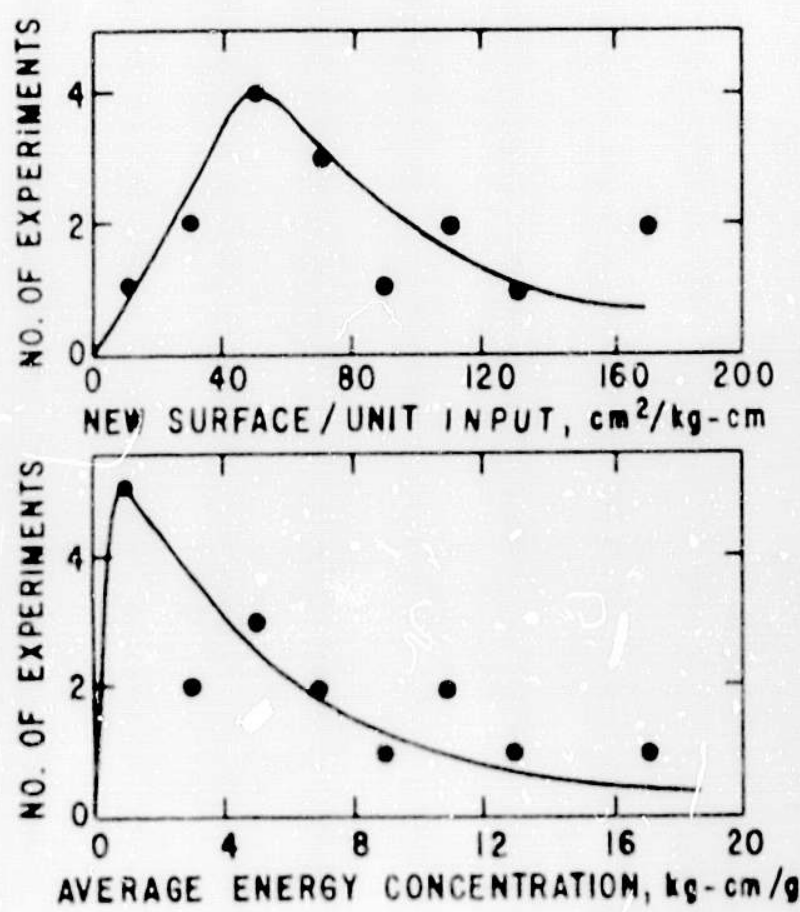

Fig. 2 .

Frequency Curves of Measured New Surface Produced per Unit of Input Energy and Average Energy Concentration at Fracture for Single Particles in Slow-Compression Tests [PIRET-1950]. (Note the inits for energy; $1 \mathrm{~kg}-\mathrm{cm}=0.098 \mathrm{~J} ; 1 \mathrm{~g}$ ot quartz has a volume of $2.65 \mathrm{~cm}^{3}$.)

The variability of fracture surface results indicated in Figs. 1 and 2 for slow-compression crushing is not found in impact tests; this variability results from statistical averaging, which occurs because the brittle body is not cleaved in two but is fractured into a very large number of particles of variable sice. Thus, the results of impact fracture can be described by statistical methods as described below and 1llustrated in Appendices B and C. Although the uniformity cannot be described by the methods of continum mechanics (described above in Section II-C), they can be described statistically by a probability distribution (described below in Section II-E).

\section{E. Graphical Analysis on Lognormal Coordinates}

Most solid particulates formed by 1mpact fracture have size distributions that can be plotted as lognormal probability distributions [HERDAN]. Lognormal 
probability graph paper has special coordinat's such that data representing particle-size fractions are plotted as straight lines, when the particlesize distributions (as a whole) can be characterized by the two parameters of the cumulative lognormal probability function: $D_{g}$, the mass median or geometric mean diameter, and $\sigma_{g}$, the geometric standard deviation. Linear graphics allow convenient interpolation and extrapolation of size measurements beyond the limited size range of particular sieving measurements. Also, the lognormal parameters ( $D_{g}$ and $\left.\sigma_{g}\right)$, once determined from sieving data, can be used to calculate the size fractions (for any particle size) for the distributions by mass, by surface area, and by particle number [HERDAN]. The mathematics of the lognormal probability distributions are outlined in Appendix $C$. The application to the physical process of brittle fraciure is illustrated by the simplified fracture model shown in Appendix B.

Lognormal graphical analysis of fracture particulates is incorporated in the methodology for characterization of brittle fracture in experimental tests, as described in Sections IV, V, and VI of this report.

F. Modeling Impact Stresses

In the above review of the state of the art of the characterization of impact fracture of brittle materials, the basic roles of elestic stress and elastic strain energy were outlined. These roles (in contrast to the brittlefracture process itself) are well-known formulations involving the theory of elasticity, continuum mechanics, dimensional analysis, and scale-modeling theory [LANGHAAR].

Furthermore, deformation by plastic flow (typical for metals) is also characterized by dimensioi $I$ nodeling, tecause plastic deformation is governed by the characteristic dynamic flow stress $\sigma_{d}$, a property of the material. That is,

$$
\mathrm{W}_{\mathrm{d}}=\sigma_{\mathrm{d}} \Delta \mathrm{V}_{\mathrm{d}}
$$

where $W_{d}$ is the energy consumed in plastic deformation and $\Delta V_{d}$ is the displacement volume of the deformation. ( $\Delta \mathrm{V}_{\mathrm{d}}$ is simply the volume of material "moved," when the original configuration and the deformed configuration are compared) [SHAPPERT].

In the case of brittle fracture, stress is also the driving force, as in plastic deformation. However, there is a time dependence (discussed above) in brittle fracture which is not involved in plastic flow. (Plastic flow is instantaneous when the plastic flow stress is reached.) The time factor is addressed in Section VII.

In the following sections of this report, a methodology is outlined for characterizing the impact fracture of brittle materlals, with an emphasis on the determination of the respirable fraction and total surface area of the fracture particulate. Results of initial impact tests are presented, together with an interpretation of them according to the methodology. 


\section{SUMMARY OF METHODOLOGY}

\section{A. General Approach}

In the review of the state of the art of impact fracture of brittle materials, we saw that the theoretical methods of physical mechanics are inadequate for dealing with the radically nonequilibrium brittle-fracture processes or for dealing with the discontinuous stress fields involved in brittle fracture. In addition, the many results based on empirical measurements in brittle-fracture experiments appear to be specific for the certain materials, body sizes, and impact conditions employed. However, the characterization methodology presented here appears capable of meeting the objectives stated, by means of a combination of three different empirical relationships: (1) the relation of elastic strain energy stored in the material to the stress which exists in the material prior to fracture and which is the driving force for fracture; (2) the direct proportionality of surface area formed in particulate fracture to the elastic energy dissipated in the brittle material during the short time of the fracture process; and (3) the use of lognormal particle statistics to characterize the total surface area and the complete particle-size distribution (including the respirable fraction) of the fracture particulate. It will be shown that parameters identified in these three modes of analysis are related to each other and to measurements made by standard experimental techniques.

\section{Experimental Measurement:3}

Drop-weight and free-fail impacting devices are used to impact specimens of various sizes and shapes, under a practical range of impact conditions. The impact kinetic enirgy is the thost important parameter for determining the extent of fracture, and this is readily estimated for the test devices; energy is the product of mass and the distance of free fall. Also important is the time for the deceleration mass to cone to rest; this time determines the peak stress and the time available for cracks to propagate before elastic rebound can (possibly) occur. In practice, this time can be measured by high-speed photography, strain gauges, and acoustis transducers. It can also be caiculated approximately using elastic mechanics. The velocity of impact does not seem to be important, except as it is involved with input kinetic energy and deceleration time.

Standard sieving analysis is practical for size measurements down to a nominal diameter of about $60 \mathrm{\mu m}$. Optical and electron microscopic measurements can be made for smaller sizes. For insoluble materials, Coulter counter analysis can be used for particles as small as about $0.5 \mu \mathrm{m}$ and can be extended upwards to particle sizes of about $400 \mu \mathrm{m}$ (and very likely to an order-of-magnitude larger particles). There are other sizing methods, e.g., sedimentation, which are available but have not been used in our work to date. The differences among these methods lie in overall cost, measurable particle-size ranges, the amount of material needed to make accurate measurements, and the different ways in which the characteristic linear particle size is defined for the irregular shapes of particles produced by brittle fracture. Based on these criteria, the Coulter counter method seems to be the most favorable general method for initial studies, and it has an advantage over sieving in that it can be used for small test specimens (probably as sma11 as $\left.1 \mathrm{~cm}^{3}\right)$. 
Surface areas of fracture particulates are measured by the standardized BET gas adsorption technique. Calibration requires an absolute standard and considerai on of the surface properties of the material. Shape factors determined for surface areas by the BET measurement may be checked against the factors determined by other methods (microscopic, Coulter counter, sieving) to most accurately characterize the geometric surface and total surface area. The comparisons of shape factors are also part of the calibration required for BET measurements. The accuracy of BET measurements is limited by the total surface area of the sample particulate. About $1 \mathrm{~m}^{2}$ or more of sample area is required in practice. This entails a minimu impact energy of about $100 \mathrm{~J}$, which also implies a specific minimum energy density for a given specimen volume.

Geometric surface areas can also be estimated by microscopic measurements and this is being pursued.

The present state of development of this fracture characterization methodology is indicated by the results of its application to experimental data, as described in the following three sections of this report. A current development, not reported here (except for the lognormal analysis given in Appendix (), is a computer program for lognormal graphical display of data and the use of linear regression to assess the errors in the lognormal size parameters. A users' manual for this program (code-named ANALOG) is planned.

C. Correlation of Surface Area with Energy of Impact

The use of an impact alorimeter and BET surface-area measurement to establish an impact strength property of $\gamma_{\mathrm{f}}=77 \mathrm{~J} / \mathrm{m}^{2}$ for Pyrex glass and crystalline quartz was described in Section II above [PIRET-1962]. The general relation involves these parameters:

$$
\begin{aligned}
& S_{f}=\text { total surface area of the fracture particulate, } m^{2} \\
& W_{i}=i n p u t \text { kinetic energy of impact, } J \\
& \gamma_{\mathrm{f}}=\text { fracture surface energy, } \mathrm{J} / \mathrm{m}^{2} \\
& \varepsilon=\text { efficiency factor with which gross input energy is } \\
& \text { dissipated in the brittle specimen }
\end{aligned}
$$

The basic relation is

$$
S_{f}=\frac{\varepsilon W_{1}}{r_{f}}
$$

where $W_{1}$ is measurea by the height $H(m)$ of the deceleration mass $M(\mathrm{~kg})$ and the impact velocity $U_{0}(\mathrm{~m} / \mathrm{s})$. That is,

$$
\mathrm{W}_{1}=1 / 2 \mathrm{MU}_{\mathrm{O}}^{2}=9.8 \mathrm{MH}
$$


where the deceleration mass 1 s the mass of the specimen itself, as in freefall tests,

$$
\frac{W_{j}}{V_{0}}=\frac{\rho}{2} U_{0}^{2}=9.8 \rho \mathrm{H}
$$

where $V_{0}\left(\mathrm{~m}^{3}\right)$ is the volume of the specimen and $\rho$ its density $\left(\mathrm{kg} / \mathrm{m}^{3}\right)$.

Equation 3 shows the scaling law for impact-energy density for a body in free-fall: the impact-energy density and the impact velocity are the same for all bodies of the same material density falling the same distance, independent of body size. This assumes there is no significant air resistance, a condition which is true for most cases of practical interest.

In Section VII of this report the application of the methodology to stresses is discussed. Here, the important point is that stresses arise from the deceleration of mass $M$, which results in the reduction of velocity from the value at contact $\left(\mathrm{U}_{\mathrm{O}}\right)$. If the body is brought to full arrest (velocity $\mathrm{U}=0$ ) before fracture, all the impact-energy density $\mathrm{W}_{1} / \mathrm{V}_{\mathrm{O}}$ is converted to elastic energy, which in turn determines the levei of elastic stress in the body, regardless of size. Such a condition would make fracture independent of velocity.

If we rewrite Eq. 1 in terms of energy density, we have

$$
\frac{S_{f}}{V_{O}}=\frac{\varepsilon}{\gamma_{f}} \frac{W_{i}}{V_{0}}
$$

This is a relation in which the measured fracture surface area $\mathrm{S}_{\mathrm{f}}$, expressed as the ratio $S_{f} / V_{0}$, is independent of body size, for a given energy density.

Piret's impact calorimeter was used to determine $\varepsilon$ and to show the remarkable constancy of $\gamma_{f}$, i.e., $Y_{f}$ is independent of energy density for Pyrex and quartz. For most practical conditions encountered in these impact testa, $0.5 \leqslant \varepsilon>1.0$. The absence of dents in the metal surfaces of the impact device serves to validate this apprcximation. Stress waves may well be important for triggering the chain reaction leading to particulate fracture, but they do not dissipate a significant amount of input energy (for velocities of practical interest). Inertial effects are similarly not significant for conditions of practical interest.

\section{Particle-Size Parameters}

From standard sieving or Coulter counter analysis, the particle-size distribution is obtained as the mass fraction of all particles less than some linear size D. These mass fractions are equated to the cumulative lognormal probability function for the distribution of the size-D particles by the volume (or mass) of material, which we symbolize by $\mathrm{P}_{\mathrm{V}}(\mathrm{D})$. The cumulative mass fraction (as a function of the upper-1imit size D) is equal to the cumulative 
volume fraction for a given material. By plotting these empirical values of $P_{v}(D)$ on lognormal probability coordinates, it can be determined whether the empirical particle-size distribution is described by lognormal probability; and, if so, a graphical determination is made of the two parameters of the lognormal function: the geometric mean diameter $D_{g}$ and the geometric standard deviation $\sigma_{g}$ [HERDAN]. When these parameters are known, the mass fraction of any size D can be calculated, independent of the range of measured sizes, based on the assumption that the particle sizes are lognormally distributed. The graphical analysis is especially convenient in that data following the lognormal size distributions can be plotted as straight lines, thus facilitating the interpolation and extrapolation to particles of respirable size.

Another convenient feature of this analysis is that, once $D_{g}$ and $\sigma_{g}$ are determined, the distribution of particle surface area and the distribution of particles by number can also be found. This allows calculation and plotting of values of the surface-area distribution $P_{S}(D)$ and the particlenumber distribution $P_{n}(D)$ for any $D$.

Typically, the measured values of the cumulative mass fraction do not follow the linear lognormal $\mathrm{P}_{\mathrm{V}}(\mathrm{D})$ distribution for the small number of the very largest particles produced in impact fracture, that is, particles of diameter larger than about $4 \mathrm{~mm}$. In graphical analysis, $\mathrm{D}_{\mathrm{L}}$ is used to designate the largest particle size which follows the linear lognormal plot. From tests made thus far on material representative of brittle waste forms, this upper-limit size $\mathrm{D}_{\mathrm{L}}$ is sufficiently large so that the corresponding value of the cumulative surface-area fraction, $P_{S}\left(D_{L}\right)$ is greater than $95 \%$. Thus, the portion of the fraction particulate that is described by the lognormal size parameters $\mathrm{D}_{\mathrm{g}}$ and $\sigma_{\mathrm{g}}$ includes more than $95 \%$ of the total fracture surface. It also includes all the particles of respirable size, $D \leq 10 \mu \mathrm{m}$, since Coulter counter measurements down to about 3 um show straight-line lognormal plots. The mass (or volume) fraction of particles of respirable size is given by the lognormal function $\mathrm{P}_{\mathrm{V}}(10 \mu \mathrm{m})$ and is found either graphically or by calculation. This is illustrated in the followirg sections on application of this methodology.

The ratio of fracture surface area $S_{f}$ to total body volume $V_{0}$ shown in Eq. 4 above, as related to input energy density $W_{i} / V_{0}$, cán also be expressed in terins of the lognormal size parameters:

$$
\frac{S_{f}}{V_{O}}=\frac{a_{g} g_{g}}{D_{g}}
$$

where $\alpha_{g}$ is a dimensionless shape factor that must be determined empirically (e.g., by measurements of the two lognormal parameters and the BET surfacearea). In preliminary tests made thus far, $\alpha_{g}$ appears to be a constant for a given material, independent of particle size.

The mathematical basis and details of the lognormal size parameters are given in Appendix C. A computer program has been developed for computer graphics and for error analyses of the respirable fraction and of the values of $D_{g}$ and $\sigma_{g}$ determined from the measurement data. 
The lognormal size parameters, in summary, are $\mathrm{D}_{g}, \sigma_{g}, \alpha_{g}$, and $\mathrm{D}_{\mathrm{L}}$. Correlations of these parameters with material properties and with impact conditions are illustrated in later sections on application of the methodology. These parameters, together with $\gamma_{f}$ and $\varepsilon$, provide for a complete characterizat: on of impact fracture of brittle waste forms, according to the criteria established by the nbjectives stated previously.

E. Materials Applicability

Based on reports of Piret and Herdan, as well as the review of the literature on fracture mechanics, the characterization parameters discussed above are expected to be adequate to describe the impact fracture behavior of all monolithic homogeneous brittle materials similar to structural grades of commercial glasses and ceramics. In addition, based on the data of Piret and PNL, the methodology should be applicable to the impact fracture of prefractured specimens and even of particulates, so long as the materials are truly brittle.

However, one class of materials of limited applicability would be heterogeneous materials containing portions that deform by plastic flow. Problems would also be expected for a conglomerate of weakly cemented grains (or an incompletely sintered ceramic). In the latter case, the size distribution of the fracture particulate should be complex, one distribution corresponding to the disaggregation of the grains and another distribution for the fractured grains. This result would probably take the form of a bimodal lognormal distribution, but would probably also have a complex relation to energy density and other impact conditions.

Based on the few available data, composite bodies consisting of glass monoliths cast in metal canisters are not expected to be a problem for characterization. Plastic deformation of the metal will reduce the energy available for brittle fracture. However, it is well known that plastic deformation is characterizable in terms of energy dissipated $W_{d}$, the plastic flow stress $\sigma_{\mathrm{d}}$, which is a property of the material, and the displacement volume $V_{\mathrm{d}}$ of the deformation, as defined in Eq. 4, Section II-F. Essentially, plastic flow and brittle fracture both have stress as a driving force and they compete for energy. However, typical canisters have metal walls with a thickness of $1 \%$ to $3 \%$ of the diameter of the waste form, and preliminary stress calculations indicate that such walls will not significantly reduce the extent of fracture of the brittle materials.

\section{APPLICATION OF THE METHODOLOGY TO OTHERS' DATA}

In Section II, previous laboratory- and engineering-scale tests (made by others) of impact fractures of brittle materials representative of solid waste forms were described. The data from these tests point out two important aspects of impact fracture of brittle materials: (1) the relation between fracture resistance and the chemical composition of wastes, and (2) the dependence of the form of the fractured material on impact conditions (for a given material). The methociology for 1mpact-fracture characterization presented here is intended to address both these concerns, i.e., materials characterization and accident analysis. 
The results of the engineering-scale tests (reviewed in Section II-B) reported the surface area and the amount of material of respirable size produced on fracture for a particular waste glass [PNL-1975]. These data were reported graphically as empirical plots with indicated margins of uncertainty, as functions of the velocity of impact. The plots were not linear. In the proposed methodology, the severity of impact is measured principally as the input kinetic energy $\left(1 / 2 \mathrm{MU}^{2}\right)$, which is proportional to the square of the velocity. Figures 3 and 4 illustrate that Smith's [PNL-1975] data vary linearly when plotted vs. the square of the velocity of impact, rather than vs. the first power of the velocity.

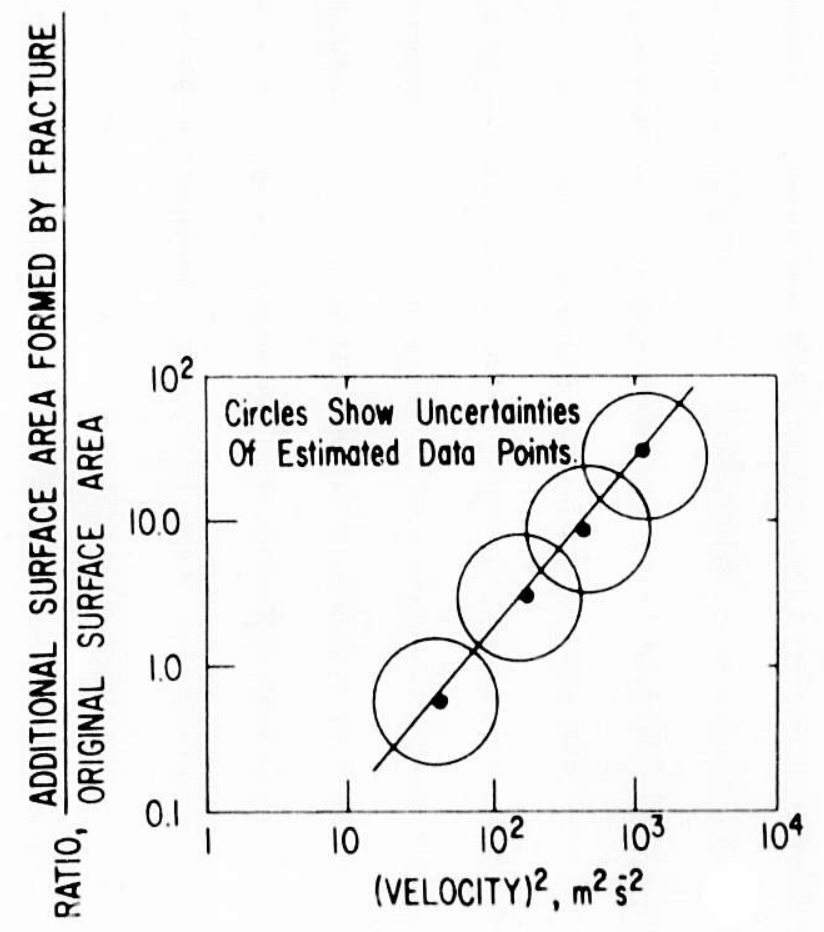

Fig. 3.

Data from [PNL-1975] on Increased Surface Area for Canistered Glass Waste Form Plotted as a Function of the Relative Kinetic Energy of Impact

The broken lines of Fig. 4 refer to preimpact condition which was attributed to fracture caused by thermal shock in the cooling of the glass when it was cast into the canister. The three sets of data--"optimistic," "pessimistic," and "best"--refer to the range of experimental results encountered in these impact tests for different sizes of canistered glass waste forms.

Thus, the square of the 1 mpact velocity has been identified as a parameter (or system variable) which can be used to characterize the effects of concern--specifically, the fracture surface area and the fracture particulate of resptrable size.

Particle-size data [PNL-1979B, PNL-1979D] on the fracture of a fullsize $(2000-\mathrm{kg})$ waste glass canister are shown in Fig. 5. The cumulative mass fractions $P_{v}(D)$ are shown as a function of size for both the preimpact condition of the waste glass and for the postimpact condition, after the 


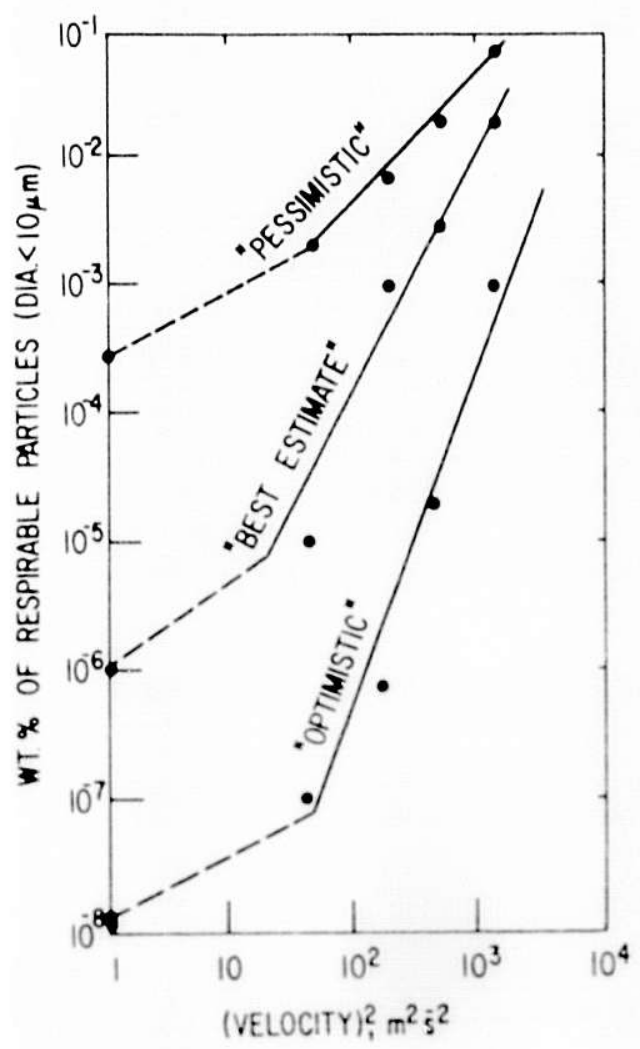

Fig. 4 .

Data from [PNL-1975] on Respirable Fraction for Canistered Glass Waste Form plotted as a Function of the Relati Kinetic Energy of Impact. (Broken lines refer to the preimpact condition in which fractures caused by cooling of the molten glass exist.)

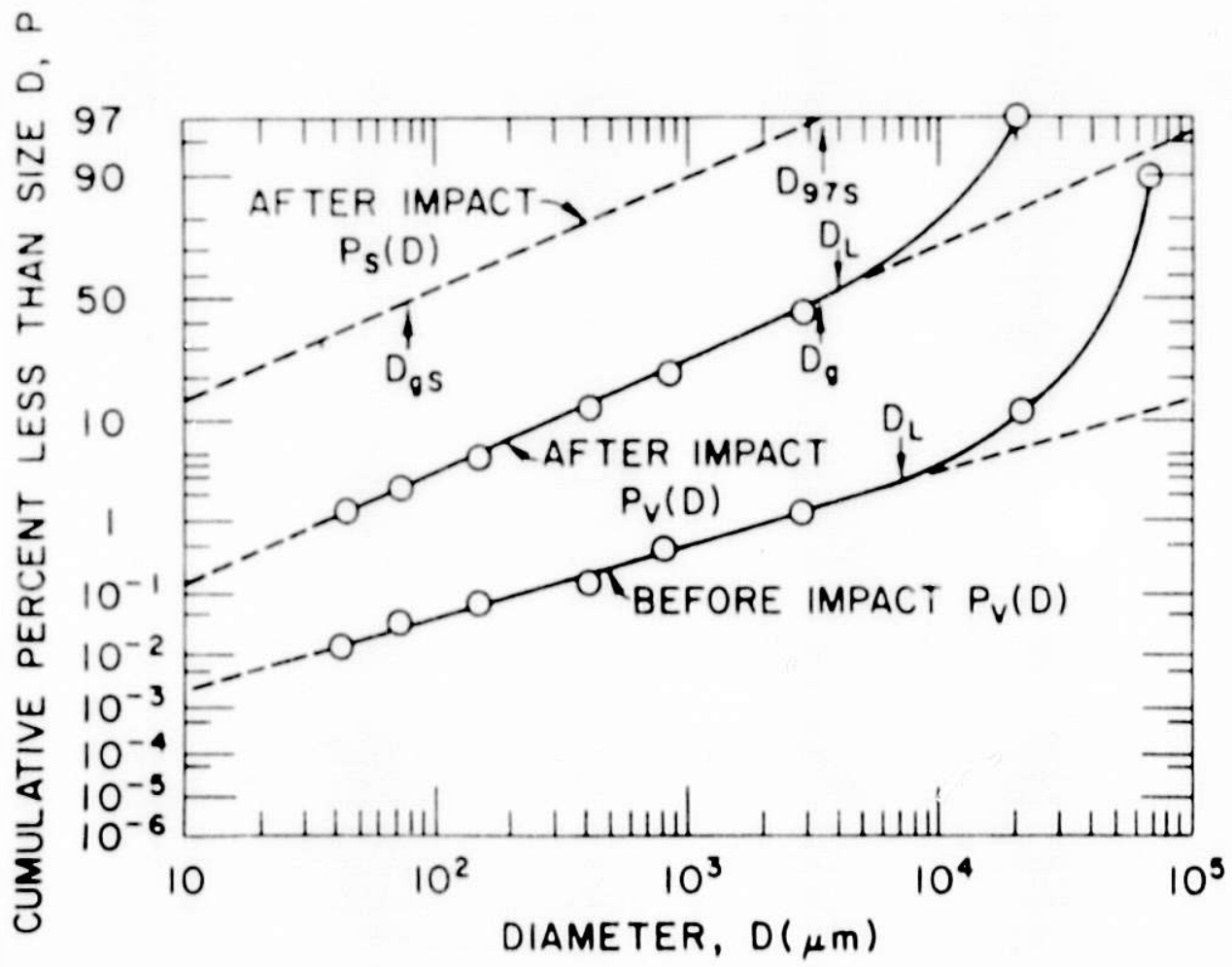

Fig. 5. Lognormal Analysis of Particle-Size Data Reported by PNL for $0.61-m-d i a$ Canister of Glass (before and after being dropped from $7.6 \mathrm{~m}$ onto an unyielding surface). [PNL-1979B, -1979D] 
waste canister had fallen $7.6 \mathrm{~m}$ onto an essentially unyielding surface. In this graph, the particle-size distribution of lognormally distributed particulates is linear. The $P_{v}(D)$ distributions are those of mass fractions or volume fractions. The $\mathrm{P}_{\mathrm{S}}(\mathrm{D})$ distribution (after impact) represents the distribution of surface area of the fracture particulate calculated from the lognorinal parameters determined from the sieving data.

The engineering-scale tests described above are concerned with accident analysis. Laboratory-scale tests of the fracture of small bare specimens are concerned with the dependence of the fracture behavior of waste materials on composition.

In Fig. 6 are shown the size distributions of fracture particulates from four different simulated waste materials, measured in laboratory-scale tests. The Savannah River Laboratory (SRL) data were for (1) a borosilicate waste glass in the form of a cylindrical specimen $12.5 \mathrm{~mm}$ in diameter and 25-mm long and (2) a 'neat' high-alumina Portland cement cylinder $25 \mathrm{~mm}$ in dianeter and 12.5-min long. The Battelle Pacific Northwest Laboratory (PNL) data were for commercial soda-lime glass at two different input-energy densities for cylinders $11 \mathrm{~mm}$ in diameter and 12.5-mm long. The Argonne National Laboratory (ANL) data were for 19 Pyrex glass spheres (6.2 mm in dianeter) impacted at two different energy densities $\left(6.9 \mathrm{~J} / \mathrm{cm}^{3}\right.$ and $3.3 \mathrm{~J} / \mathrm{cm}^{3}$ ). (The numbers on the plotted lines for the PNL and ANL data indicate the different energies

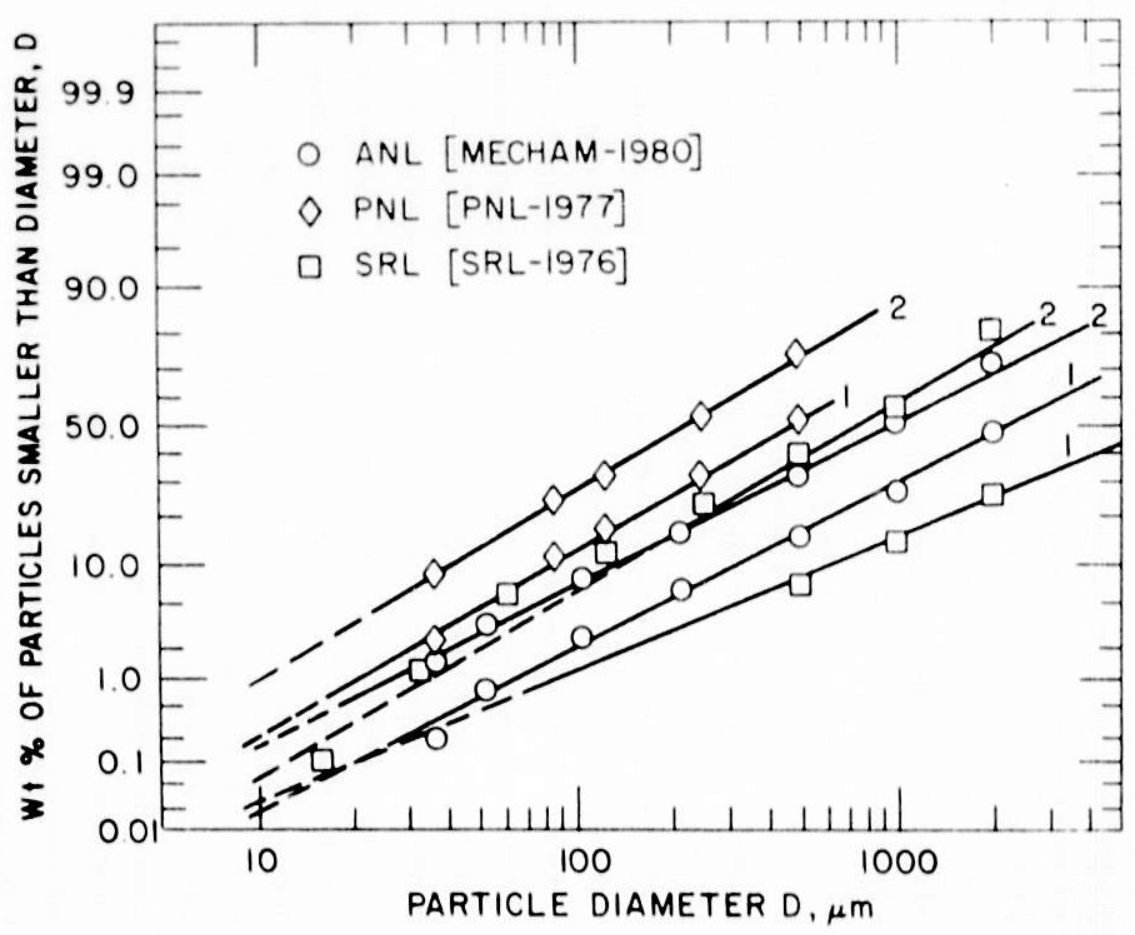

F1g. 6. Lognormal Plot of Measured Particle-Size Distributions for Various Impact Tests of Simulated Waste Materials [MECHAM-1980]. ANL Neg No. 308-79-792 
for a given material, where energy 2 is greater than energy 1.) The significance of this figure is that all data plot on lognormal coordinates in approximately straight lines, indicating that the fracture particulates can be described mathematically by lognormal parameters for different materials, sizes, and impact energies.

In Fig. 7 are shown the plots of size distributions of fracture particulates from the small PNL cylinders for three different glass compositions at four different input-energy densities. The linear plots on the lognormal probability coordinates show the relative fracture resistance of the three materials: vitreous silica, soda-lime glass, and a special glass, frit 73-1.

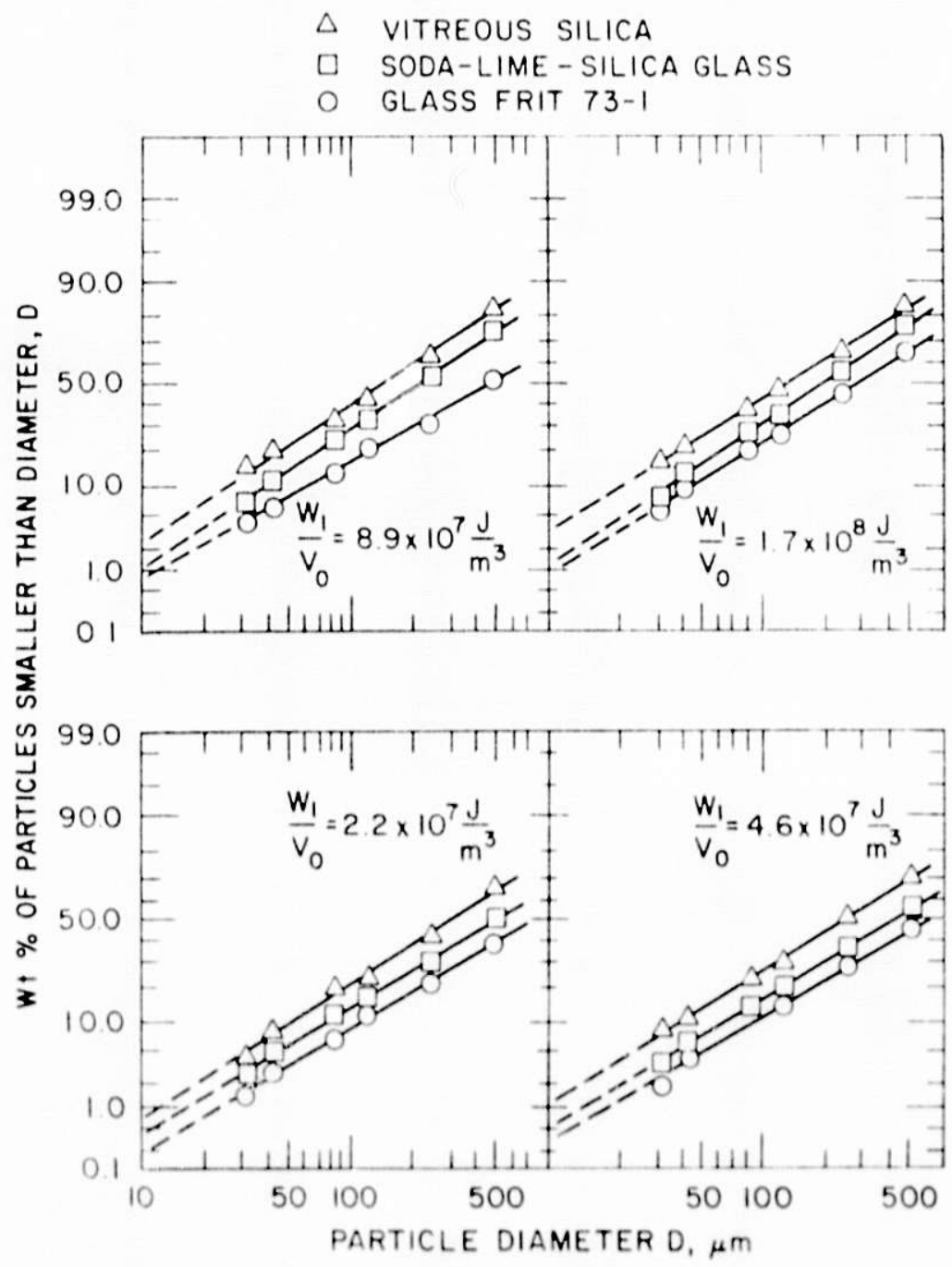

Fig. 7. Lognormal Plots of Particle-Size Data [PNL-1977] for Three Impacted-G1ass Compositions at Four Impact-Energy Densities. ANL Neg No. 308-79-790 
Table 1 shows the lognormal parameters $D_{g}$ and $\sigma_{g}$ determined graphically for the different materials and energy densities $\left(w_{i} q v_{0}\right)$. The mass traction of the particles of respirable size, $P_{v}\left(D_{r}\right)$, was determined graphically by extrapolation of the linear particle-size distribution obtained by plotting sieving data on lognormal coordinates. The surface area/volume ratio, $\mathrm{S} / \mathrm{ag}_{\mathrm{g}}$, for the fracture particulate was calculated using the $D_{g}$ and $\sigma_{g}$ values by the methodology described in Section III.

Table 1. Lognormal Parameters of Impact Fracture for Three Different Glass Compositions

\begin{tabular}{|c|c|c|c|c|c|c|}
\hline Glass Type & $\begin{array}{l}\mathrm{W}_{\mathrm{i}} / \mathrm{V}_{\mathrm{O}} \\
\mathrm{J} / \mathrm{cm}^{3}\end{array}$ & $\begin{array}{l}\mathrm{D}_{\mathrm{g}}, \\
\mu \mathrm{m}\end{array}$ & $\sigma_{g}$ & $\underset{\%}{\mathrm{P}_{\mathrm{v}}\left(\mathrm{D}_{\mathrm{r}}\right),{ }^{\mathrm{a}}}$ & $\begin{array}{l}\text { Calc. } \\
\frac{\mathrm{S}}{\alpha_{\mathrm{g}} \mathrm{V}}, \\
\mathrm{m}^{-1}\end{array}$ & $\begin{array}{l}\text { Calc. } \\
\begin{array}{l}\frac{Y_{f}}{\varepsilon}, \\
\quad J / m^{2}\end{array}\end{array}$ \\
\hline $\begin{array}{l}\text { Soda-1ine- } \\
\text { silica Glass }\end{array}$ & $\begin{array}{r}170 \\
89 \\
46 \\
22\end{array}$ & $\begin{array}{l}192 \\
220 \\
370 \\
490\end{array}$ & $\begin{array}{l}3.7 \\
3.7 \\
4.1 \\
4.4\end{array}$ & $\begin{array}{l}1.2 \\
0.8 \\
0.6 \\
0.4\end{array}$ & $\begin{array}{l}1.8 \times 10^{4} \\
1.2 \times 10^{4} \\
7.9 \times 10^{3} \\
5.7 \times 10^{3}\end{array}$ & $\begin{array}{l}4.5 \times 10^{2} \\
3.6 \times 10^{2} \\
2.8 \times 10^{2} \\
1.8 \times 10^{2}\end{array}$ \\
\hline $\begin{array}{l}\text { Glass Frit } \\
73-1\end{array}$ & $\begin{array}{r}170 \\
89 \\
46 \\
22\end{array}$ & $\begin{array}{l}290 \\
490 \\
530 \\
720\end{array}$ & $\begin{array}{l}4.3 \\
4.4 \\
4.4 \\
4.2\end{array}$ & $\begin{array}{l}1.0 \\
0.4 \\
0.4 \\
0.2\end{array}$ & $\begin{array}{l}1.0 \times 10^{4} \\
6.2 \times 10^{3} \\
5.6 \times 10^{3} \\
4.0 \times 10^{3}\end{array}$ & $\begin{array}{l}8.1 \times 10^{2} \\
6.8 \times 10^{2} \\
3.8 \times 10^{2} \\
2.7 \times 10^{2}\end{array}$ \\
\hline $\begin{array}{l}\text { Fused Silica } \\
\text { (vitreous) }\end{array}$ & $\begin{array}{r}170 \\
89 \\
46 \\
22\end{array}$ & $\begin{array}{l}135 \\
150 \\
220 \\
300\end{array}$ & $\begin{array}{l}4.1 \\
4.0 \\
4.0 \\
4.0\end{array}$ & $\begin{array}{l}3.2 \\
2.8 \\
1.4 \\
0.6\end{array}$ & $\begin{array}{l}2.0 \times 10^{4} \\
1.8 \times 10^{4} \\
1.2 \times 10^{4} \\
9.0 \times 10^{3}\end{array}$ & $\begin{array}{l}4.0 \times 10^{2} \\
2.4 \times 10^{2} \\
1.8 \times 10^{2} \\
1.2 \times 10^{2}\end{array}$ \\
\hline
\end{tabular}

Extrapolated values of the weight fraction for $D_{r}=10 \mu \mathrm{m}$.

The value of the mean surface/volume shape factor $\alpha_{g}$ was not available for these specific tests. However, from one PNL measurement on soda-lime glass, it was calculated that $\alpha_{g}=21$, which is probably typical for glasslike materials when linear size is measured by sieving. The energy-surface parameter $\left(\gamma_{\mathrm{f}} / \varepsilon\right)$ shown in Table 1 was also calculated from the lognormal parameters. The rather high values of $\gamma_{f} / \varepsilon$, compared to [PIRET-1962] impactcalorimeter measurements, probably indicate low values of the efficiency factor $\varepsilon$. These low values of $\varepsilon$ may be the result of the very high energy densities used in these tests. For example, the maximum energy density for a body of density $3 \mathrm{~g} / \mathrm{cm}^{3}$ impacted by falling a height of $10 \mathrm{~m} \mathrm{is} 0.30 \mathrm{~J} / \mathrm{cm}^{3}$ or $3.0 \times 10^{5} \mathrm{~J} / \mathrm{m}^{3}$. The lowest energy density in Fig. 7 is $2.2 \times 10^{7} \mathrm{~J} / \mathrm{m}^{3}$.

Figure 8 shows particle-size distributions reported for small PNL specimens of soda-lime glass for a given total energy density when this input energy is applied in varying numbers of blows. Of course, after the first blow, the specimen is no longer monolithic. The straight lines indicate lognormality. The greater the number of impacts, the smaller is the overall size of the 


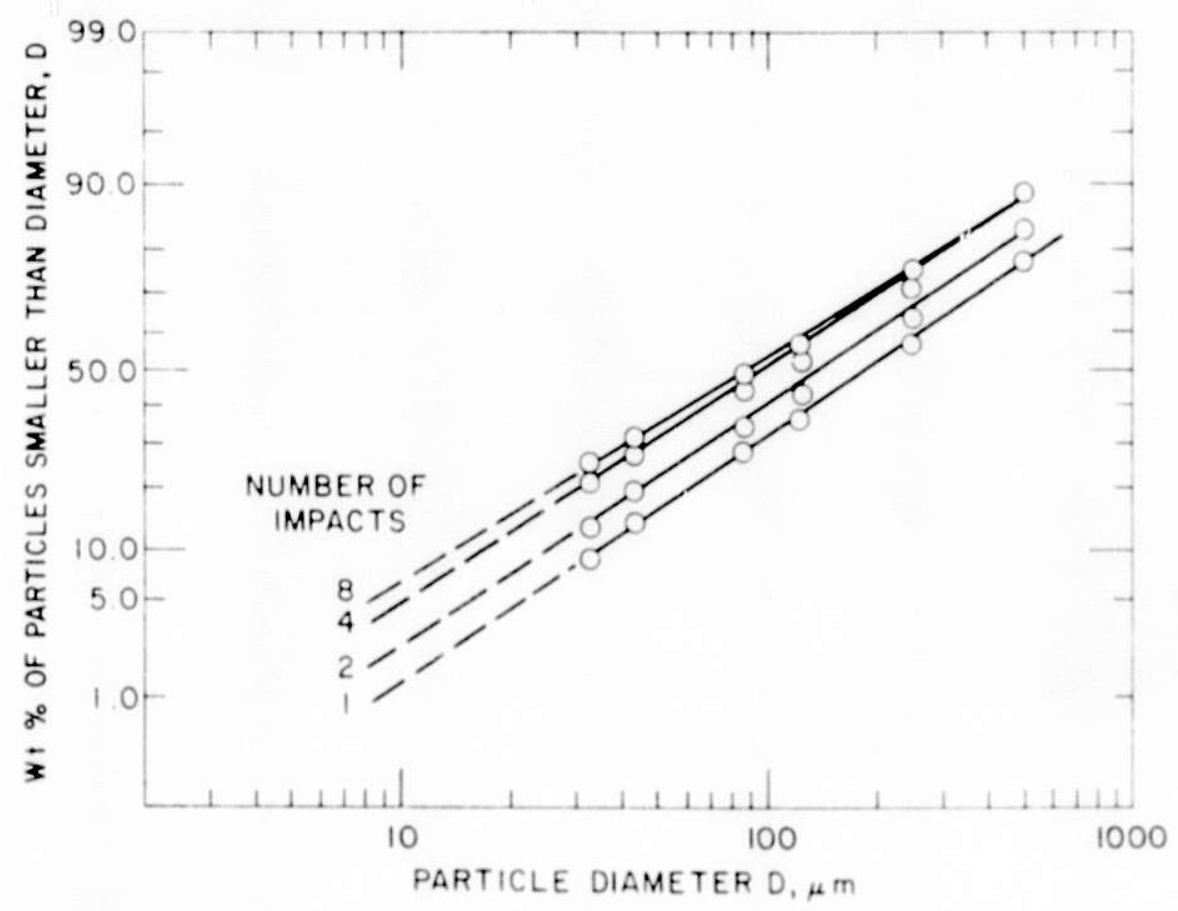

Fig. 8. Lognormal Plot of Data Reported [P(NL-1977]

for Impacted-Glass Specimens Receiving the Same Total Energy But in a Varying Number of Impacts. ANL Neg. No. 308-79-791

fracture particulate and the larger is the total surface area. The surfacespecific fracture strength, $\gamma_{f} / \varepsilon$, is thus lower for a single impact than for multiple impacts. This is probably due to the fact that the higher peak stresses involved in a single impact result in more energy losses via deformation of the metal components of the test device; this is reflected in a lower value of the energy efficiency factor $\varepsilon$.

Empirical plots on linear coordinates were reported for the fracture particulates formed by 215-J impacts on small cylindrical specimens of Pil waste glass type ICM-11 [PNL-1979A, Fig. 22]. Although the original plots had marked curvature, these data gave linear plots on lognormal coordinates, as seen in Fig. 9.

The methodology described in this report consists principally of lognormal particle-size analysis and the correlation of input kinetic energy with the surface area of the fracture particulate. The above analysis of impact data obtained from various sources for a variety of materials, sizes, and impact conditions has shown the general applicability of the methodology, as well as the similarity of fracture behavior for glasslike materials of widely differing chemical compositions. 


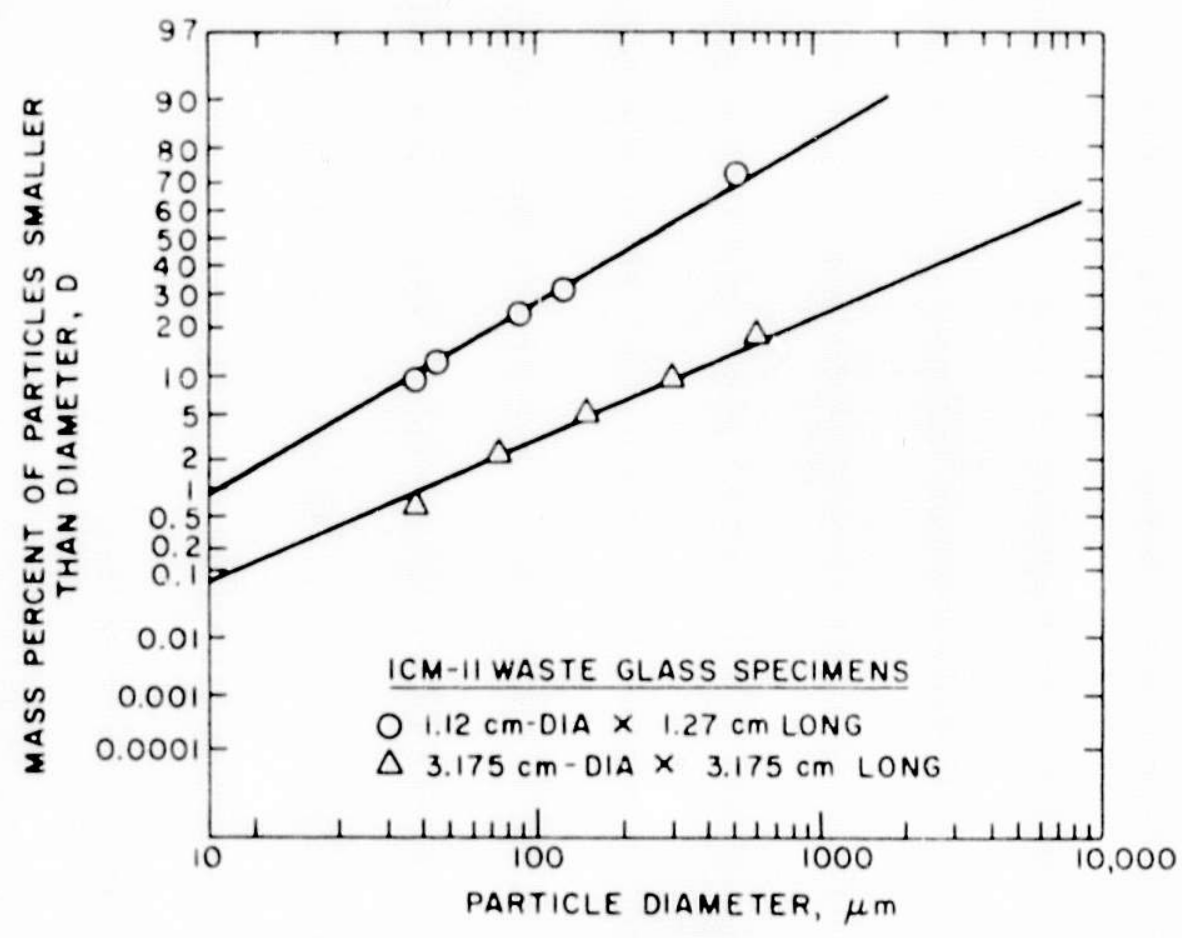

íg. 9. Lognormal Plots of Particle-Size Data for Two Sizes of PNL Waste Glass ICM-11

\section{v. RESULTS AND DISCUSSION OF INITIAL ANL TESTS ON VARIOUS MATERIALS}

Probability theory has been applied to brittle fracture with the result that general probability functions consistent with the lognormal probability function have been defined as appropriate [EPSTEIN, I. EVANS]. However, no use or verification by experimenters of these formulations was found in the literature. Definitive size-distribution functions cannot be established axiomatically, because of the approximate nature of statistics. For example, for a moderate range of particle sizes, empirical size data appear to conform to normal as well as to lognormal statistics.

The general implications of straight-line lognormal particle-size graphs has been pointed out by a small-particle statistician [HERDAN], but this technique has not been applied to experimental fracture tests. That is, experimentalists appear to doubt that any mathematical formulation is practical which does not take into account the atomic structure, crystallinity, grain size, etc. of fractured materials.

In the previous section, the lognormal particle-size characterization was successfully applied to rather limited existing literature data on a variety of materials. In this section we report the results of our own experimental tests made on materials believed to be representative of the range of structures that might be exhibited by various solid waste forms under development. The materials were (1) Pyrex glass, a well-characterized borosilicate glass which is commercially avallable and widely used for 
laboratory glassware; (2) reactor-grade $\mathrm{UO}_{2}$ ceramic, a microcrystalline refractory oxide sintered to near-theoretical density; (3) Macor, a proprietary glass-ceramic of typical white opacity, claimed to have a mica-like second phase which functions as a "crack stopper" and which makes this material machineable; (4) optical-quality natural crystalline quartz, which provided nearly single-crystal structure to our specimens; (5) nepheline syenite, a common feldspar rock mineral with large, coarse, and well-defined grains; (6) natural sandstone, a conglomerate of hard crystalline silica grains weakly cemented by a second phase to form a porous and friable rock mass; and (7) fused quartz, the manufactured vitreous form of silica, a high-melting structural and optical glass. The grain sizes of the $\mathrm{UO}_{2}$, nepheline syenice, and sandstone were determined microscopically. The vitreous materials were annealed, and removal of strains was verified with polarized light.

Impact tests were made in the same manner and at the same severity for all materials. Impact was provided by a 10-kg steel tup dropped on the side of cylindrical specimens of about the same size. The specimens were impacted in a closed chamber (to avoid particle losses) with a metal bellows to allow transmission of the impact from the tup (the deceleration mass). A crosssectional diagram of the sealed impact chamber is shown in Fig. 10. Except as indicated, the chamber is of stainless steel; all connections are welded except for the standard flanged connection. Piping, valves, and pressure gauge connected to the top flange are not shown in the figure.

The free-fall distance of the tup was selected so that each test provided the same kinetic-energy input per cubic centimeter of material, namely, $w_{i} / v_{0}=1.2 \mathrm{~J} / \mathrm{cm}^{3}$. For each material except quartz and sandstone, $a$ replicate test was made, and the particle sizes were measured (1) by sieving in a standard ATM Corp. Sonic Sifter apparatus (weighings made on a Mettler analytical balance with a 0.1-ing accuracy) and (2) by a standard Coulter counter apparatus, which measured particle sizes down to about $2 \mu \mathrm{m}$. Particle transfers from the impact chamber were made wet (with water washes) to avoid particle losses. Particles smaller than $90-\mu \mathrm{m}$ mesh size were separated by wet sieving, and the water suspension was sampled as part of the preparation of samples for the Coulter counter. Particles larger than $90 \mu \mathrm{m}$ were dried in a vacuum furnace and analyzed with the Sonic Sifter (dry sieving). Sieves were equilibrated in laboratory air before weighing.

All the impacted specimens consisted of single monolithic cylinders, except the $\mathrm{UO}_{2}$ ceramic which was available in standard cylindrical pellets of a rather small size. To make a volume equivalent to the other specimens, three $\mathrm{UO}_{2}$ pellets were placed end-to-end on their sides and impacted together in each of these tests. The volumes of the cylinders (and other data) are given in Table 2 .

In the drop-weight test device, the surfaces contacting the specimens were hardened tool-steel plates, about 12.5-mm thick. The bottom plate rested on the bottom of the stainless-steel impact chamber, which in turn rested on the concrete floor of the laboratory.

The masses of particles separated by size (in the two size-analysis devices) were normalized by the total mass (volume) of the material 1mpacted. These calculated cumulative mass fractions gave data points which were plotted 

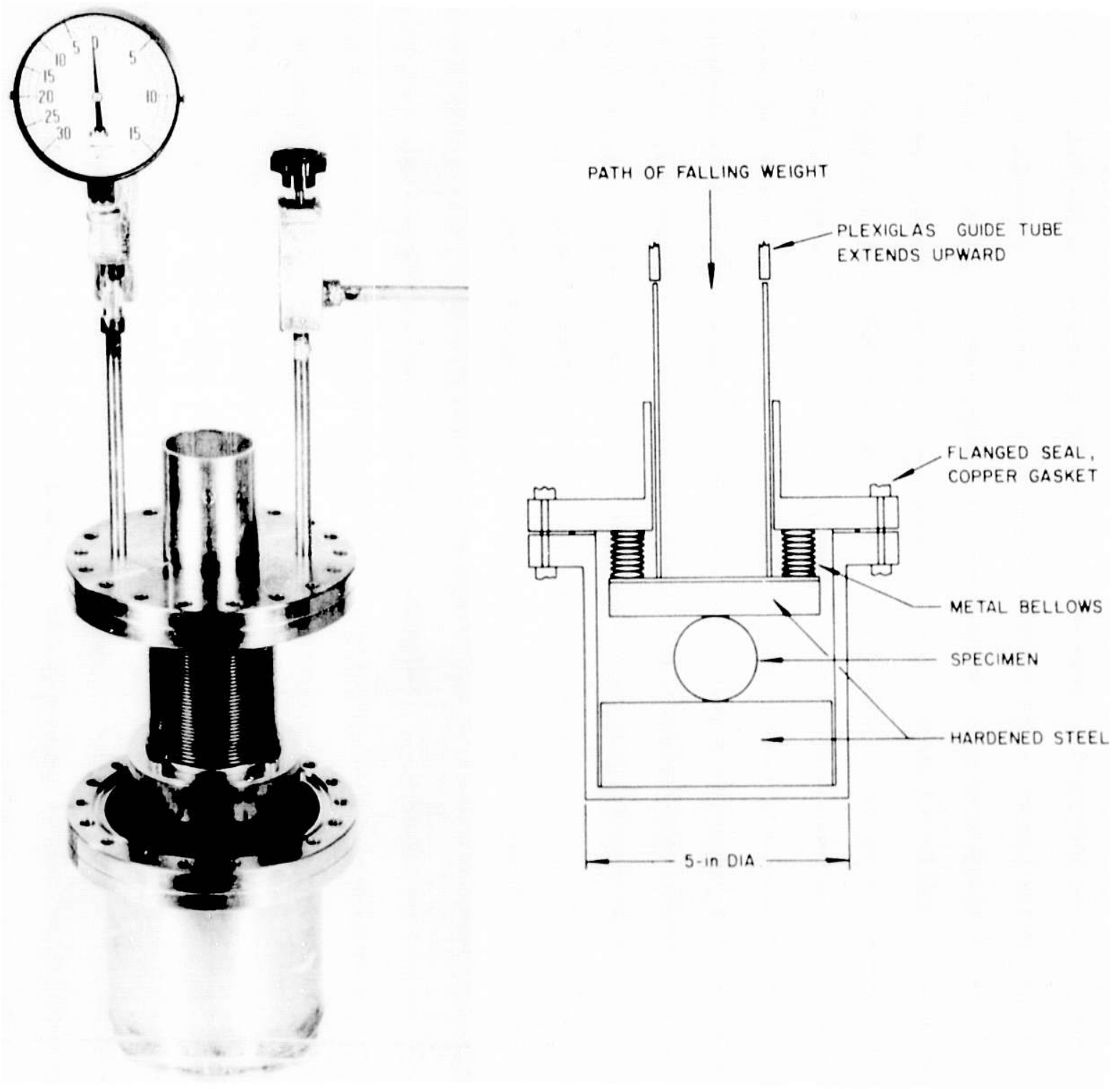

Fig. 1n. Bellows Chamber for Impacting Brittle Specimens

on standard lognorinal-probability coordinates. All fracture particulates plotted as approximately straight lines for all particles below some upperlimit $)_{L}$, which was characteristic of the material. The straight-line portions of the data are shown together $\mathrm{L}$ Fig. 11 for comparison. (More detalled plots of all measured size data will be presented below.) of (he seven materlals tested, the sandstone produced relatively larger fractions of particle sizes smaller than diameter $U$, Indicating that $i t$ was the weakest material (i.e., the least resistance to partlculate fracture); and the MACOR machlneable glass-ceramle produced relatively smaller fractions of particle 
Table 2. A Summary of Lognormal Parameters Derived by Graphical Analysis of the Particle-Size Distributions of Seven Haterials Impacted at $1.2 \mathrm{~J} / \mathrm{cm}^{3}$

\begin{tabular}{|c|c|c|c|c|c|c|c|c|c|c|c|}
\hline Material & $\begin{array}{l}\text { Test } \\
\text { Desig- } \\
\text { nation }\end{array}$ & $v_{0}, m^{3^{a}}$ & $w_{1}, J$ & $\mathrm{D}_{M}, \mathrm{~m}^{\mathrm{b}}$ & $\mathrm{D}_{\mathrm{L}}, \mathrm{m}$ & $D_{g}$, in & $\sigma_{\mathrm{g}}$ & $\mathrm{D}_{\mathrm{gs}}$, 1 & D98s, in & $\mathrm{P}_{\mathrm{v}}(10 \mu \mathrm{m})$ & $P_{S}\left(D_{L}\right)^{C}$ \\
\hline Pyrex-1 & $\mathrm{P}-1$ & $7.3 \times 10^{-5}$ & 88 & $1.8 \times 10^{-2}$ & $7.0 \times 10^{-3}$ & $1.1 \times 10^{-2}$ & 6.5 & $4.2 \times 10^{-4}$ & $1.1 \times 10^{-2}$ & $6.0 \times 10^{-5}$ & 0.95 \\
\hline Pyrex-2 & $\mathrm{P}-2$ & $3.2 \times 10^{-5}$ & 38 & $8.0 \times 10^{-3}$ & $3.0 \times 10^{-3}$ & $1.4 \times 10^{-2}$ & 7.8 & $2.1 \times 10^{-4}$ & $1.3 \times 10^{-2}$ & $2.0 \times 10^{-4}$ & 0.91 \\
\hline $\begin{array}{l}\text { Fused } \\
\text { Quartz-1 }\end{array}$ & $F-1$ & $3.86 \times 10^{-5}$ & 46 & $1.4 \times 10^{-2}$ & $1.9 \times 10^{-3}$ & $2.7 \times 10^{-2}$ & 9.6 & $1.6 \times 10^{-4}$ & $1.5 \times 10^{-2}$ & $2.2 \times 10^{-4}$ & 0.85 \\
\hline $\begin{array}{l}\text { Fused } \\
\text { Quartz-2 }\end{array}$ & $F-2$ & $3.9 \times 10^{-5}$ & 47 & $1.9 \times 10^{-3}$ & $1.5 \times 10^{-3}$ & $2.1 \times 10^{-2}$ & 8.75 & $1.9 \times 10^{-4}$ & $1.46 \times 10^{-2}$ & $2.3 \times 10^{-4}$ & 0.81 \\
\hline $\begin{array}{l}\text { Crystalline } \\
\text { Quartz }\end{array}$ & $c-1$ & $5.78 \times 10^{-5}$ & 70 & $8.0 \times 10^{-3}$ & $2.4 \times 10^{-3}$ & $2.9 \times 10^{-2}$ & 8.5 & $2.9 \times 10^{-4}$ & $2.1 \times 10^{-2}$ & $1.7 \times 10^{-4}$ & 0.82 \\
\hline $\mathrm{UO}_{2}-1$ & $\mathrm{U}-1$ & $2.0 \times 10^{-6^{a}}$ & 7.2 & $1.1 \times 10^{-2}$ & $1.0 \times 10^{-2}$ & $1.8 \times 10^{-2}$ & 8.18 & $2.1 \times 10^{-4}$ & $1.1 \times 10^{-2}$ & $2.0 \times 10^{-4}$ & 0.96 \\
\hline $\mathrm{UO}_{2}-2$ & $U-2$ & $2.0 \times 10^{-6^{a}}$ & 7.2 & $1.1 \times 10^{-2}$ & $1.7 \times 10^{-3}$ & $3.2 \times 10^{-2}$ & 9.4 & $2.1 \times 10^{-4}$ & $1.9 \times 10^{-2}$ & $2.0 \times 10^{-4}$ & 0.91 \\
\hline MACOR-1 & $M-1$ & $3.5 \times 10^{-5}$ & 42 & $8.0 \times 10^{-3}$ & $3.4 \times 10^{-3}$ & $1.1 \times 10^{-1}$ & 10.0 & $5.5 \times 10^{-4}$ & $5.5 \times 10^{-2}$ & $4.0 \times 10^{-5}$ & 0.78 \\
\hline MACOR-2 & $M-2$ & $8.4 \times 10^{-6}$ & 11 & $1.6 \times 10^{-2}$ & $6.0 \times 10^{-3}$ & $2.0 \times 10^{-1}$ & 14.2 & $1.8 \times 10^{-4}$ & $3.5 \times 10^{-2}$ & $9.0 \times 10^{-5}$ & 0.95 \\
\hline $\begin{array}{l}\text { Nephel1ne } \\
\text { Syenite-1 }\end{array}$ & $N-1$ & $3.1 \times 10^{-5}$ & 37 & $2.2 \times 10^{-2}$ & $3.4 \times 10^{-4}$ & $1.5 \times 10^{-2}$ & 8.9 & $1.3 \times 10^{-4}$ & $1.1 \times 10^{-2}$ & $1.5 \times 10^{-4}$ & 0.68 \\
\hline $\begin{array}{l}\text { Nepheline } \\
\text { Syent te-2 }\end{array}$ & $N-2$ & $3.1 \times 10^{-5}$ & 37 & $2.6 \times 10^{-2}$ & $3.0 \times 10^{-4}$ & $1.7 \times 10^{-2}$ & 8.10 & $2.1 \times 10^{-4}$ & $1.4 \times 10^{2}$ & $1.3 \times 10^{-4}$ & 0.62 \\
\hline Sandstone & $s-1$ & $1.72 \times 10^{-5}$ & 21 & $8.0 \times 10^{-3}$ & $1.3 \times 10^{-4}$ & $7.0 \times 10^{-3}$ & 7.8 & $1.0 \times 10^{-4}$ & $6.3 \times 10^{-3}$ & $6.0 \times 10^{-4}$ & 0.65 \\
\hline
\end{tabular}

${ }^{a}$ Total $v_{0}$ consisted of three pellets of stated volume.

$b_{D_{M}}$ is the maximum particle size observed.

cThese are parameters of the lognormal distribution of fractional surface areas of the fracture particulate calculated by the methods described in Appendix B. D $1 \mathrm{~s}$ the geometric mean; D $98 \mathrm{~s} 1 \mathrm{~s}$ the particle diameter for which $98 \%$ of the total surface area $1 \mathrm{~s}$ made of smaller-sized particles; $\mathrm{P}_{\mathrm{S}}\left(\mathrm{D}_{\mathrm{L}}\right)$ is the cumulative percent of surface area for particles smaller than $\mathrm{D}_{\mathrm{L}}$, the upper-11mit size for lognormally distributed particles. 


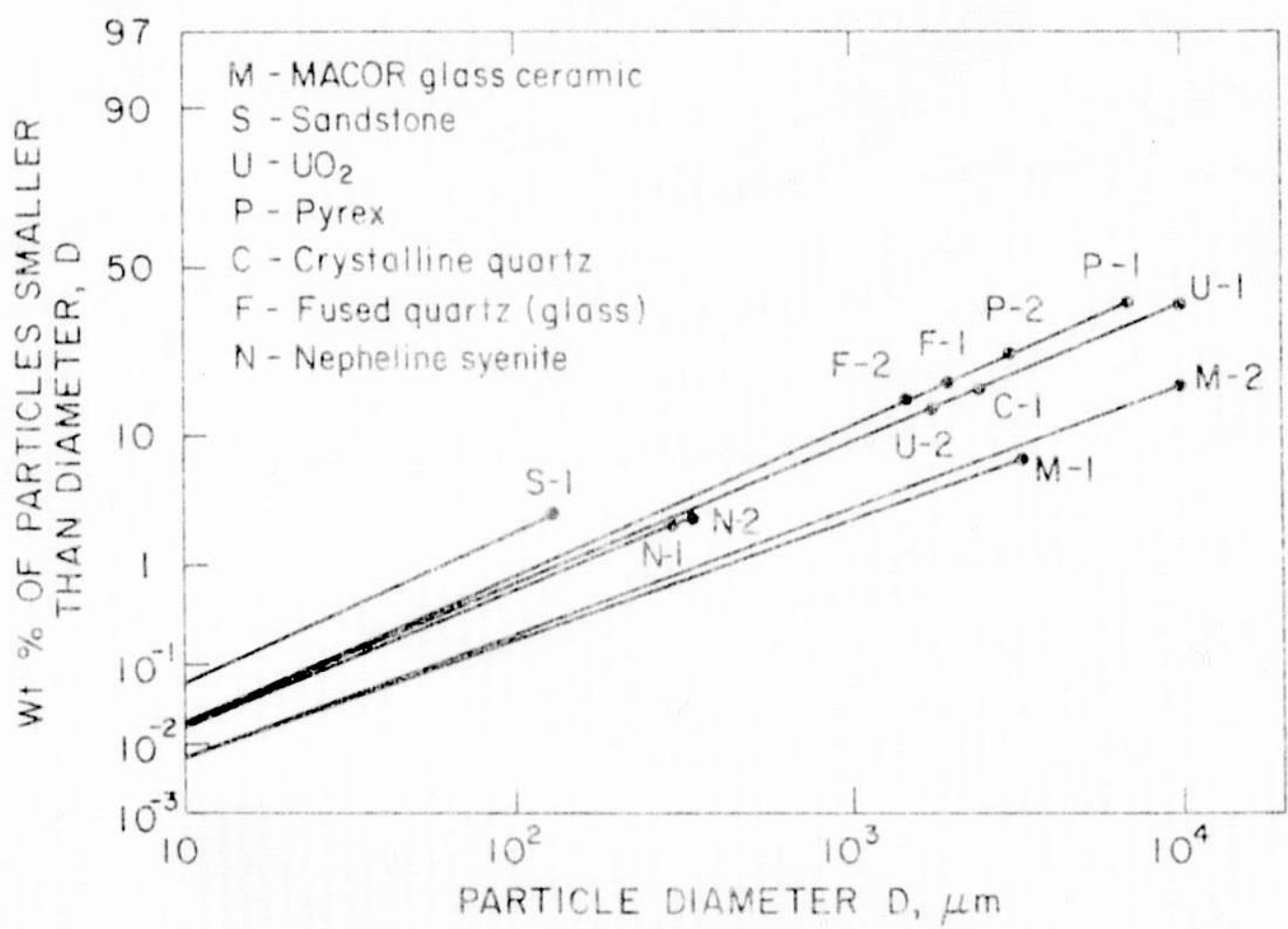

Fig. 11. Lognormal Plot of Particle-Size Data for Fracture Particulates of Seven Different Materials

sizes smaller than diameter D, indicating that it has the greatest impact resistance. All the other materials showed very similar size distributions, indicating approximately the same strength, the same amount of fracture surface, and the same respirable fraction. Values of the lognormal parameters deternined by graphical analysis are summarized in Table 2 .

Detailed data for the particle-size distributions shown are plotted in Figs. 12 to 22. A slight discrepancy between Sonic Sifter data and Coulter counter data appears because these two devices assign linear particle size D on different principles. Ultimately this will be corrected by a standard calibration. Sieve size D corresponds to the square mesh openings; Coulter counter size D corresponds to the diameter of a sphere of equal volume to the particle. Of course, these particles are of very irregular shape, but they are present in such large numbers that statistical mean sizes can be defined and measured.

The graphical analysis consisted of drawing the best straight line (by inspection) through the plotted points. The germetric mean was the size corresponding to the mass median, i.e., the size D corresponding to the $50 \%$ mass fraction. The geometric standard deviation $\sigma_{g}$ corresponds (as mathematically defined) to the ratio of the size D corresponding to the $50 \%$ size $\left(D_{g}\right)$ and the $16 \%$ size $\left(D_{16 V}\right)$, i.e., $\sigma_{g}=D_{g} / D_{16 V}$. Typically, the impacted specimen included a relatively few large fragments which did not follow the straight-1ine relationship. The upper size $D_{L}$ at which this departure 


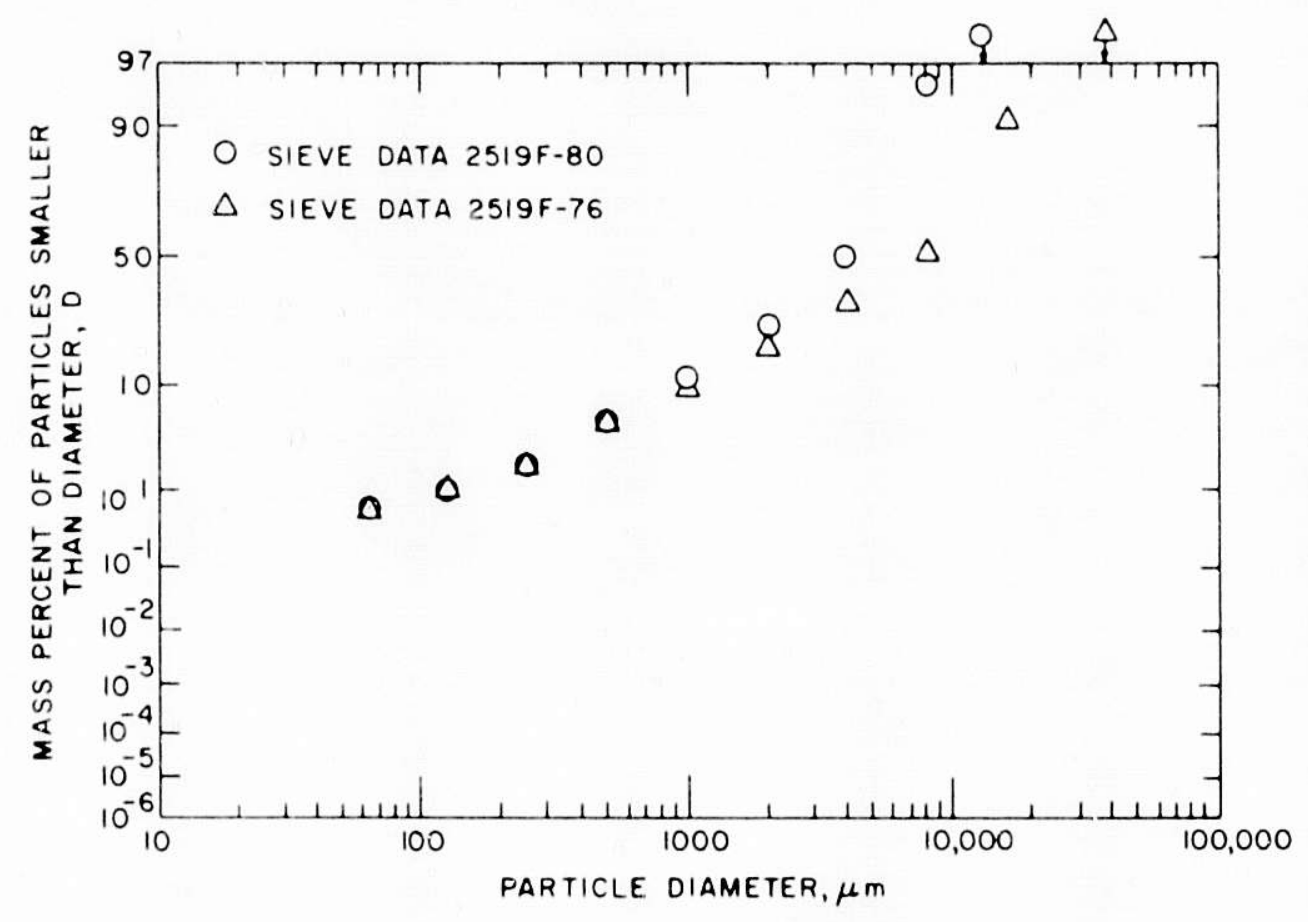

Fig. 12. Size Data for Pyrex Cylinders Impacted at $1.2 \mathrm{~J} / \mathrm{cm}^{3}$ $(2519 \mathrm{~F}-80=1.27-\mathrm{cm} \mathrm{dia}, 6.43-\mathrm{cm}$ length; $2519 \mathrm{~F}-76=$ $3.81-\mathrm{cm}$ dia, 6.43-cm length)

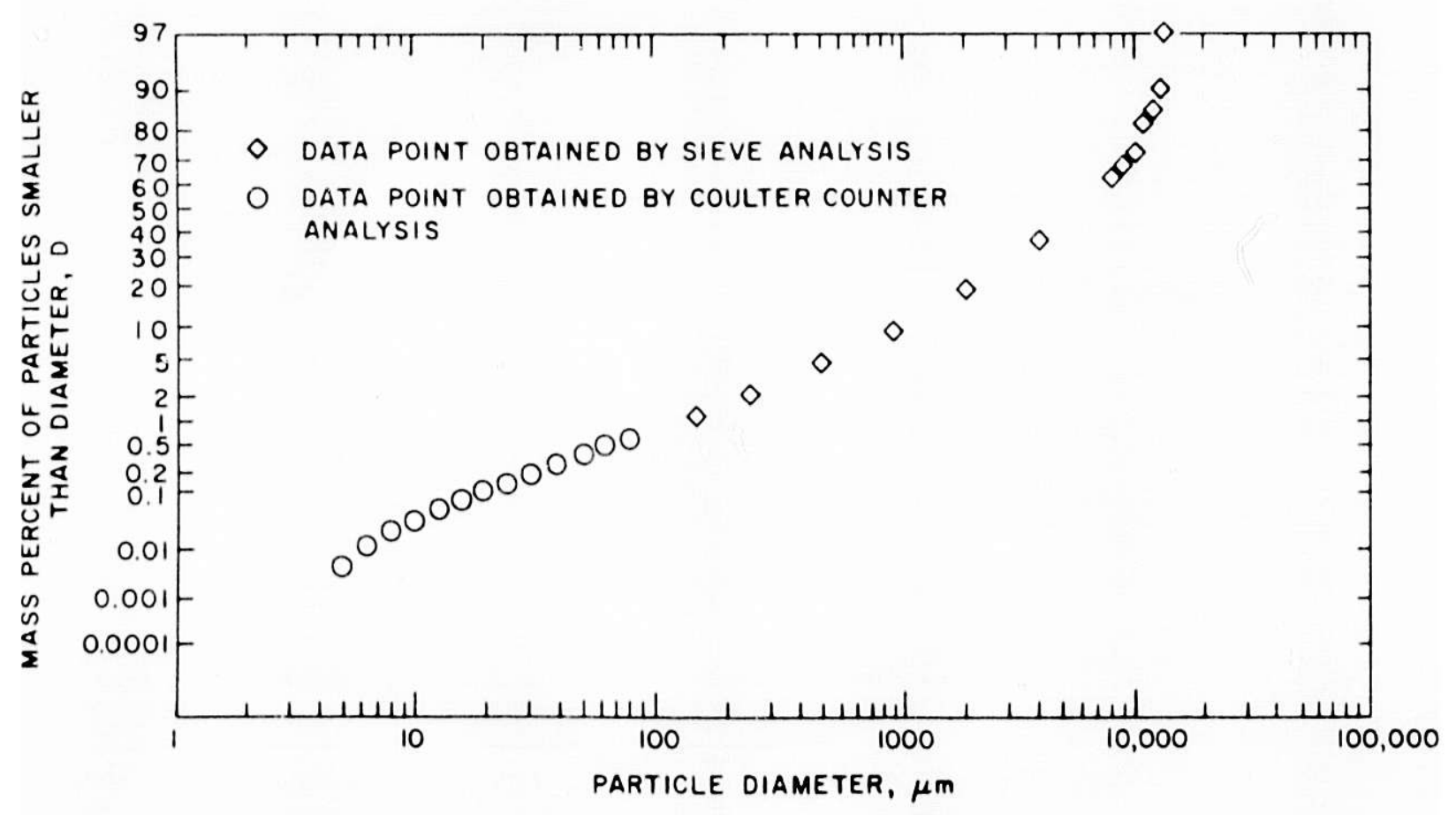

Fig. 13. Size Data for Fused Quartz Specimen No. 1 Impacted at $1.2 \mathrm{~J} / \mathrm{cm}^{3}$ (Cylinder $27.7-\mathrm{mm}$ dia $\times 63.8-\mathrm{mm}$ long) 


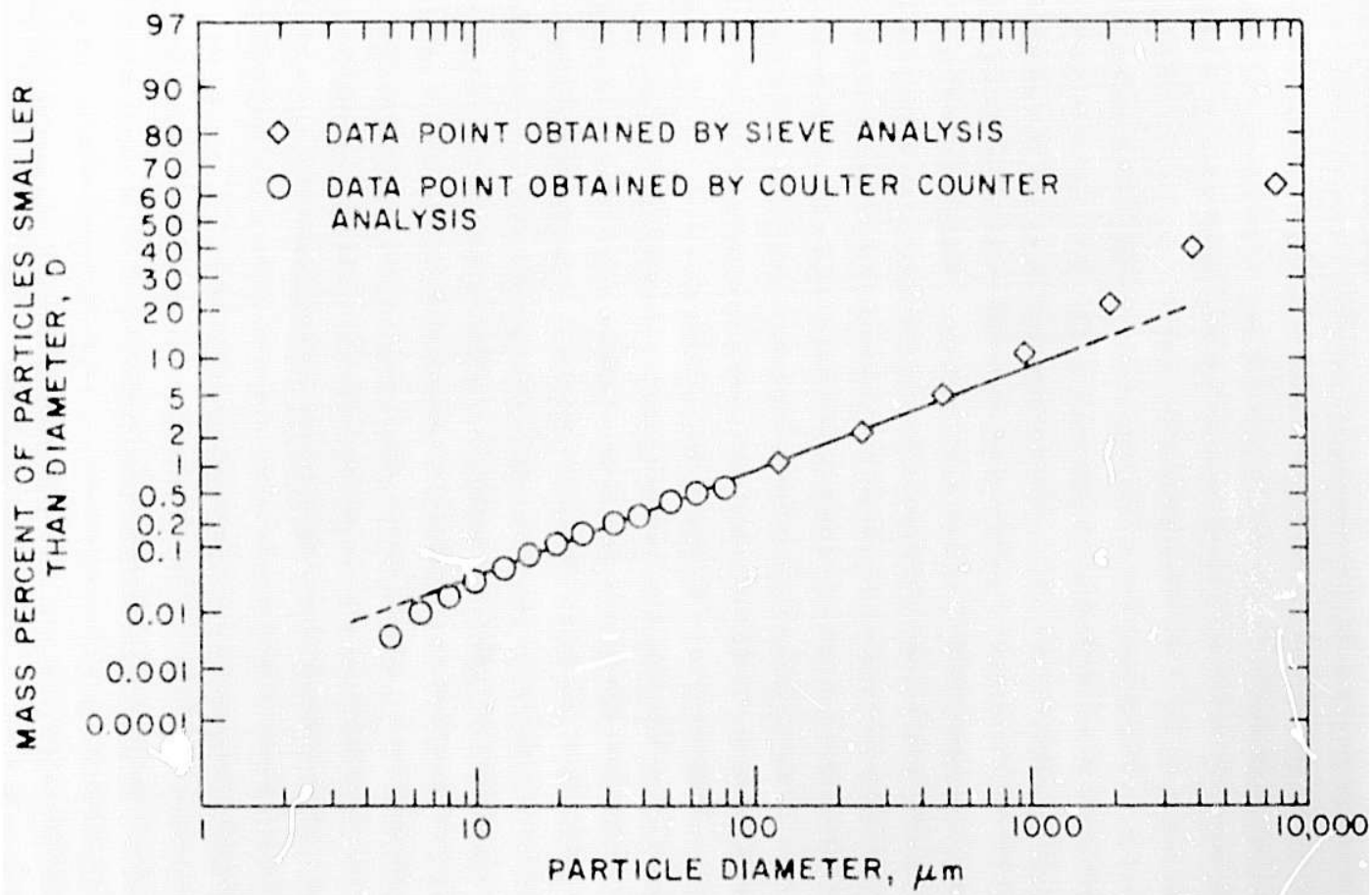

Fig. 14. Size Data for Fused Quartz Specimen No. 2

(Cylinder $27.8-\mathrm{mm}-\mathrm{dia} \times 63.8-\mathrm{mm}$ long.

Diametral drop-weight impact $1.2 \mathrm{~J} / \mathrm{cm}^{3}$ )

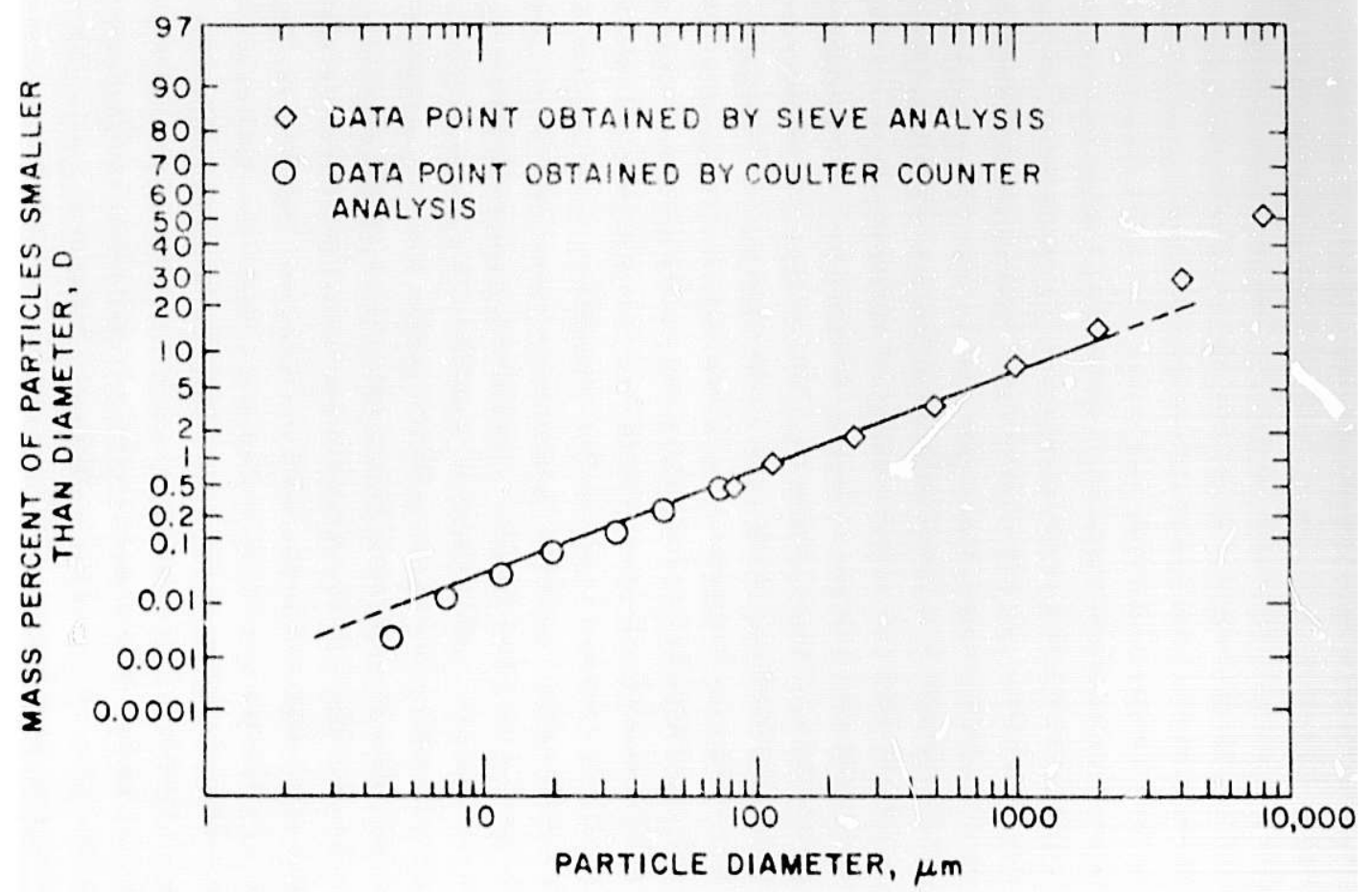

Fig. 15. Size Data for Crystalline Quartz (Cylinder 31.85-mm-dia $\times 72.5-\mathrm{mm}$ long. Diametral drop-weight impact $1.2 \mathrm{~J} / \mathrm{cm}^{3}$ ) 


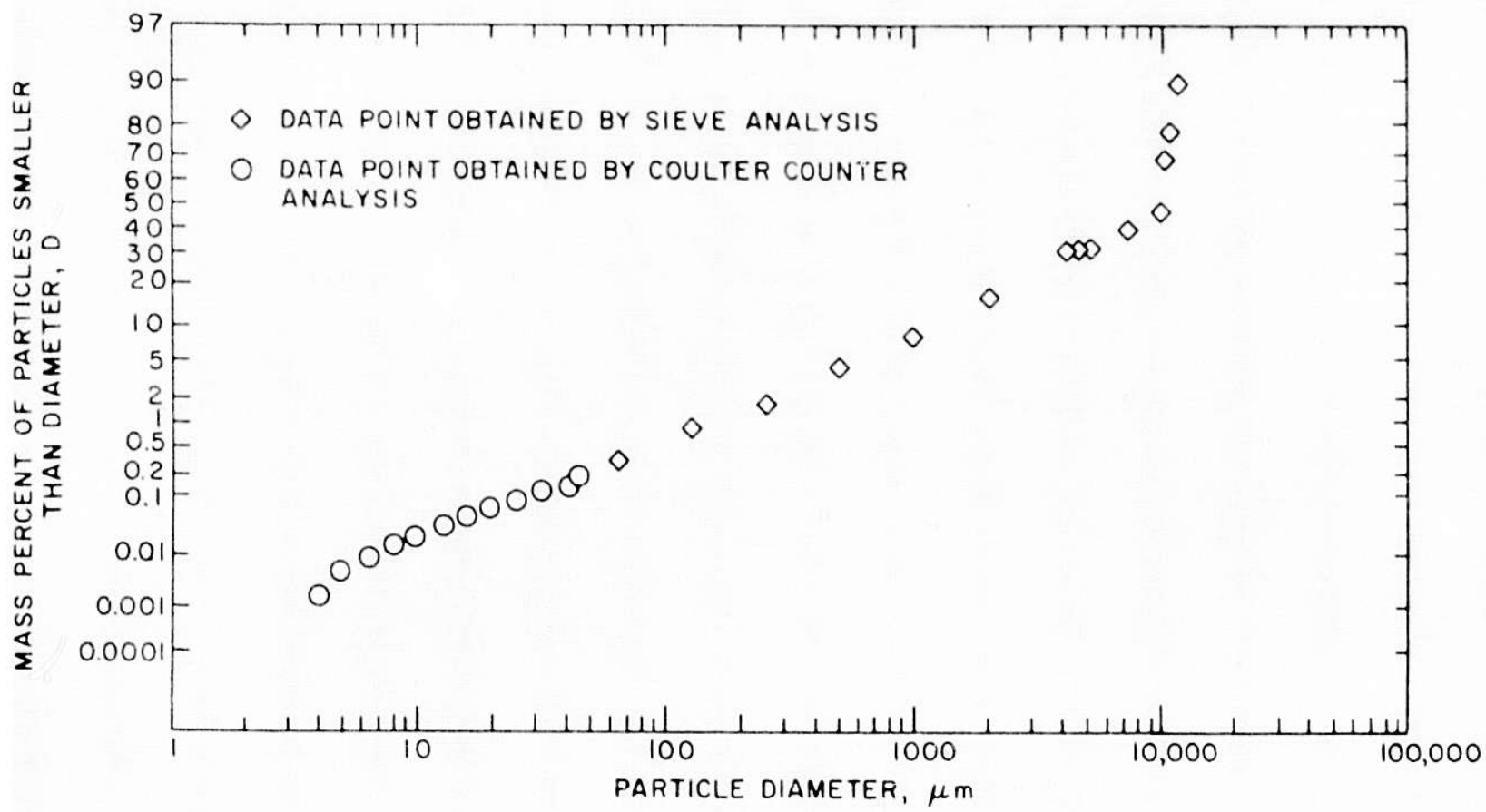

Fig. 16. Size Data for $\mathrm{UO}_{2}$ Specimen No. $1\left(1.2 \mathrm{~J} / \mathrm{cm}^{3}\right.$ diametral drop-weight impact on a set of three $\mathrm{UO}_{2}$ pellets, each $13.7-\mathrm{mm}-\mathrm{dia} \times 13.6-\mathrm{mm}$ long)

occurred can be noted from the plotted data. In general, reproducibility of the test method appears good. The respirable fractions from these tests are summarized as $\mathrm{P}_{\mathrm{V}}(10 \mu \mathrm{m})$ in Table 2; values of $\mathrm{P}_{\mathrm{V}}(10 \mu \mathrm{m})$ ranged from 0.004 wt \% (MACOR) to 0.06 wt \% (sandstone).

It appears from the plots of particle-size measurements that departures from lognormality are significant only at the large-size end of the spectrum of particle sizes. These departures have two different causes. First, for all materials, the empirical mass-fraction curve rises abruptly toward 100\% at some upper-limit size $\mathrm{D}_{\mathrm{L}}$ of the lognormal straight line. The reason for this is that there are uneven stresses in the impacted specimens and the regions of lowest stress simply are stressed at too low a level and for too short a time to suffer particulate fracture. In other words, the limited energy input is used up nearly completely in highly stressed zones, leaving the low-stressed zones nearly intact.

The second reason for departures from lognormality is that large-grained materials tend to have gross discontinuities at the grain boundaries, amounting to major networks of microcracks. Nepheline syenite is such a material. On the other hand, $\mathrm{UO}_{2}$ has small grains with smaller microcracks.

Grain sizes of both $\mathrm{UO}_{2}$ and nepheline syenite were determined by metallographic analysis. Samples of $\mathrm{UO}_{2}$ were prepared by mounting in a glass-reinforced epoxy resin, rough polishing with a 600-grit silicon carbide paper, and fine polishing on a $1-\mu \mathrm{m}$ diamond wheel. Samples were etched for 


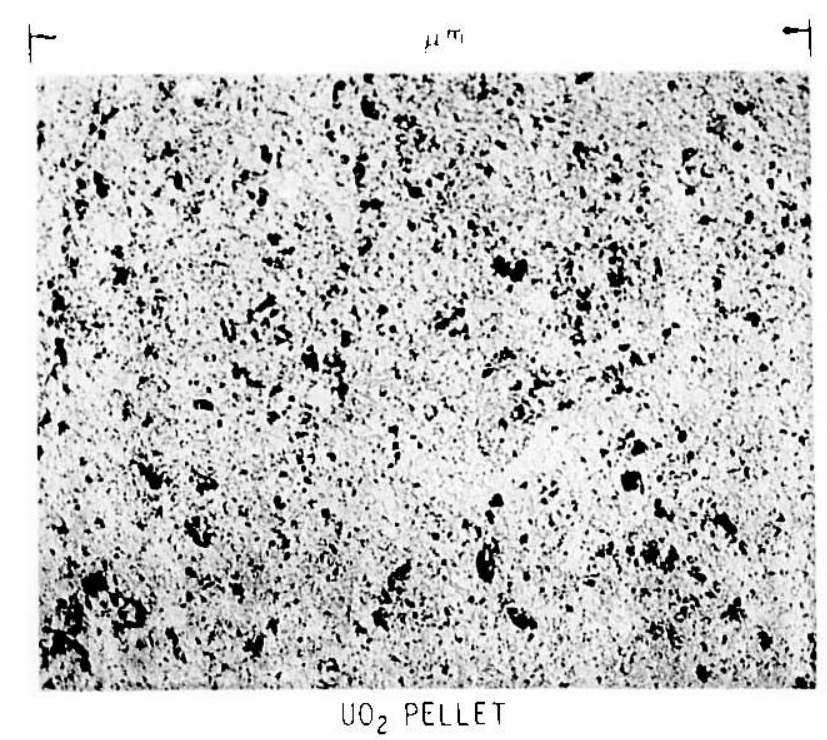

(a)

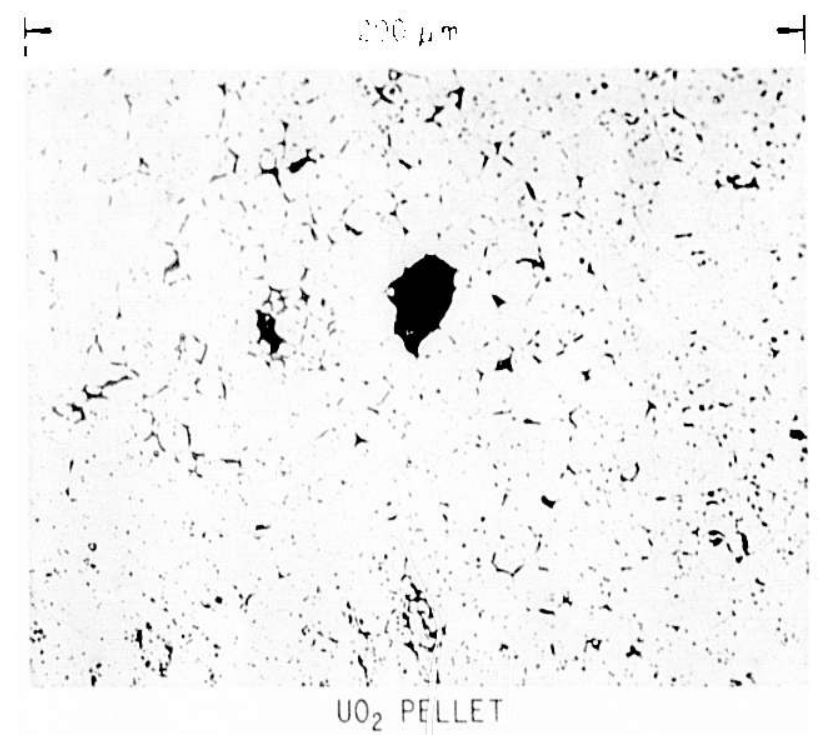

(b)

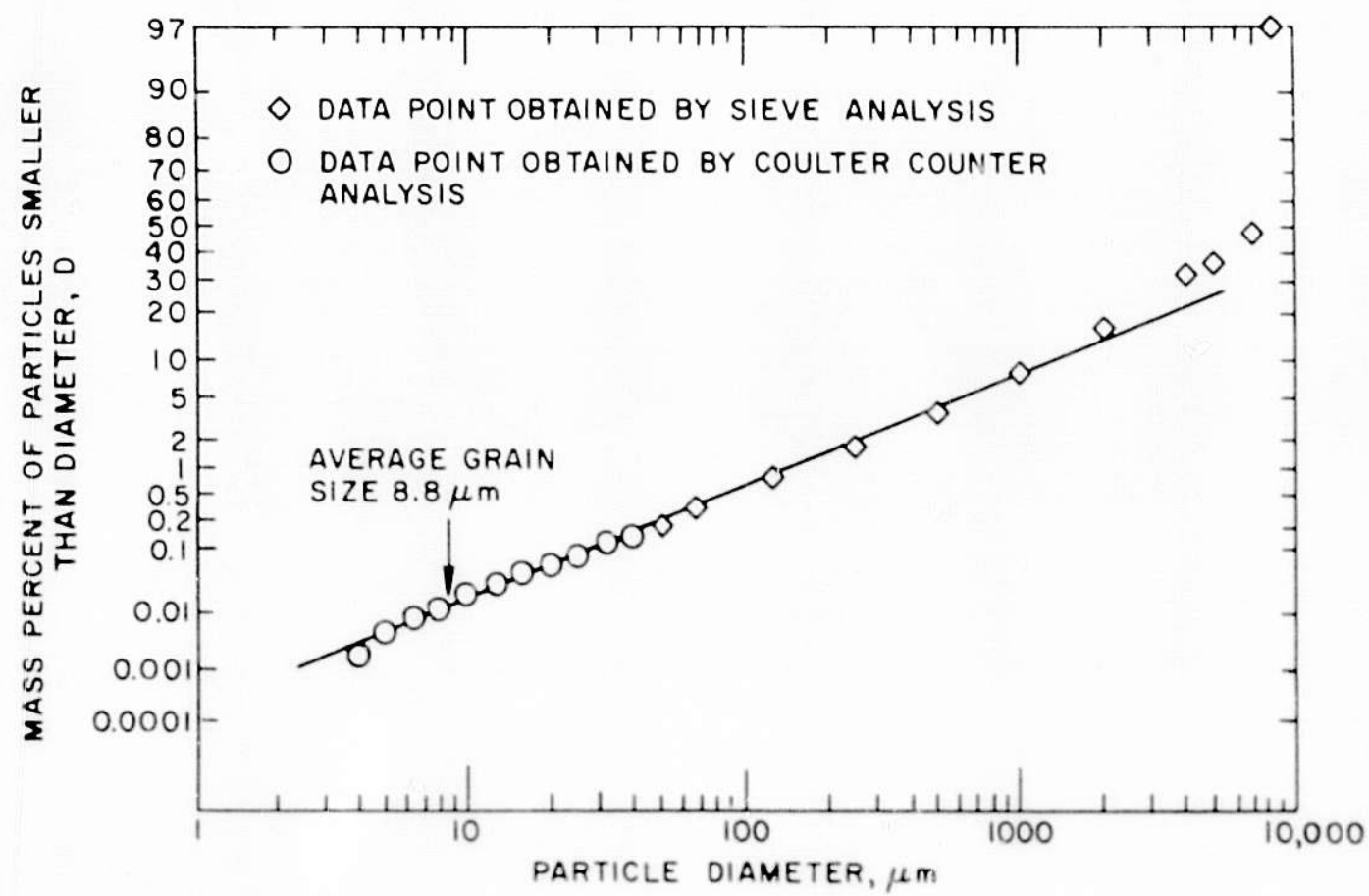

$(c)$

$\mathrm{Fi} ;$. i. Data for $\mathrm{UO}_{2}$ Specimen No. 2, Including Mean Grain Size of Original Crystalline $\mathrm{UO}_{2}$. (a) Photograph of $\mathrm{UO}_{2}$ grains at $200 \mathrm{X}$ magnification. (b) Photograph of $\mathrm{UO}_{2}$ grains at $500 \mathrm{X}$ magnification. (c) Particle-size distribution for three pellets, 13.7-mm-dia $\times 13.6-\mathrm{mm}$ long; drop-weight impact, $1.2 \mathrm{~J} / \mathrm{cm}^{3}$. 


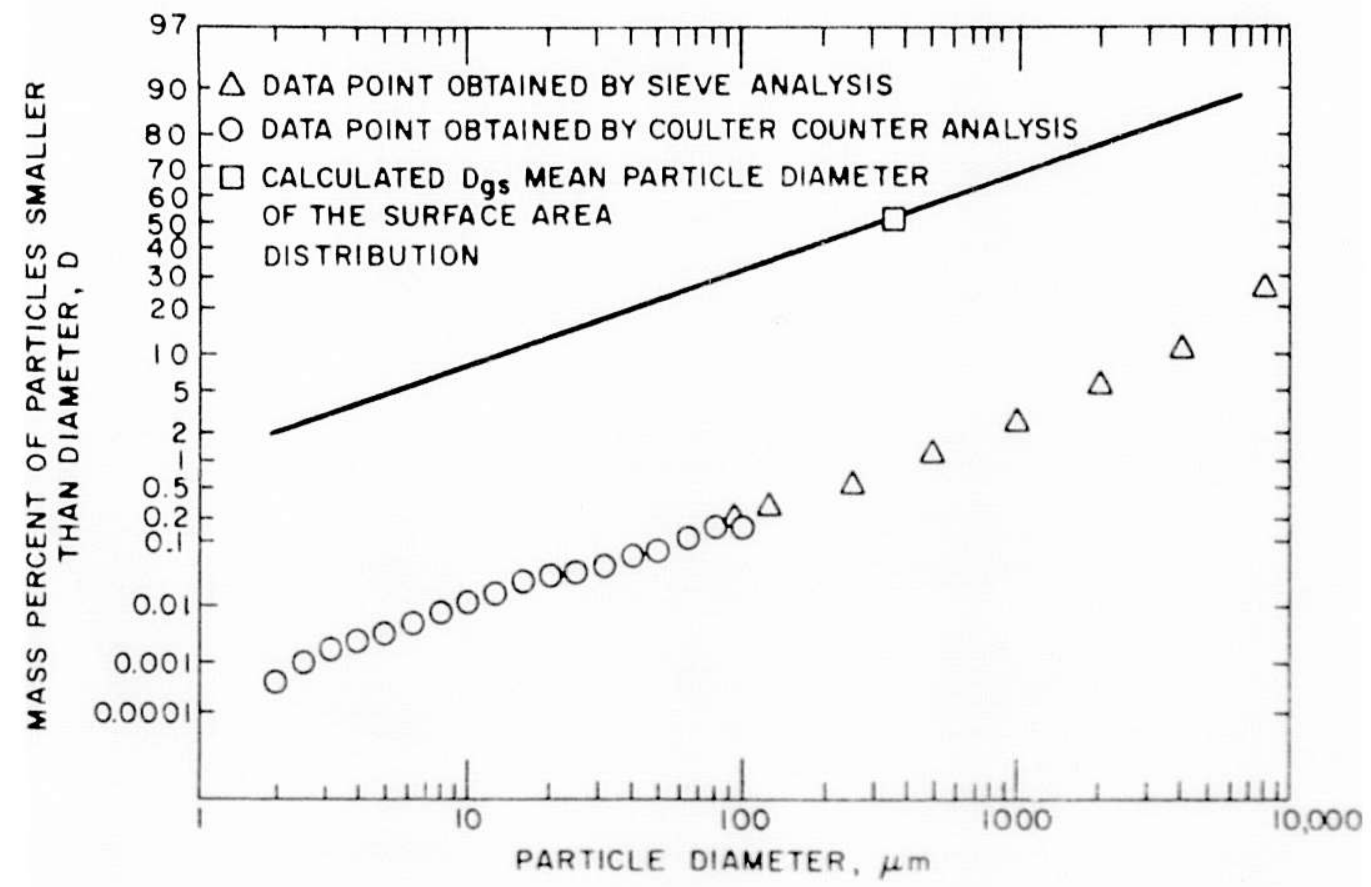

Fig. 18. Size Data for Mar = Specimen No. $1\left(1.2-\mathrm{J} / \mathrm{cm}^{3}\right.$ diametral drop-weight impact on a cylinder $26.5-\mathrm{mm}$ dia $\times 63.5 \mathrm{~mm})$

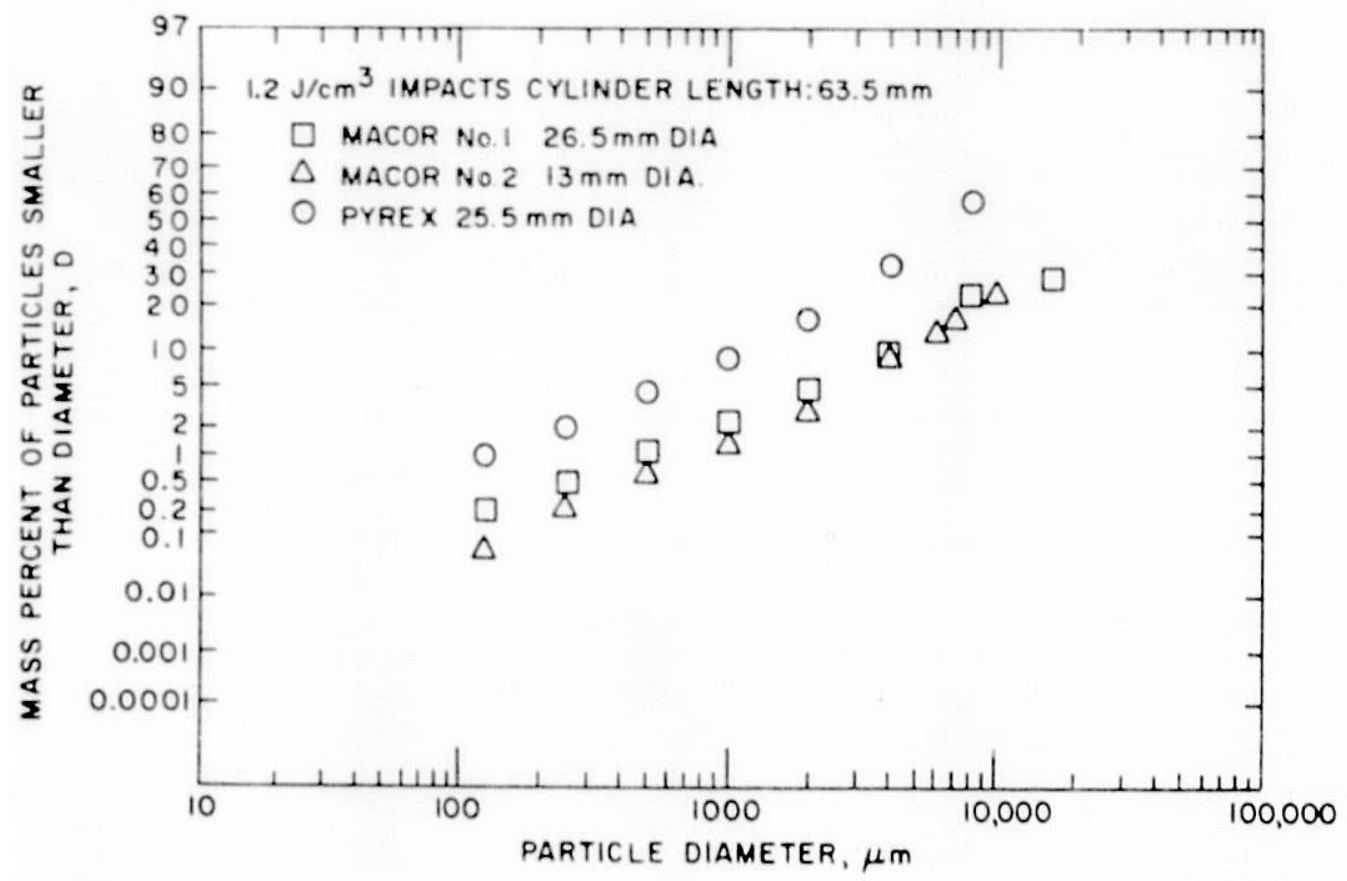

Fig. 19. Size Data for Two Macor Specimens Compared to Pyrex 

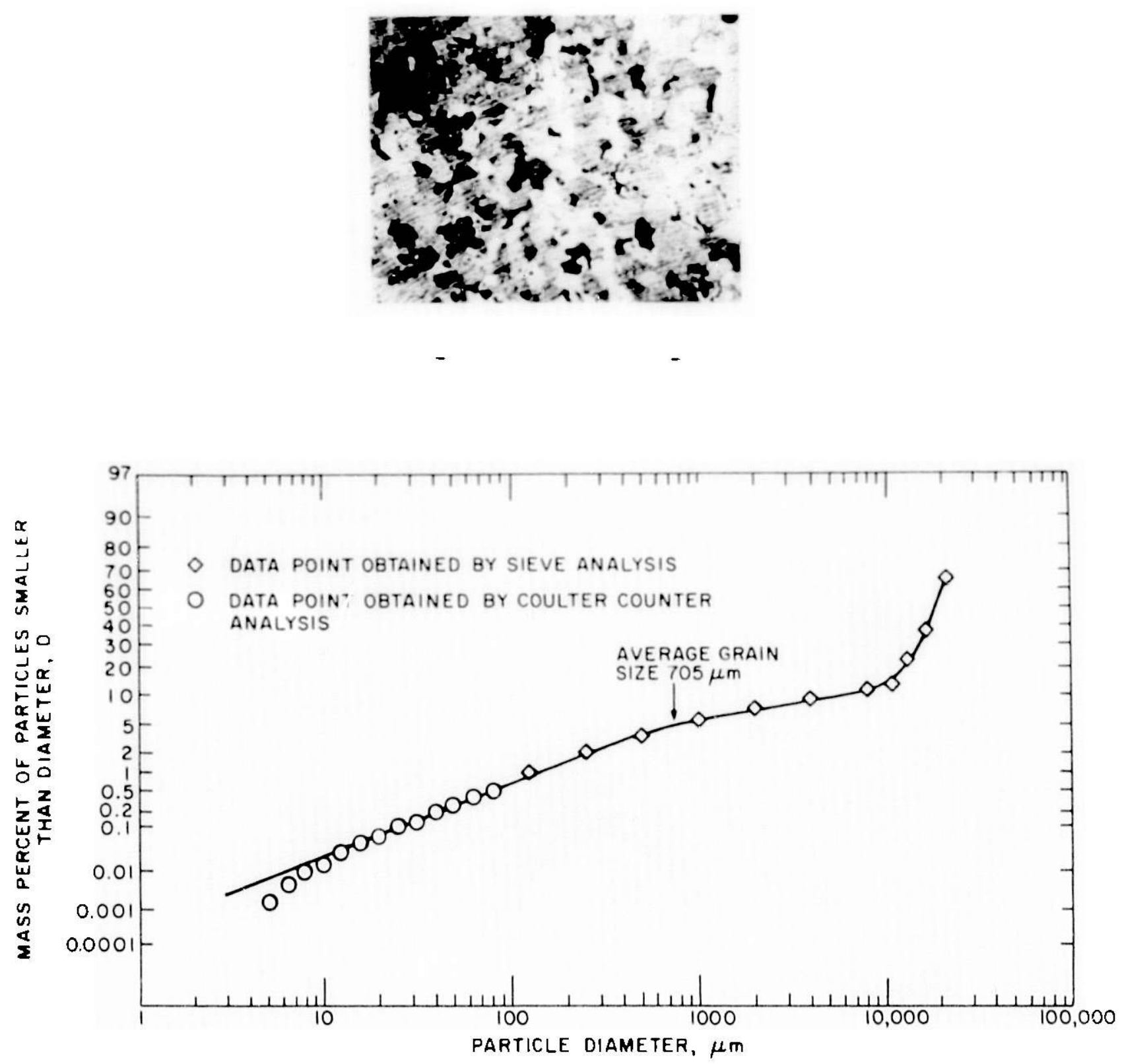

(b)

F1g. 20. Data for Nepheline Syenite Specimen No. 1. (a) Photograph of grains. (b) Particle size distribution resulting from a $1.2-\mathrm{J} / \mathrm{cm}^{3}$ diametral drop-weight impact on a cylindrical specimen obtained by core drilling $(31.9-\mathrm{mm}$ dia $\times 39 \mathrm{~mm})$. 


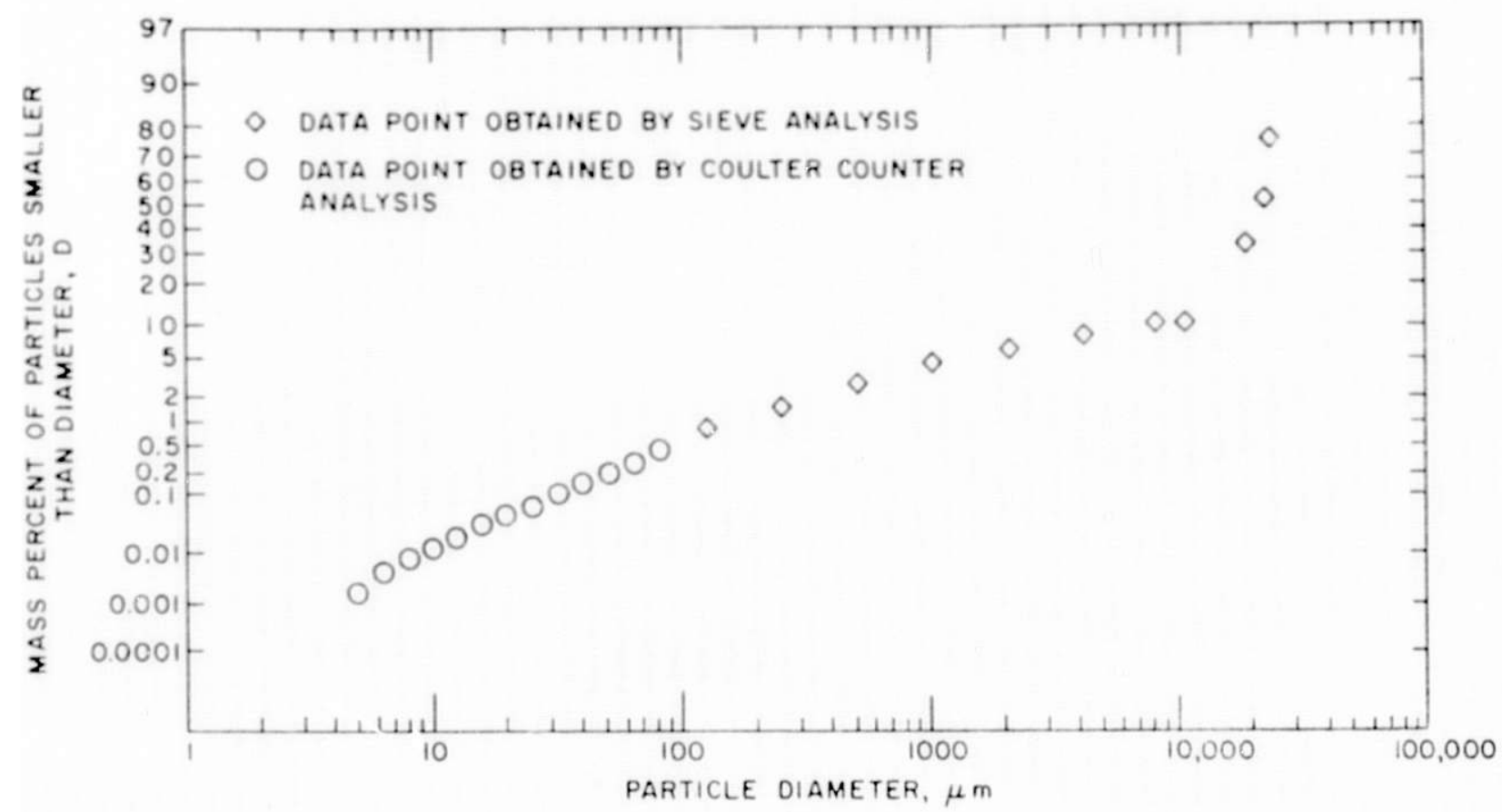

Fig. 21. Size Data for Nepheline Syenite Specimen No. 2 Obtained by Core Drilling $\left(1.2-\mathrm{J} / \mathrm{cm}^{3}\right.$ diametral drop-weight impact on a 31.9-mm dia $\times 39-\mathrm{mm}$ cylinder)

two minutes in dilute acid and photographed at $200 \mathrm{x}$ and 500x magnification.* The intercept method [HILLIARD] was used to estimate grain size. This method uses a circle overlay and involves counting the number of grain intersections over the circumferential distance. An average grain size is determined that is reproducible, but probably slightly underestimated. The nepheline grain sizes were determined in a similar way, but with a magnification of $6.49 x$. The mean grain sizes so determined were $705 \pm 100 \mu \mathrm{m}$ for nepheline syenite (Fig. 20) and $8.8 \pm 2.5 \mu \mathrm{m}$ for $\mathrm{UO}_{2}$ (Fig. 17). These grain sizes are marked on the particle-size plots; photographs of the grains are shown in these figures. For nepheline syenite (Fig. 20), the mean grain size corresponds to a transition from one lognormal straight line to another, suggesting a bimodal lognormal size distribution: one distribution corresponding to fracture along the grain boundaries and another distribution corresponding to fracture within the grains. Of course, less stress is required for fructure along the grain boundaries.

Figure 17 shows the mean grain size of $\mathrm{UO}_{2}$ on the plot of size data. Because this size, $8.8 \mu \mathrm{m}$, is close to the lower limit of Coulter counter measurement, a distinct effect is evident, when compared to the size plots of other materials. Evidently, for such a well-sintered microcrystalline ceramic

\footnotetext{
* Preparation and photography were done by $C$. Steves of the Materials Science Division, ANL.
} 


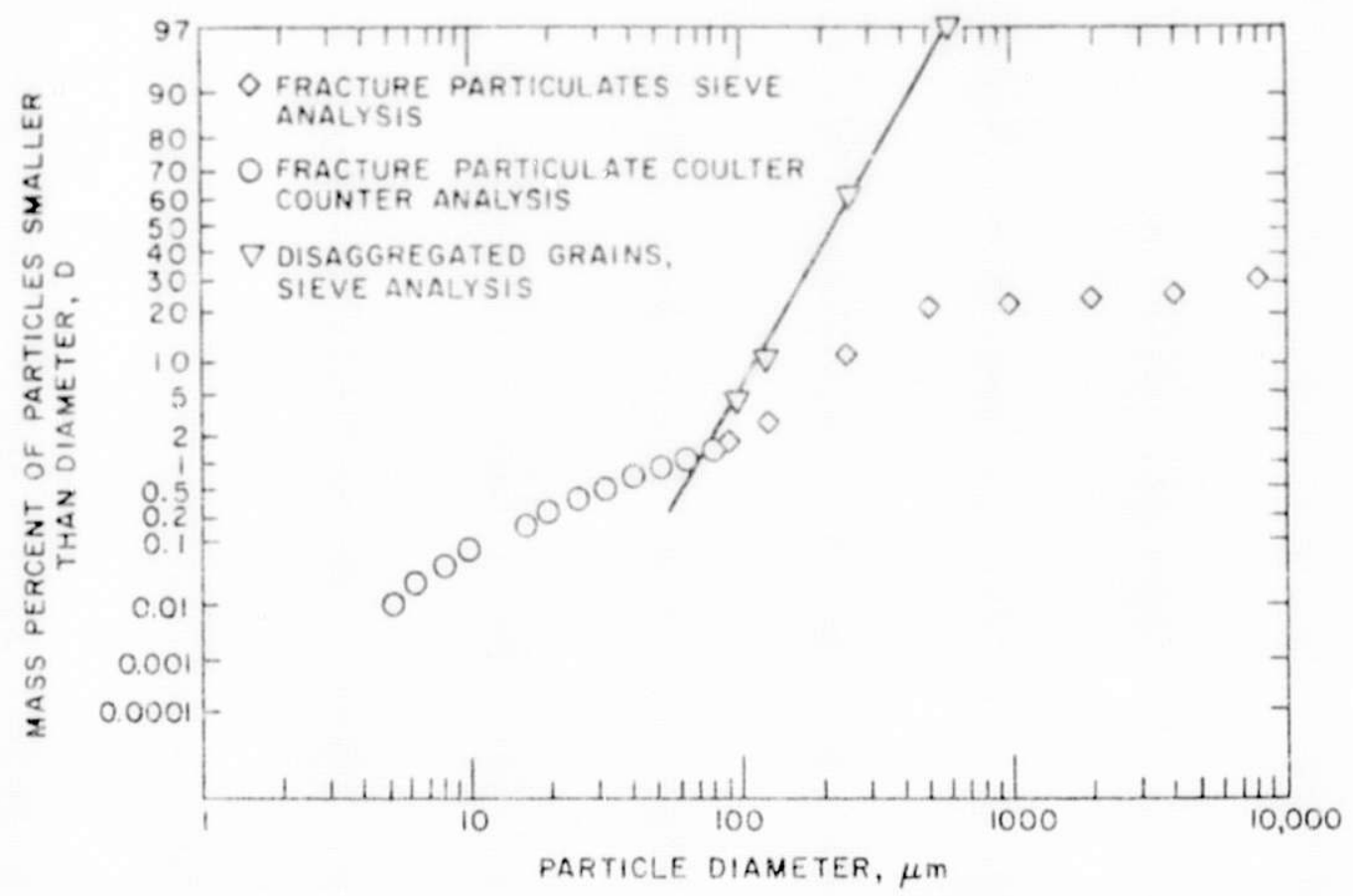

Fig. 22. Size Data for Sandstone Specimen Including Size Distribution of Grains (Cylinders, 22.1-mm dia and either $44.9-\mathrm{mm}$ or $17.6-\mathrm{mm}$ long; total vol. of two cylinders: $24.0 \mathrm{~cm}^{3}$. Diametral dropweight impact, $1.2 \mathrm{~J} / \mathrm{cm}^{3}$ )

as $\mathrm{UO}_{2}$, there is no significant fracture weakness at the grain boundaries. A linear regression analysis is being developed to systematically evaluate departures from lognormality.

In the case of sandstone, grain size was determined by disaggregating a sample of material by immersing it in a $1 \%$ sulfuric acid solution in an ultrasonic bath. The sandstone grains were dried and sieved, and the size distribution plotted with the fracture-particulate data in Fig. 22. The lognormal size distribution of the grains clearly accounts for the shape of the fracture-particulate curve. The lognormal straight line of the transgranular fracture of the grains stops at $D_{L}=100 \mu \mathrm{m}$ and further fracture corresponds to the breaking apart of the weakly cemented grains of the sandstone conglomerate.

Relative values of $\gamma_{f}$, the fracture strength in $\mathrm{J} / \mathrm{m}^{2}$, can be calculated in terms of the material shape factor $\alpha_{g}$ and the energy efficiency $\varepsilon$, by the relations previously described; however, separate determinations of $\alpha_{\mathrm{g}}$ and $\varepsilon$ were not made in this preliminary series of tests.

In conclusion, lognormal analysis of brittle-fracture particulates appears to give consistent and useful results in characterizing the impacts of a wide range of brittle materials of different grain structure and different strengths. 
VI. ANL TESTS OF PYREX SPECIMENS UNDER VARIOUS IMPACT CONDITIONS

A. Description of Initial Experiments and Results

Initial drop-weight impact tests of Pyrex glass specimens (about $70 \mathrm{~cm}^{3}$ ) were made over a range of impact conditions, and the particle-size distributions obtained by sieve analysis, as described in the preceding chapter. Pyrex was used because (a) it is readily available, (b) its properties are wall characterized, (c) it has mechanical properties believed to be close to those of borosilicate waste glass, and (d) its impact fracture strength $\left(77 \mathrm{~J} / \mathrm{m}^{2}\right)$ has been measured previously [PIRET-1962]. Pyrex can readily be shaped into convenient forms for testing. Typical Pyrex specimens are shown in Fig. 23.

In addition, Pyrex can be fully annealed or can be tempered (surfacehardened) by heat treatment to increase its threshold stress for fracture. Internal strains can be readily observed in Pyrex by use of polarized light, as shown in Fig. 24--a technique not usable for opaque waste glasses. For drop-weight tests made with a $10-\mathrm{kg}$ free-falling tup striking the side of a Pyrex cylinder $3.8 \mathrm{~cm}$ in diameter and $6.4 \mathrm{~cm}$ in length at an energy density $W_{i} / V_{0}=2.4 \mathrm{~J} / \mathrm{cm}^{3}$, the resulting particle-size distributions are plotted in Fig. 25, for experiments with three different states of internal stresses: fully annealed, not annealed (with as-received internal stresses), and tempered. Annealing consisted of holding the Pyrex specimen at $510^{\circ} \mathrm{C}$ for $3 \mathrm{~h}$, and cooling it in the closed furnace with the power off. Tempering was done by rapid cooling from the same temperature, by opening the furnace door to ambient air. Tempering greatly increases the threshold for fracture. For example, a 90-J impact test did not break a tempered specimen. Therefore, the test was repeated at $180-\mathrm{J}\left(2.4 \mathrm{~J} / \mathrm{cm}^{3}\right)$, where it fractured like an annealed specimen. The resulting particle-size distributions, shown in Fig. 25, indicate that residual stresses affect only the fracture threshold, not the particlesize distribution. In all subsequent Pyrex tests, only annealed specimens were used.

An initial series of tests has been made of Pyrex specimens of the same size (38-mm-dia) impacted in the same way (usually by a 10-kg tup on the side) and at the same energy density, in order to find the reproducibility of the size distributions of the resulting particulate, all other conditions being the same. The lognormal plots of these data are shown in Fig. 26 (tests PD73, $74,75,76$ ) for energy density $1.2 \mathrm{~J} / \mathrm{cm}^{3}$ and in Fig. 27 (tests PD65, 68, 72) for $0.41 \mathrm{~J} / \mathrm{cm}^{3}$. If the results were completely reproducible, a: 1 points should fall on the same single straight line in both Figs. 26 and 27 . The apparent nonreproducibility of the PD76 data was due to the use of a different procedure for this one test that involved wet sieving and is indicated in Fig. 26 as variant sieving; the standard sievings in Fig. 26 used dry techniques.

In order to provide an extremely intense and localized impact test, one end of a Pyrex cylinder was made in the shape of a $90^{\circ}$ circular cone aligned on the cylinder axis (see Fig. 23). The flat-ended $10 \mathrm{~kg}$ tup was dropped on the apex of the cone, from a height sufficient to give a $28.9-J$ impact. The mean input-energy density for the specimen was $0.42 \mathrm{~J} / \mathrm{cm}^{3}$; the particle-size distribution of the fracture particulate is shown in Fig. 28 (test PD96). The particle-size distribution of the particulates from an end (axial) impact and from side (diametral) impacts of Pyrex cylinders at the same energy density are also shown for comparison. 

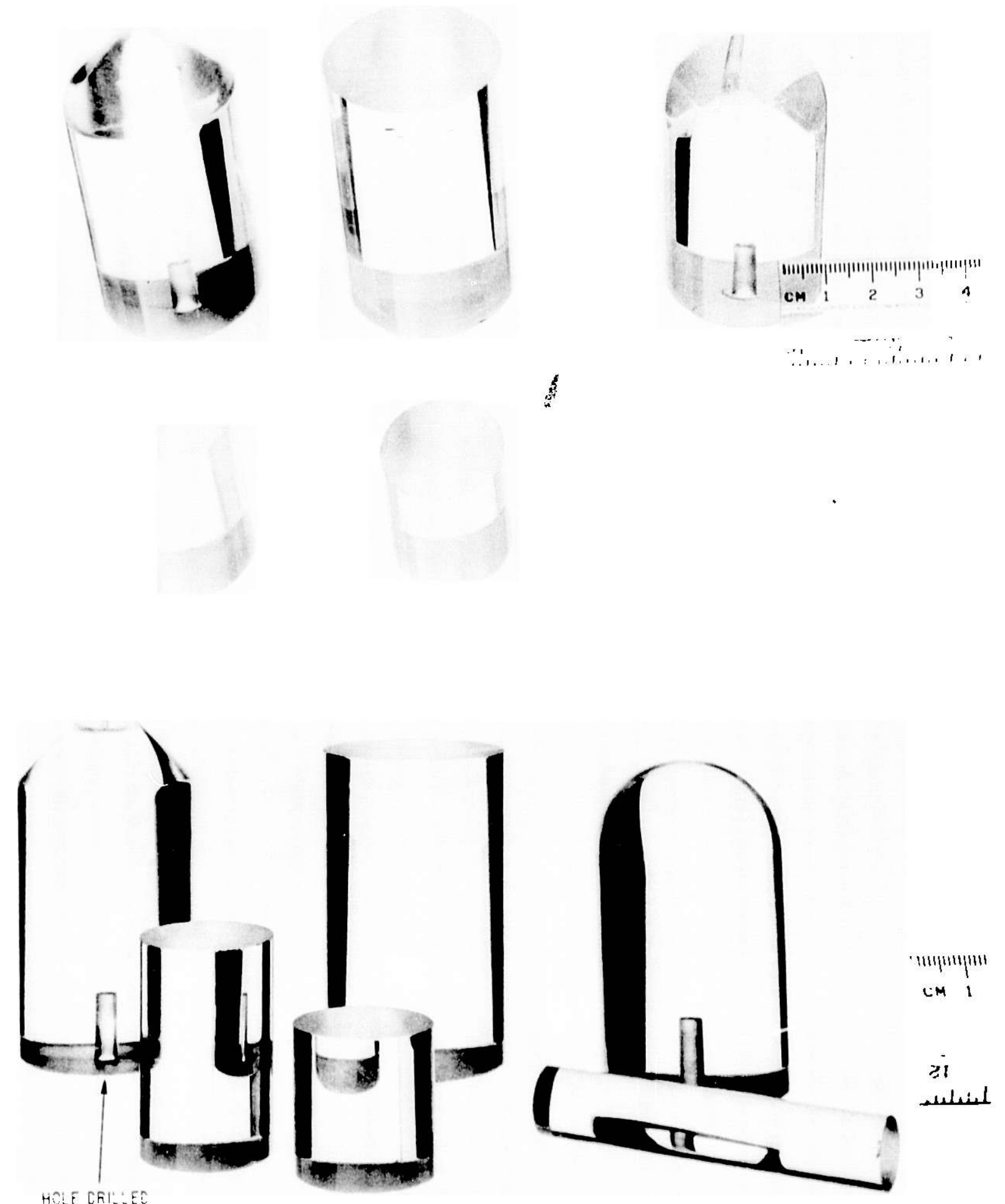

MOLE CAILEE

IRR MOUNTING FINS

(C) F.g if:

Fig. 23. Typical pyrex Specimens prepared for Impact Tests (two vicws) 

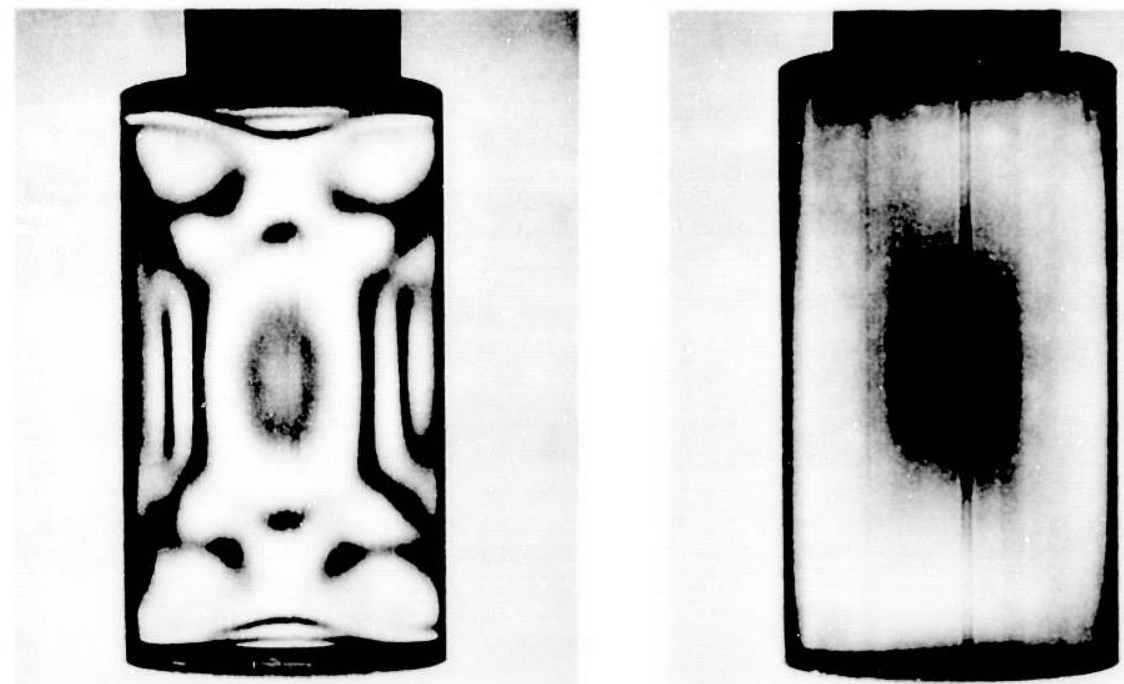

UNANNEALED

ANNEALED

(i)
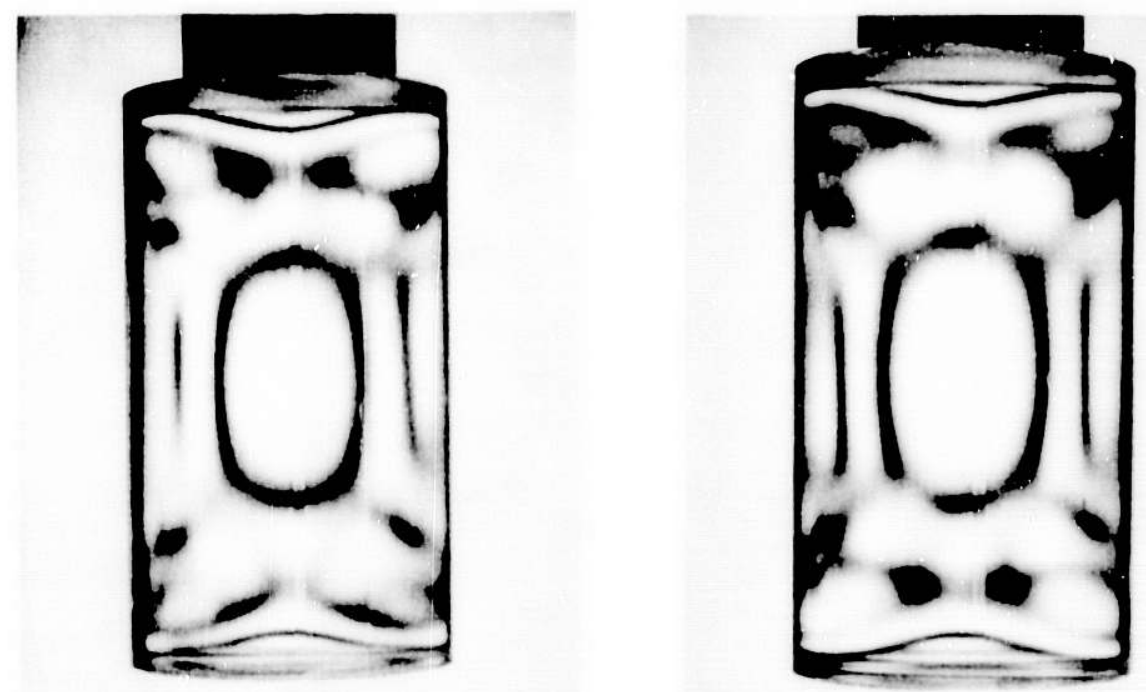

TEMFER: I

TF MFEFE: II

(b)

Fig. 24. Internal stress Paterns in Polarized lighth for Annealed, l'nimmealed, and Tempered lyores speeciments 


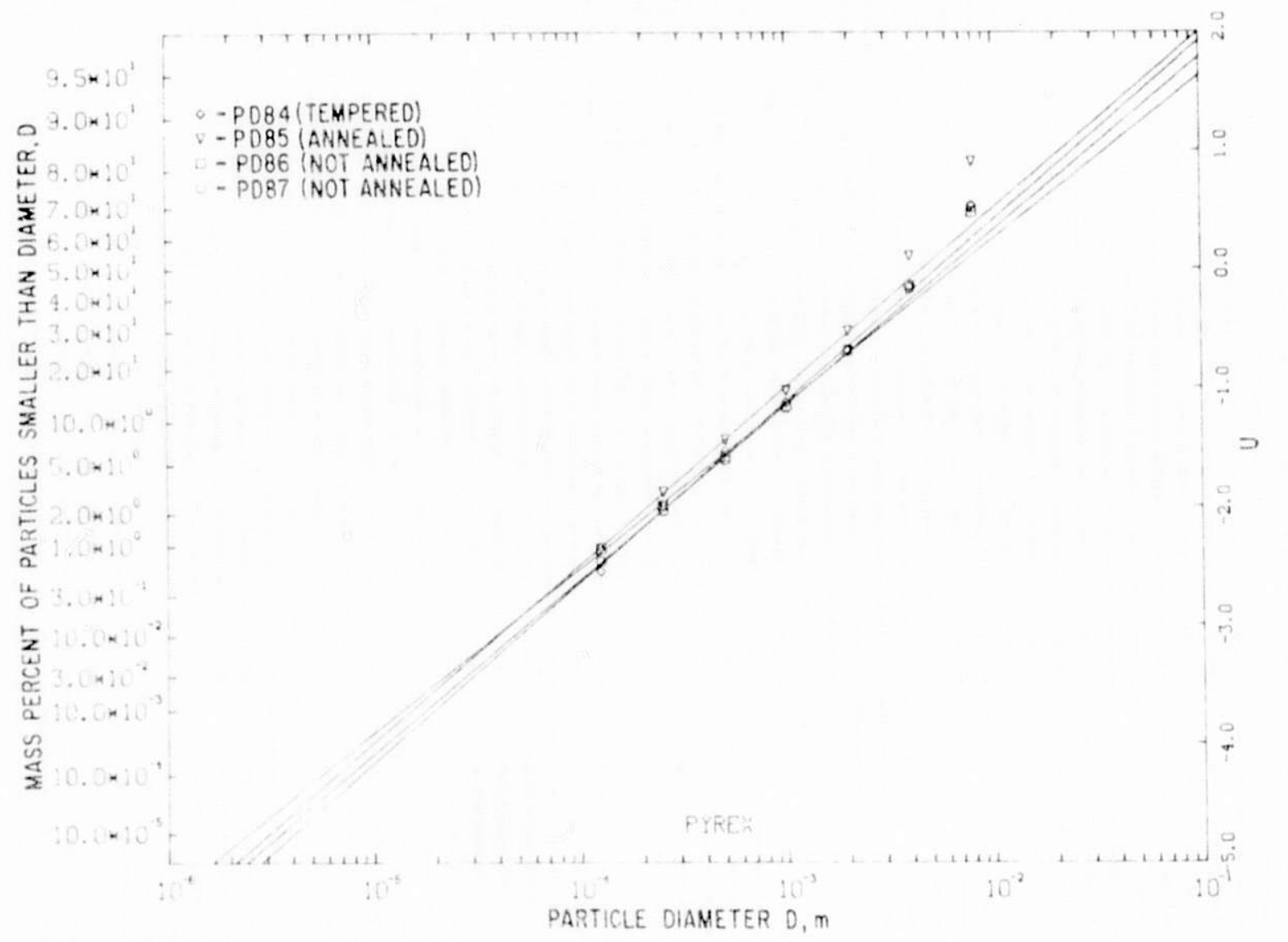

Fig. 25. Size Distributions of Fracture Particulates from Annealed, Unannealed, and Tempered Pyrex Cylinders. (In this and similar figures, u represents the standardized normal probility variate; u is explained in more detail in Appendix C.)

In these preliminary tests no attempt was made to examine the effect of specimen size or of impacting mass. However, such effects may appear because of the time-dependent nature of crack propagation and the multiple stages of the impact process as the free-falling tup causes the fragmentation of glass. A methodology $1 \mathrm{~s}$ being developed for investigation of the scaling laws for brittle fracture. Tests made thus far are belng used to define procedures for studying the comparative fracture of different materials in a standard test. For subsequent particle-size analyses, a Coulter Counter instrument will be used to measure the size fractions of particles with a diameter as small as $5 \mu \mathrm{m}$. Some of this preliminary work was reported in the previous section.

From F1gs. 25-28, 1 t is evident that sieve analyses of 1mpact fracture particulates show reproducible lognormal size distributions over a large size range. It should be noted that Figs. 25-27 show plotted data normalized to $V_{0}$, the total volume (mass) of the 1mpacted spectmen. (This standard $V_{0}$ normalization $1 \mathrm{~s}$ discussed in the text Section $V$ and in Appendix $C$ ). All data analyses and plots use this $v_{0}$ normallzation, except for the cone1mpact test (PD96) and the test data plotted in Fig. 28. An alternative 


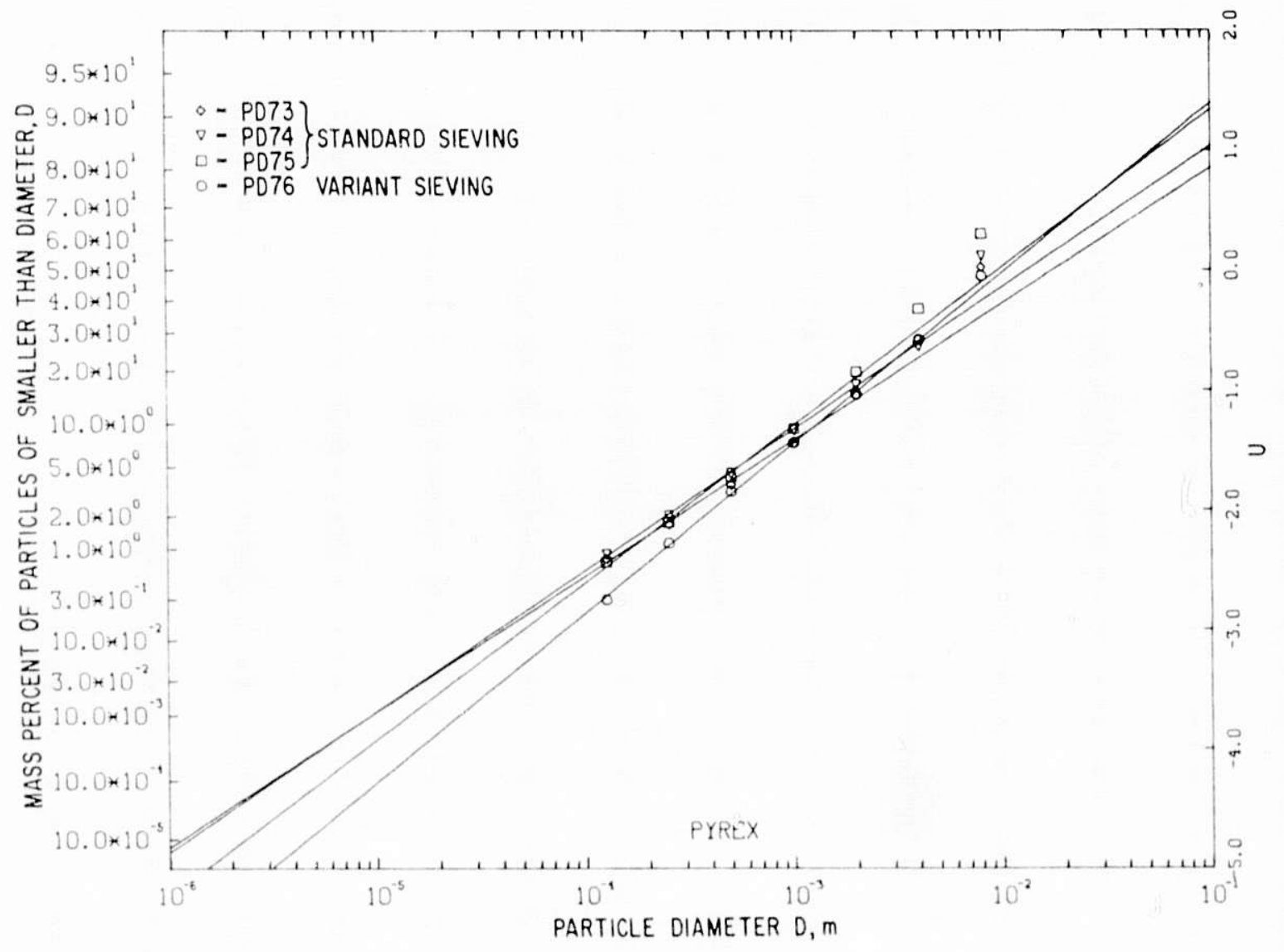

Fig. 26. Particle-Size Distributions of Particulates from Side Impacts of $38-\mathrm{mm}-\mathrm{dia}$ Pyrex Specimens Impacted with $1.2-\mathrm{J} / \mathrm{cm}^{3}$ Energy Density to Examine Test Reproducibility

and somewhat arbitrary normalization was used for the cone impact in Fig. 28 because of the extremely small amount (about $2 \%$ ) of the specimen mass or volume $V_{O}$ that was fragmented in impact. For this case, the normalization volume $\mathrm{V}_{\mathrm{n}}=2 \mathrm{~V}(8 \mathrm{~mm})$ was used; that is, the mass fractions in the size increments separated by sieving were normalized to $V_{n}$, which is twice the volume of particulate that passed through an $8-\mathrm{mm}$ square mesh opening. The significance of the normalization can be seen in the following section on the summary and analysis of data.

\section{B. Summary and Analysis of Data}

The lognormal straight-1ine plots shown in the above figures were determined by linear regression of the sieve-analysis data points over the range of 125 to $2000 \mu \mathrm{m}$. From these plots, the lognormal parameters (mean $\mathrm{D}_{\mathrm{g}}$, standard deviation $\sigma_{g}$ ) were determined. A computer program ANALOG was used to provide the linear regression and the graphics. A report is being written to describe this program for potential users. 


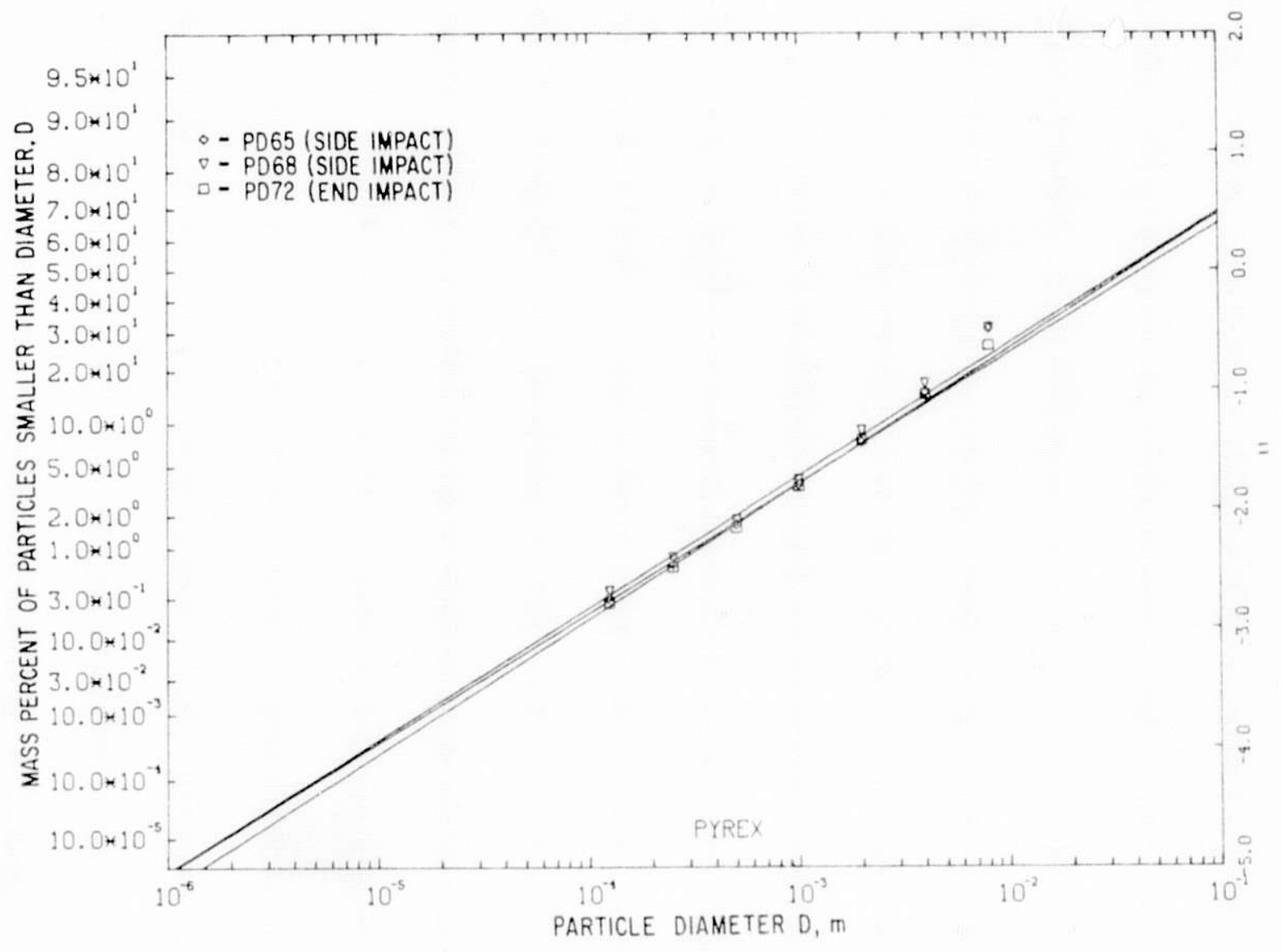

Fig. 27. Particle-Size Distributions of Particulates from Side and End Impacts of Solid Pyrex Cylinders at Energy Density $0.41 \mathrm{~J} / \mathrm{cm}^{3}$ to Examine Test Reproducibility

The test conditions, the lognormal parameters, and the error bands on the parameters ( $1 . e .$, standard deviation of $\mathrm{D}_{\mathrm{g}}$ and $\sigma_{\mathrm{g}}$ ) are given in Table 3. Also shown are the lognormal estimate of the respirable fraction $V(10 \mu \mathrm{m}) / V_{O}$ and the error band of that estimate, based on the experimental data in each test. The ability to estimate the respirable fraction is one of ihe most valuable features of this methodology; the general validity of extrapolation of these data has been illustrated in the previous section where Coulter Counter measurements have been used for verification. Future measurements will establish the precisions.

In linear regression for determination of the lognormal straight line, only data for particles passing through a 2-mm mesh were used. This is because larger particles are so few that good statistics are not possible. The optimum cutoff point may vary with the specimen size and impact conditions; this will be investigated further. One of the advantages of graphical analysis is that departures of the data from lognormality in any particle-size range are readily evident from the graph.

More quantitative analyses and comparisons of particle sizes are possible by using the calculated lognormal parameters shown in Tables 3 and 4 . 

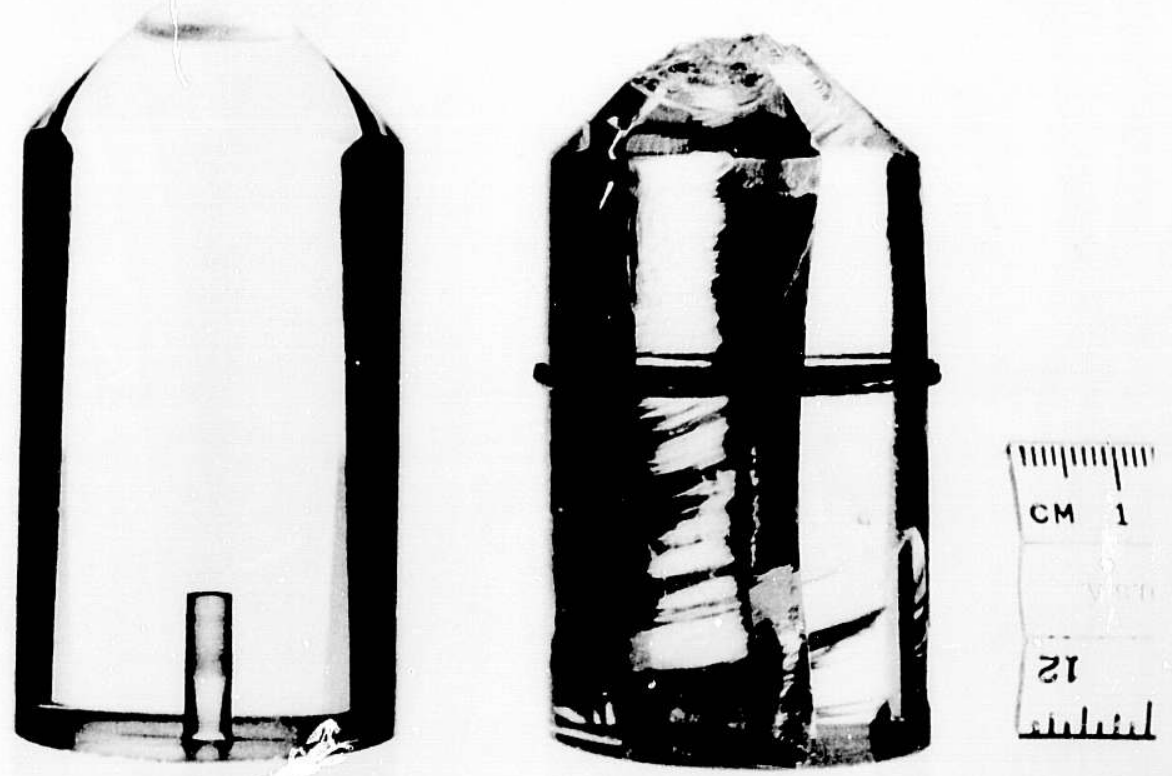

(a)

(b)

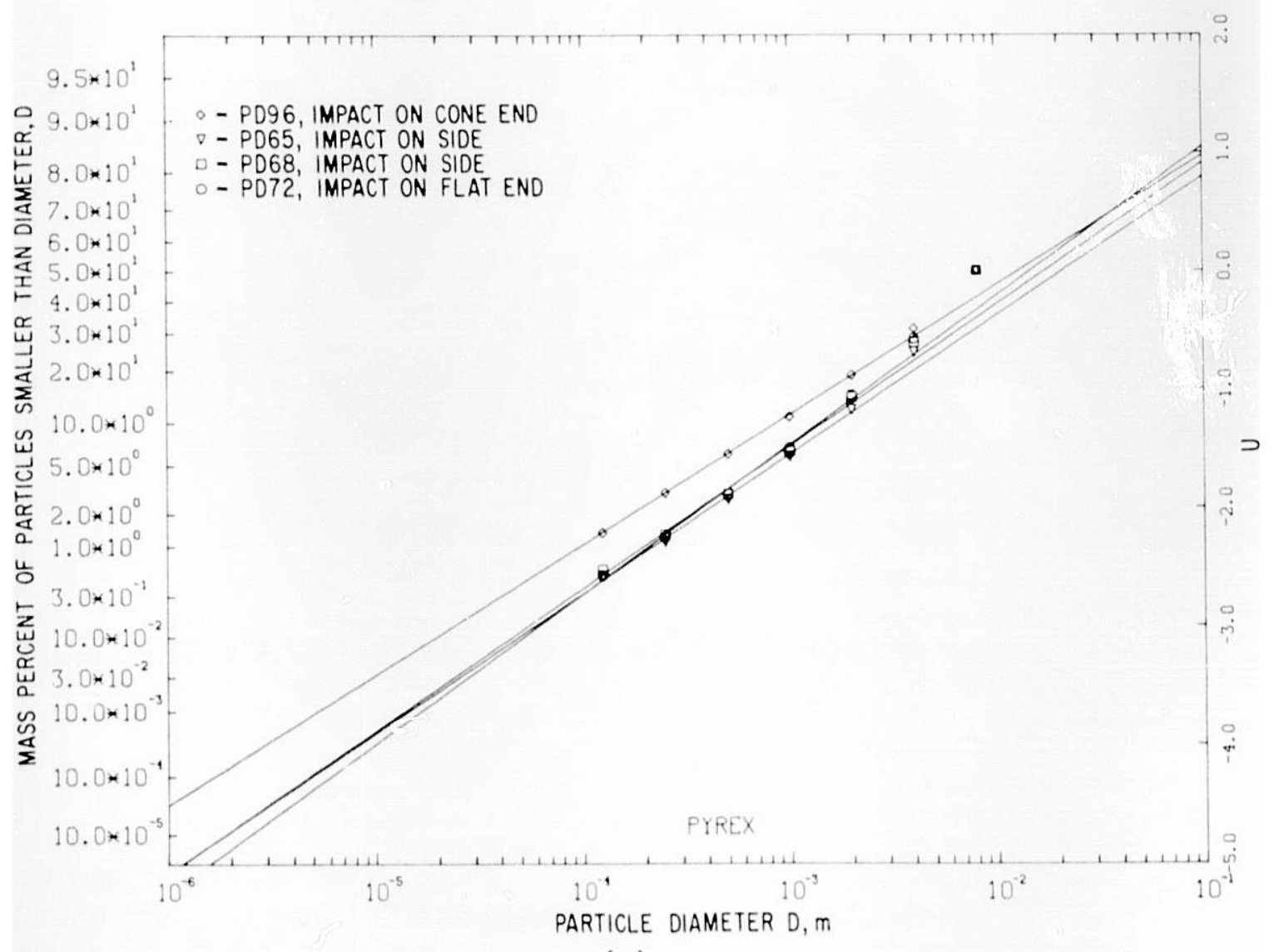

(c)

Fig. 28. Pyrex Cone-Ended Cylinder. (a) Before Impact, (b) After Impact, and (c) Particle-Size Distributions of Particulates Resulting from $0.41-\mathrm{J} / \mathrm{cm}^{3}$ [mpacts Based on an Arbitrary Normalization as Described in Text 
Table 3. Lognormal Parameters of Impact Tests on 38-mm-dia Pyrex Cylinders with $V_{0}$ Normalization

\begin{tabular}{|c|c|c|c|c|c|c|c|c|}
\hline Test & $\begin{array}{l}\text { Impact } \\
\text { Type }\end{array}$ & $\begin{array}{l}\text { Energy } \\
\text { Density } \\
\mathrm{W}_{\mathrm{i}} / \mathrm{V}_{\mathrm{O}} \\
\mathrm{J} / \mathrm{cm}^{3}\end{array}$ & $\begin{array}{l}\text { Resp } \\
\text { Fra } \\
\text { V(10 }\end{array}$ & $\begin{array}{l}\text { rable } \\
\text { tion } \\
\mu \mathrm{m}) / \mathrm{V}_{\mathrm{O}}, \\
\%\end{array}$ & $\begin{array}{l}\text { Mean } \\
\text { Diameter } \\
\mathrm{D}_{\mathrm{g}}, \mathrm{mm}\end{array}$ & $\begin{array}{c}\text { Standard } \\
\text { Deviation } \\
\sigma_{g}\end{array}$ & $\mathrm{D}_{98 \mathrm{~s}} / \mathrm{D}_{\mathrm{g}}{ }^{\mathrm{a}}$ & ${ }^{a \gamma_{f}}{ }_{\mathrm{J} / \mathrm{m}^{2}} \varepsilon^{b}$ \\
\hline PD65 & Diametral & 0.41 & 0.0038 & \pm 0.0006 & $44 \pm 8.0$ & $8.3 \pm 0.4$ & 0.79 & $1.9 \times 10^{3}$ \\
\hline PD68 & Diametral & 0.41 & 0.0042 & \pm 0.0011 & $36 \pm 12$ & $8.0 \pm 0.7$ & 0.85 & $1.7 \times 10^{3}$ \\
\hline PD72 & Axial & 0.41 & 0.0025 & \pm 0.0005 & $39 \pm 9.0$ & $7.7 \pm 0.4$ & 0.92 & $2.0 \times 10^{3}$ \\
\hline PD73 & Diametral & 1.2 & 0.011 & \pm 0.003 & $18 \pm 5.0$ & $7.6 \pm 0.5$ & 0.94 & $2.8 \times 10^{3}$ \\
\hline PD74 & Diametral & 1.2 & 0.012 & \pm 0.001 & $13 \pm 2.0$ & $7.1 \pm 0.2$ & 1.1 & $2.3 \times 10^{3}$ \\
\hline PD75 & Diametral & 1.2 & 0.0045 & \pm 0.0014 & $9.6 \pm 3.0$ & $5.8 \pm 0.4$ & 1.5 & $2.5 \times 10^{3}$ \\
\hline PD76 & Diametral & 1.2 & 0.0010 & \pm 0.0002 & $10 \pm 1.8$ & $5.1 \pm 0.2$ & 1.8 & $3.3 \times 10^{3}$ \\
\hline PD84 & Diametral & 2.4 & 0.0034 & \pm 0.0005 & $4.6 \pm 0.7$ & $4.7 \pm 0.1$ & 2.0 & $3.4 \times 10^{3}$ \\
\hline PD85 & Diametral & 2.4 & 0.0016 & \pm 0.0004 & $5.4 \pm 0.2$ & $4.6 \pm 0.2$ & 2.1 & $4.1 \times 10^{3}$ \\
\hline PD86 & Diametral & 2.4 & 0.0047 & \pm 0.0009 & $6.6 \pm 1.5$ & $5.3 \pm 0.2$ & 1.7 & $4.0 \times 10^{3}$ \\
\hline PD87 & Diametral & 2.4 & 0.0022 & \pm 0.0004 & $6.1 \pm 0.9$ & $+.8 \pm 0.1$ & 2.0 & $4.3 \times 10^{3}$ \\
\hline
\end{tabular}

${ }^{\text {This }}$ ratio is calculated from lognormal parameters as $\mathrm{D}_{98 \mathrm{~s}} / \mathrm{D}_{\mathrm{g}}=\sigma^{2-1 \mathrm{n}} \sigma_{\mathrm{g}}$.

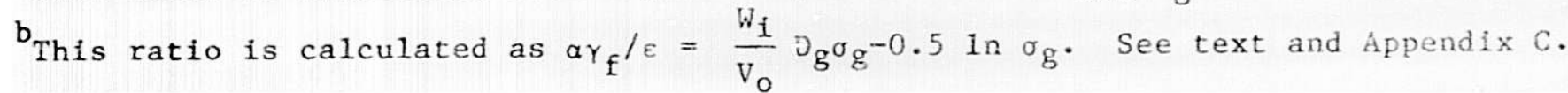


Table 4. Lognormal Parameters of Impact Tests

on 38-mm-dia Fyrex Cylinders with

the Arbitrary $2 \mathrm{~V}(8 \mathrm{~mm})$ Normalization

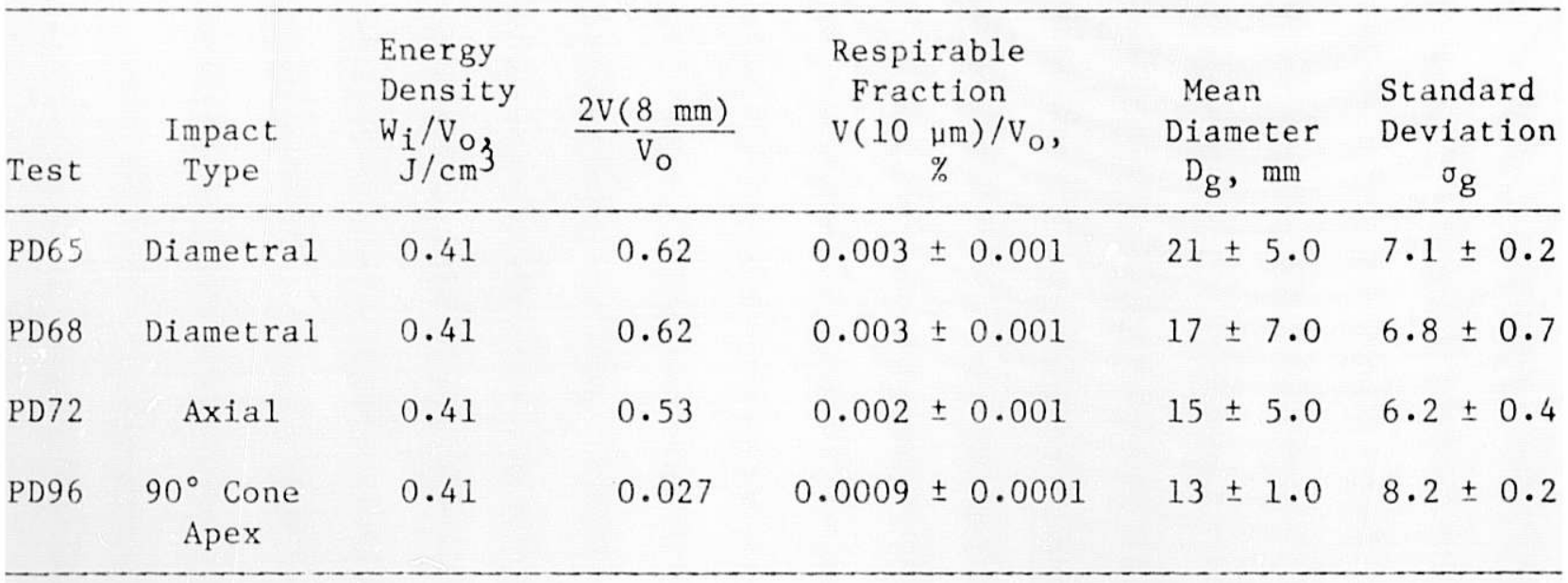

Table 3 shows the calculated parameters fo. the runs with standard $\mathrm{V}_{\mathrm{O}}$ normalization, for which the size data are plotted in Figs. 25-27. The chief parameters (respirable fraction $\mathrm{V}(10 \mu \mathrm{m}) / \mathrm{V}_{\mathrm{O}}$, mean diameter $\mathrm{D}_{\mathrm{g}}$, and geometric mean standard deviation $\sigma_{g}$ ) appear to agree within the standard error bands for all the diametral impacts at a given energy density. The only axial impact test discussed here (PD72 at $0.41 \mathrm{~J} / \mathrm{cm}^{3}$ ) did not differ significantly from the diametral impacts at the same energy density. More tests are required to establish the effect of different specimen sizes and different impact configurations, and the reproducibility of diametral and axial tests.

The mathematical parameters $\left(D_{98 s} / D_{g}\right)$ and $\left(\alpha_{\gamma f} / \varepsilon\right)$ shown in Table 3 and 4 illustrate some overall properties of the fracture particulates ad provide a possible basis for further correlations of fracture effects in terms of energy density and impact configuration. $\mathrm{D}_{\mathrm{g}}$ is the geometric mean or mass median diameter determined from sieving data. D98s is the diameter for which the cumulative surface-area fraction is $98 \%$. That is, $98 \%$ of the surface area is comprised by all particles with diameters less than D98s. The fact that the ratio $\mathrm{D}_{98 \mathrm{~s}} / \mathrm{D}_{\mathrm{g}}$ is in the approximate range of 1 to 2 indicates a regularity of the surface-area distribution compared to the mass distribution of particle size. Subsequently, surface-area measurements will be made to develop these correlations. The mathematical relations between the two types of lognormal distributions are outlined in Appendix C.

The parameter $\left(\alpha_{\mathrm{f}} / \varepsilon\right)$ is based on the methodology presented above in Section III-C. This parameter is an "effective" property of impact resistance, measured in units of input energy per unit of surface area formed for particles with a mean shape factor $\alpha$ (which is not determined in these preliminary tests). For the range of energy densities shown, the value of $\left(\alpha_{\gamma_{f}} / \varepsilon\right)$ is a weak function of energy density, varying only by a factor of 2.5 .

The parameters shown in Table 4 are those derived from $2 \mathrm{~V}(8 \mathrm{~mm})$ normalization described above, and used for the cone-impact test (PD96) and the other runs shown in Fig. 28. Since tests PD65, PD68, a d PD72 were also analyzed by the standard $V_{0}$ normalization (Table 3 ), the ffects of the two 
procedures can be seen by comparing values of $\mathrm{D}_{\mathrm{g}}, \sigma_{\mathrm{g}}$, and the respirable fraction $V(10 \mu \mathrm{m}) / V_{0}$ calculated on the basis of the total specimen volume $V_{O}$. This analysis provides a preliminary comparison of diametral and axial impacts with the extreme type of impact represented by impact on the apex of a $90^{\circ}$ cone. It is believed that all realistic impacts show less extreme stress concentration than that for the cone impact test.

In Table 5 is shown a preliminary attempt to define a possible correlation of lognormal parameters with impact energy density. For diametral impact tests at each energy density, mean values of the parameters $D_{g}$ and $\left(\alpha \gamma_{f} / \varepsilon\right)$ are shown in Table 3 . This mean value, $\left(D_{g}\right)$ was multiplied by the energy density $\left(W_{i} / V_{0}\right)$ to give the mean size parameter shown in Table 5 . The fact that this parameter has a nearly constant value, $1.5 \times 10^{4} \mathrm{~J} / \mathrm{m}^{2}$, independent of energy density, indicates a possibly useful correlation in further studies.

Similarly, the fracture energy parameter, shown in Table 5, is the ratio of mean values of $\left(\alpha \gamma_{f} / \varepsilon\right)$ divided by the square root of the energy density. This parameter has a value of about 2.5 (in the units used), independent of energy density and may also provide a useful correlation. While the 0.5 power of $\left(\mathrm{w}_{i} / \mathrm{V}_{0}\right)$ is arbitrary here, it happens that mean stress is proportional to the square root of elastic strain energy stored in a material subject to elastic compression. Further experiments are in progress to examine these potential correlations and to relate them to the brittle-fracture process.

The above discussion summarizes the preliminary results obtained from sieving data for initial Pyrex tests. Standardized procedures for sieving and Coulter Counter analysis have been defined based on the experience gained from these tests and will be used in future tests. The physical appearance of the fracture particles obtained in sieving in the size ranges shown is illustrated in Fig. 29.

Table 5. Preliminary Correlations of Lognormal Parameters with Energy Density for Diametral Impacts of 38-mm-dia Pyrex Cylinders ${ }^{a}$

\begin{tabular}{lcc}
$\begin{array}{l}\text { Energy } \\
\text { Density } \\
\begin{array}{l}\mathrm{W}_{\mathrm{i}} / \mathrm{V}_{\mathrm{O}}, \\
\mathrm{J} / \mathrm{cm}^{3}\end{array}\end{array}$ & $\begin{array}{c}\text { Mean Size } \\
\text { Parameter } \\
\left(\mathrm{W}_{\mathrm{i}} / \mathrm{V}_{\mathrm{O}}\right) \mathrm{D}_{\mathrm{g}}, \mathrm{b} \\
\mathrm{J} / \mathrm{m}^{2}\end{array}$ & $\begin{array}{r}\text { Fracture Energy Parameter } \\
\left(\frac{\alpha \gamma_{\mathrm{f}}}{\varepsilon}\right)^{\mathrm{C}} /\left(\mathrm{W}_{\mathrm{i}} / \mathrm{V}_{\mathrm{O}}\right)^{0.5}\end{array}$ \\
\hline 0.41 & $1.6 \times 10^{4}$ & 2.8 \\
1.2 & $1.5 \times 10^{4}$ & 2.5 \\
2.4 & $1.4 \times 10^{4}$ & 2.5 \\
\hline
\end{tabular}

a Farameters based on $V_{0}$ normalization.

$b_{\text {The mean value of }} D_{g}$ from all tests in Table 3 for diametral impacts at the given energy density.

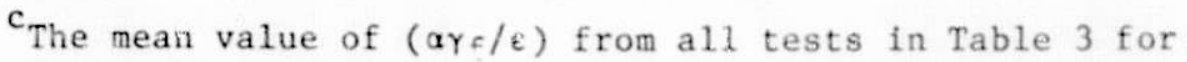
diametral $1 m_{i}$ acts at the given energy density. 

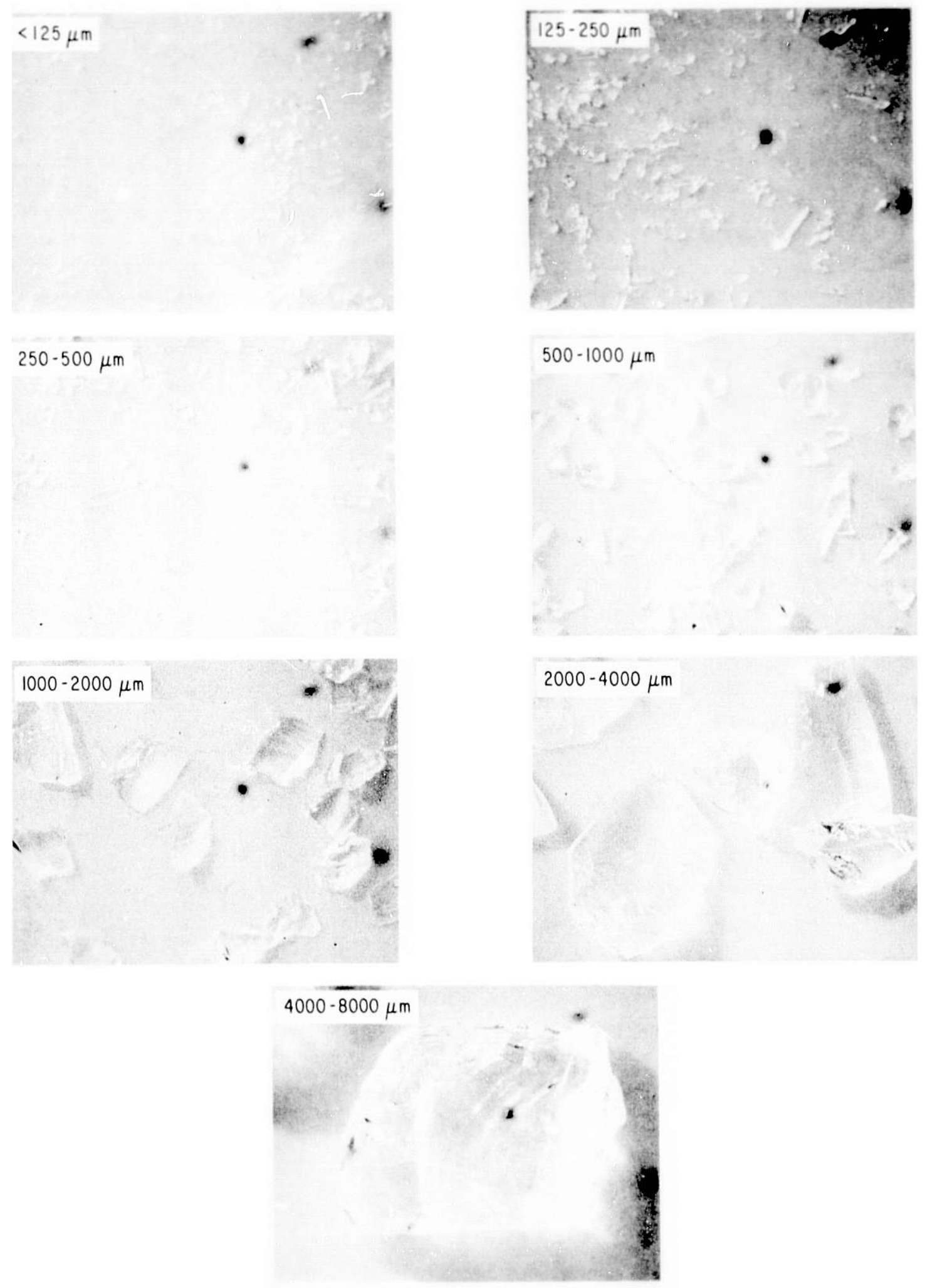

Fig 29. Typical Pyrex Particles in Varlous Size Ranges that Result from Impact Tests 
VII. ENERGY, STRESS, AND TIME PARAMETERS

The characterization of the relations of energy, stress, and time in metric units is very straightforward: mass (kilograms), energy (joules), force (Newtons), stress or pressure (Pascals), length or distance (meters), time (seconds), and velocity (meters/second). In these units, the input energy $W_{1}(J)$ can be calculated in terms of the kinetic energy of the deceleration mass $\mathrm{M}(\mathrm{kg})$ and the height of free-fall $\mathrm{H}$ (in) as

$$
W_{1}=1 / 2 \mathrm{MU}_{0}^{2}=9.8 \mathrm{MH}
$$

where $U_{0}$ is the maximum velocity $(\mathrm{m} / \mathrm{s})$ just before 1 mpact and 9.8 is the gravitational acceleration $9.8 \mathrm{~m} / \mathrm{s}^{2}$. If $\mathrm{V}_{0}\left(\mathrm{~m}^{3}\right)$ is the volume of the body impacted, then the energy density $W_{1} / V_{0}$ is given by

$$
\frac{W_{1}}{V_{0}}=1 / 2 \mathrm{M}\left(\frac{U_{0}^{2}}{V_{0}}\right)=9.8 \mathrm{M}\left(\frac{H}{V_{0}}\right)
$$

In drop-weight tests, $M$ is the mass of the tup, and the velocity of collision depends on the height of free-fall. In earlier sections, a constant mass $M$ was used in drop-weight tests, so that although the impact velocity varied considerably, the results of fracture correlated with energy dencity, indicating that fracture is independent of velocity.

The velocity of the tup is assumed in our tests to decrease from $U_{0}$ to zero, and the tup is assumed to have an essentially unyielding surface. The deceleration du/dt produces a force $F$ which is a function of time in the impact process:

$$
F(t)=M \frac{d u}{d t}
$$

This deceleration force $F(t)$ is balanced by an opposing elastic compression force $F(X)$ in the impacted body, where $X$ is the linear compression of the body on the force axis. For a unfform load-bearing cross-sectional area $A$ in the body, whose length along the force axis is $\mathrm{L}$, the elastic force $\mathrm{F}(\mathrm{X})$ is related to the stress $\sigma$ and the strain $X / L$ by the elastic modulus $E$ (a property of the material):

$$
F(X)=A \sigma=A E \frac{X}{L}
$$

After the time of initial contact, the time rate of change of $\mathrm{x}, \mathrm{dx} / \mathrm{dt}, \mathrm{is}$ equal to the velocity of the body as function of time $U(t) . F(t)$ and $F(X)$ are equal and opposite so that $F(X)=-F(t)$, and

$$
M \frac{d U}{d t}=M \frac{d^{2} X}{d t^{2}}=-\left(\frac{A E}{L}\right) X
$$


If the quantity ( $\mathrm{AE} / \mathrm{L})$ is constant, independent of time, this differential equation has the solution

$$
x=\left(\frac{110}{C^{1 / 2}}\right) \sin c^{1 / 2} t
$$

where $C=A E / M L$. An equivalent form, based on the definition of $W_{i}$ given above, is

$$
\frac{\sigma}{E}=\frac{X}{L}=\left(\frac{2 W_{i}}{E V_{O}}\right)^{1 / 2} \sin \left[\left(\frac{A E}{M L}\right)^{1 / 2} t\right]
$$

Thus the stress $\sigma$ is a function of input energy $W_{i}$ and time, but not of mass or velocity per se. The maximum stress occurs when $X$ reaches its maximum, which is when the sine function is at its maximum value of 1 ; therefore the maximum stress depends on energy density alone.

The maximum time $t_{m}$ corresponding to maximum stress is

$$
t_{m}=\frac{\pi}{2}\left(\frac{M L}{A E}\right)^{1 / 2}
$$

If fracture does not take place, the time $t_{m}$ is also the time for elastic rebound, by which the stresses would return to zero. Therefore, in this simple case, the time to achieve full compression (maximum stress and kinetic energy reduced to zero) is proportional to the square root of the term ML/AE, so that it is independent of velocity and energy. The chief point here is that the maximum stress is proportional to the square root of input energy density and is independent of mass (body size) and velocity, for a given energy density. The time involved is proportional to the square root of the mass and is independent of the energy associated with that mass. Thus, in drop-weight impact tests with the same tup mass, the same time of complete elastic compression is involved for specimens of the same size, regardless of energy density. Also, the peak stress is the same for the same energy density regardless of the velocity of impact associated with that energy density. Thus, the differences in fracture results are a result of the different properties of the material. This accounts for the uniformity of results reported in the previous sections.

It is the time-dependent nature of brittle fracture, and the effect of deceleration mass on the time $t_{m}$, that must be taken into account in the design of tests in which the impacted body is in free-fall. If the freefalling body has small mass, the time for full elastic compression may be too small for fracture to occur, and the body may undergo elastic rebound before fracture can occur. Free-fall tests are being planned. However, the basic principles demonstrated here apply to all 1mpacts of practical interest, regardless of body size or impact velocity. The basic parameters are energy density and time. 
High-speed motion pictures were made of impacts of pyrex sperimens. Views from contact $(t i m e t=0)$ up to about 300 us $\left(3 \times 10^{-4}\right.$ s) are shown $1 \mathrm{n}$ Fig. 30. The frame speed (ahout $150 \mu \mathrm{s} / \mathrm{frame}$ ) was not fast enough to show the earliest stages of fracture, which occurred before 150 ws.

Types of specimens proposed for both iree-tall and drop-welght lests are shown In Fig. 3l. The fins are for use in our free-fall test devicte (up to 30-m height). The metal object is a welded steel canfster, inter which glass can be cast.
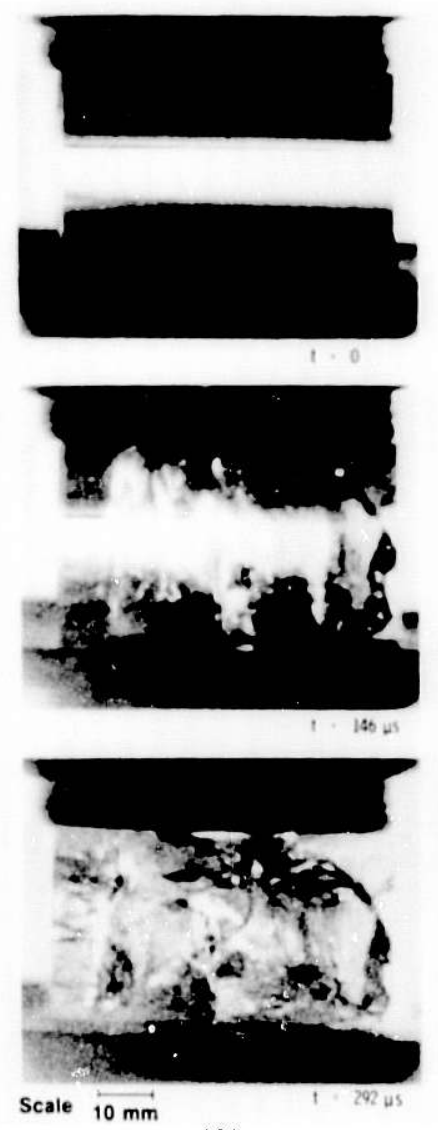

(A)
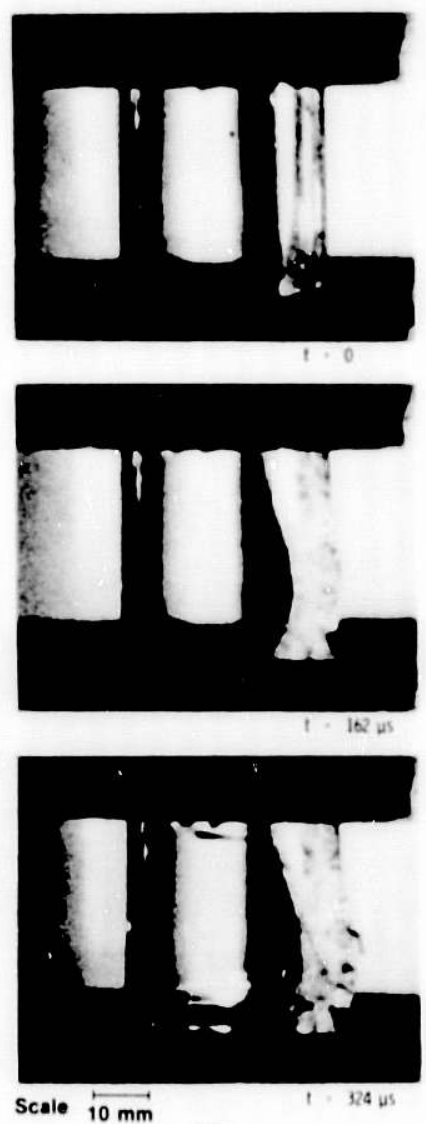

(B)
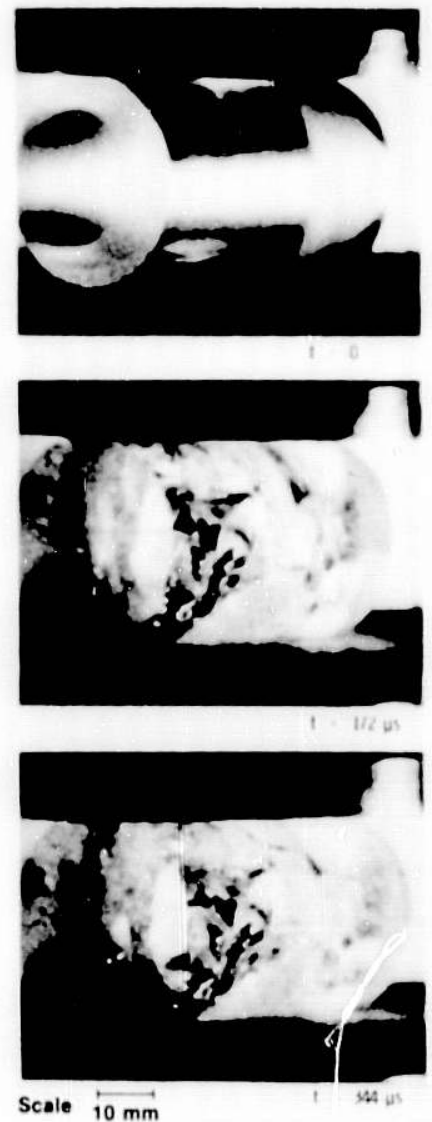

(C)

Fig. 30. High-Speed Motion Pictures of the Impact Fracture (at $91 \mathrm{~J}$ ) of Pyrex Specimens. (a) Side view of a diametral impact (diameter 3.81 , length $6.41 \mathrm{~cm}$ ); (b) Side view of an axial 1 mpact (diameter $3.81 \mathrm{~cm}$, length $3.81 \mathrm{~cm}$ ); (c) Angle view of a diametral 1mpact (diameter $3.81 \mathrm{~cm}$, length $6.41 \mathrm{~cm}$ ). 


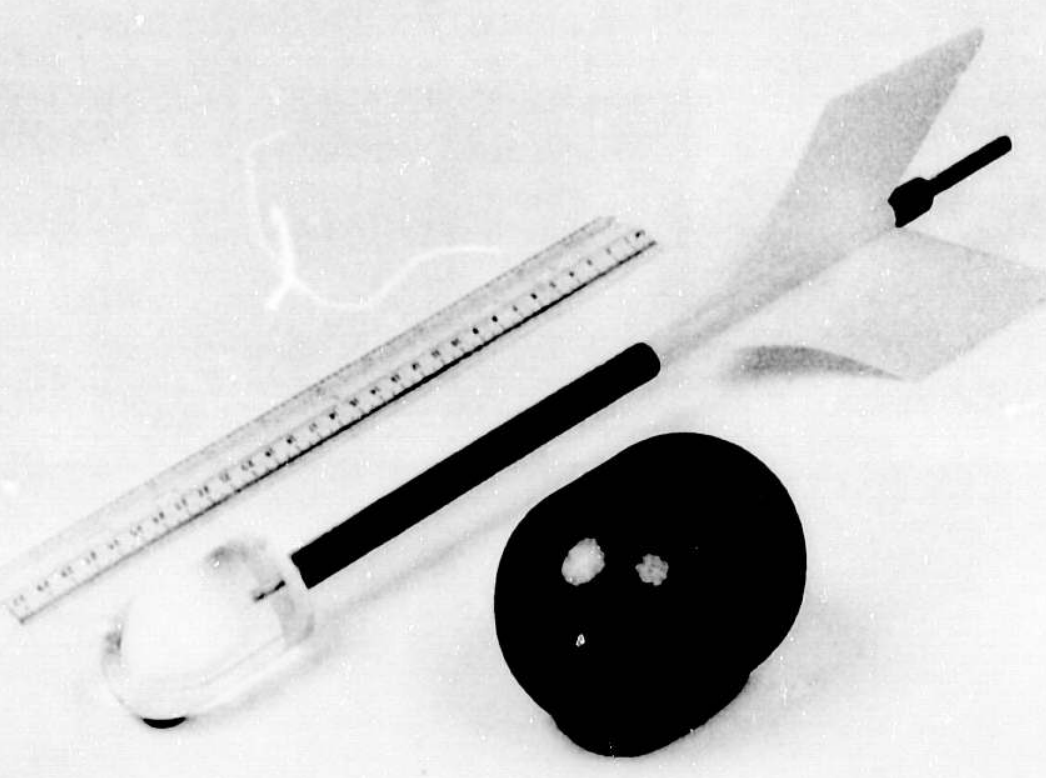

Fig. 31. Some Glass and Canistered Specimens Proposed for Future Free-Fall and Drop-We1ght Tests 
APPENDIX A

STRESS, ENERGY, AND SURFACE AREA

Imagine a solid bar of uniform cross-sectional area A being pulled apart by opposing forces applied at both ends. If the tensile force is $\mathrm{F}$, then a uniform stress $\sigma$ in the bar is given by

$$
\sigma=\frac{\mathrm{F}}{\mathrm{A}}
$$

The elastic stress $\sigma$ is uniform through the bar. For a given final $\mathrm{F}$ and $\sigma$, there is mechanical work $W$ performed in this elastic stretching of the bar. The property of elasticity is formulated in terms of a material property, E, Young's modulus of elasticity, the original length of the bar $L$, and the absolute linear displacement (elastic deformation as change of length) $x$ :

$$
\sigma=\frac{E X}{L}
$$

In Eq. 2, $\mathrm{E}$ is a constant. Both $\mathrm{E}$ and $\sigma$ have the same dimensions (force/length ${ }^{2}$ ). The stored energy $\mathrm{W}$ in the bar can be stated in differential terms as

$$
\mathrm{dW}=\mathrm{FdX}=\operatorname{A\sigma dX}=\frac{\mathrm{AEX}}{\mathrm{L}} \mathrm{dX}=\frac{\mathrm{AL} \sigma \mathrm{d} \sigma}{\mathrm{E}}
$$

For a given final value of linear displacement $X$, the energy $W$ stored in the bar as a whole, whose volume $\mathrm{V}=\mathrm{AL}$, is

$$
w=\int_{0}^{X} \mathrm{FdX}=\frac{\mathrm{AEX}^{2}}{2 \mathrm{~L}}=\frac{\mathrm{V \sigma}^{2}}{2 \mathrm{E}}
$$

The dimensions of $W$ are (force) (length).

From Eq. 4, stress $\sigma$ and energy $W$ are functions of $X$ and related as

$$
\sigma(X)=\left[2 E\left(\frac{W}{V}\right)\right]^{1 / 2}=\frac{F(X)}{A}
$$

Imagine the gradual increase of $F, \sigma$, and $X$ until the limit of elastic behavior of Eq. 2 is exceeded, and inelastic deformation (which for a brittle material is fracture) takes place. That is, the bar breaks in two at the cross-section A normal to the force axis. This cleavage fracture produces new surface areas, namely $2 \mathrm{~A}$. If $\gamma$ is the surface specific energy of fracture, then

$$
Y=\frac{2 A}{W}
$$


If we rewrite Eq. 4 in terms of the critical stress for fracture $\sigma_{c}$, we have

$$
\mathrm{W}_{\mathrm{C}}=2 \mathrm{Ar}=\frac{\mathrm{AL}_{\mathrm{C}_{c}}^{2}}{2 \mathrm{E}}
$$

or, in terms of $\gamma$,

$$
\sigma_{c}=2\left(\frac{E}{V}\right)^{1 / 2}\left(\frac{A}{r}\right)^{1 / 2}
$$

There is an anomaly in this simple model of brittle fracture. We have assumed that fracture is caused by stress $\sigma_{c}$, but that only one cleavage fracture takes place, even though all of the bar is stressed equally. In static (dead weight) application of force, fracture typically occurs at only one plane. This is because fallure occurs at the one cross section which has the largest flaw (i.e., the "weakest link"). But for uniform stress causing fracture, the bar could break simultaneously at $n$ planes. Since the value of the surface area $A$ is variable for a given fracture-causing stress, depending on the distribution of flaws in the material, the value of the surface-specific energy property, $\gamma$, is indeterminate.

In practice, $\gamma$ is indeterminate in static loading (slow-compression crushing) but is a statistical mean property $\gamma_{f}$ in impact fracture, as discussed in the Background section of this report. In impacts of brittle materials, many fracture cleavages take place, resulting in a particulate whose size distribution is described by a probability function. This concept of brittle fracture is developed further in the Methodology Summary Section IV of this report and in Appendices $B$ and $C$. 
APPENDIX B

\author{
BINARY-CLEAVAGE MODEL PARAMETERS
}

Tests of the brittle strength of structural materials are usually made with slow applications of force or with dead-weight loading. The common configurations used are those illustrated in Fig. B-1, namely, the 3-point bend test and the diametral compression test. These have been analyzed in detail in the literature [MARSCHALL, MARION]. The dianetral compression test has been proposed as a standard static test tensile for brittle waste forms by the Materials Characterization Center (MCC), which is part of the DOEsponsored Waste Management Program.

BRITTLE SOLIDS SHOW BINARY CLEAVAGE IN STATIC-LOAD FRACTURE TESIS

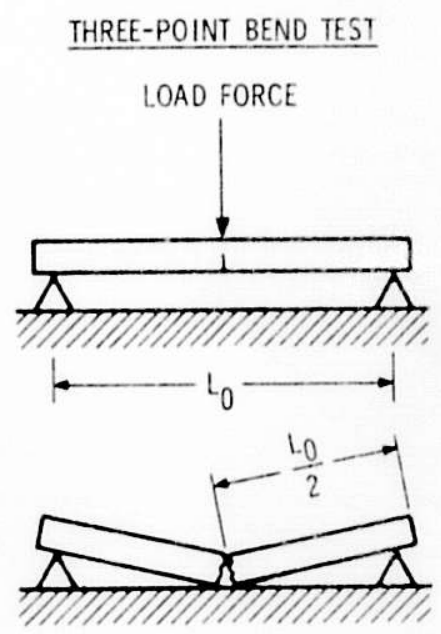

DIAMETRAL COMPRESSION TEST

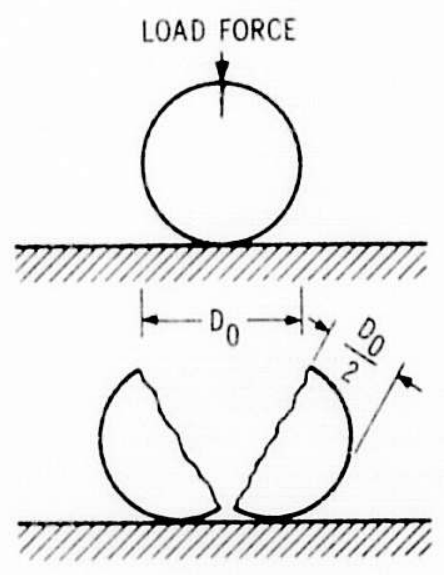

Fig. B-1. Binary-Cleavage Mode of Brittle Fracture in Standard Strength Tests [MARION]

Most of the impact tests made in our brittle fracture study have been drop-weight tests using the diametral compression configuration of solid cylindrical specimens. This method yields reproducible particle-size distributions.

A binary-cleavage mode of brittle fracture is shown in these two most common tests shown in Fig. B-1. In order to visualize the extension of this mode of fracture to 3-dimensional impact fracture, a diagram of the subdivision of a cube is shown in Fig. B-2. Consider binary-cleavage Stage 1, indicated in Fig. B-2 at the left vertical edge of the solid cube. In Stage 1 , the entire cube is divided in two equal volumes along the fracture plane indicated by Stage 1. In Stage 2, each of the two previously subdivided volumes are cleaved in two. In Stage 3, each of the four pleces are subdivided, and so on. This illustrates cleavage in one dimension. Imagine the same stagewise processes going on in each of the three dimensions simultaneously. The figure shows the result of equal cleavages in all 3 


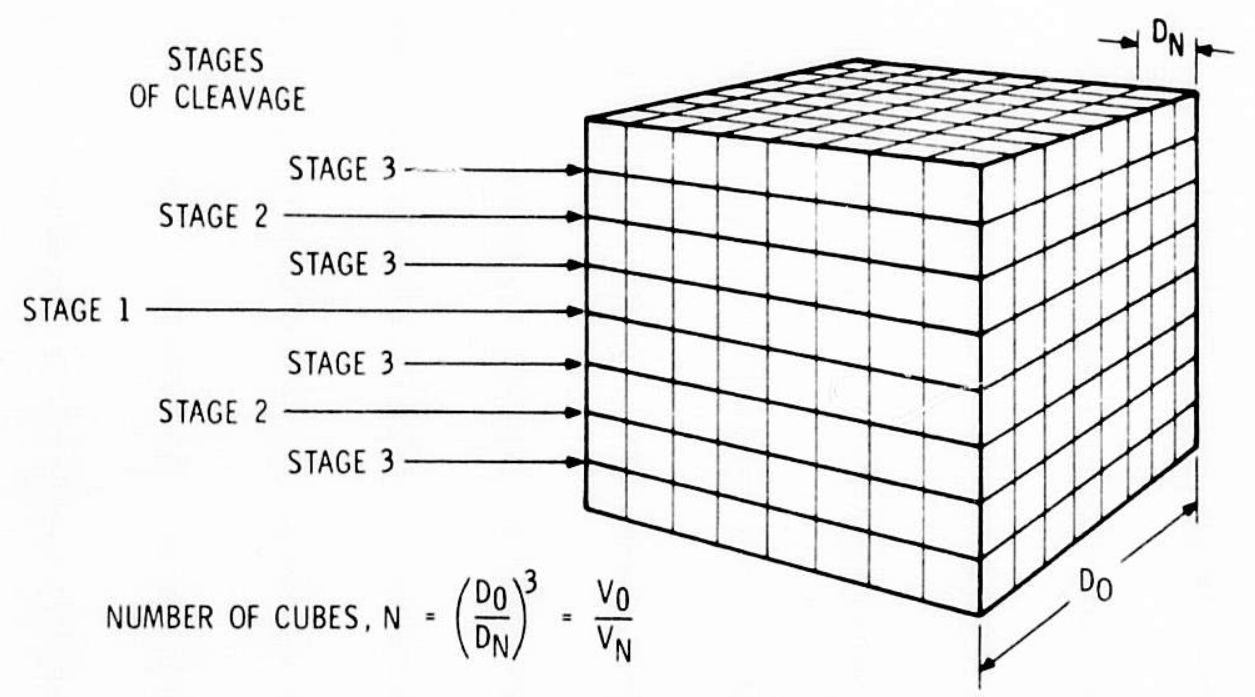

PARTICLE SIZE DETERMINED BY $n$ STAGES OF BINARY-CLEAVAGES APPLIED TO THE WHOLE VOLUME $\mathrm{V}_{0}$ :

$$
\begin{gathered}
\frac{D_{N}}{D_{0}}=2^{-n} ; N=\frac{V_{0}}{V_{N}}=2^{3 n} . \\
\text { Fig. B-2. } \begin{array}{l}
\text { Successive Stages of Binary } \\
\text { Cleavage in a Cube }
\end{array}
\end{gathered}
$$

dimensions. After $\mathrm{n}$ stages, the cube has been subdivided into $\mathrm{N}$ equal-sized cubes each with a linear size $D$ which can be related to the original size $D_{0}$ by the relation

$$
\frac{\mathrm{D}}{\mathrm{D}_{\mathrm{O}}}=\left(\frac{1}{2}\right)^{\mathrm{n}}
$$

The number of cubes is

$$
N=\frac{v_{0}}{D^{3}}=\left(\frac{D_{0}}{D}\right)^{3}=2^{3 n}
$$

or

$$
\ln \Delta=3 \ln \left(D_{0} / D\right)=3 n \ln 2
$$

If the cube so subdivided is treated as a fracture particulate produced by compression, the geometric mean particle size $D_{g}$ is given as a function of $\mathrm{n}$ by Eq. 1,

$$
D_{g}(n)=D_{0} 2^{-n}
$$

The standard deviation 1 s of course zero for cubical particles all of the same size. If simtlar cubes were subdivided in repeated tests of the same type, it might be expected, for large numbers of particles, say $N=10^{6}$, that 
the number of stages would vary somewhat about a mean value $\bar{n}$. These variations in $n$ would give variations in $D$ expressed by

$$
\frac{\mathrm{D}}{\mathrm{D}_{\mathrm{g}}}=\left(\frac{1}{2}\right)^{\mathrm{n}-\overline{\mathrm{n}}}
$$

or

$$
-\frac{\ln \left(D / D_{g}\right)}{\ln 2}=n-\bar{n}
$$

The minus sign follows from the fact that larger $n$ gives smaller $D$. If $n$ is distributed normally, $D$ is distributed lognormally in terms of the standardized normal variate $u$.

$$
\frac{D}{D_{g}}=\sigma_{g}^{u}
$$

Note the simflar form of Eqs. 5 and 7 . This seens to be a plausible explanation of size variations in the impact fracture of brittle materials.

Consider the cubical cleavage model as a model of fracture. Multiple fractures occur in the two tensile-strain dimensions, and we may imagine multiple fractures of the sort shown in Fig. B-3, where it is supposed that the compressive force is applied evenly to the top of the cube. The long

CASE A: NO STRAIN

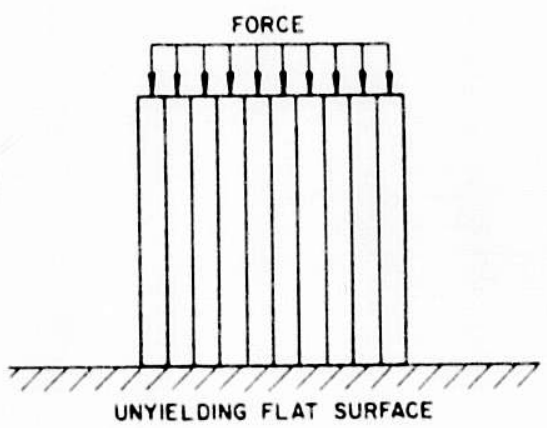

CASE B: STRAIN TO FRACTURE

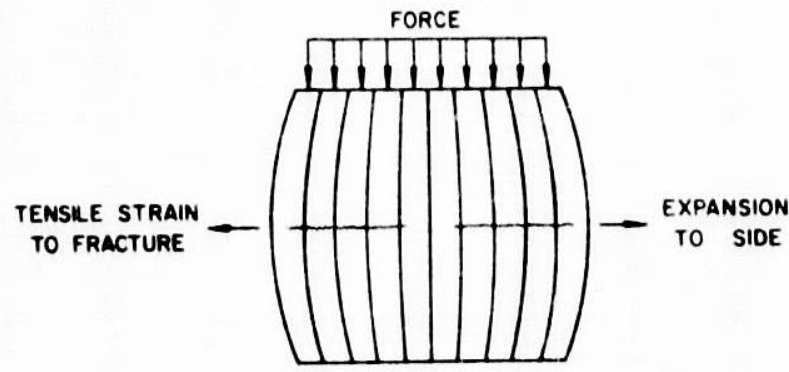

F1g. B-3. Compressive Fracture of a Cube 
slender columns produced by the primary cleavages will bow outward and fracture by bending as shown in the lower view in Fig. B-3. This bending is most extreme at the free surfaces of the cube and is driven by the stored compressive energy. The long columns of Fig. B-3 fracture at various places along the length and the particles produced fly outward in directions normal to the axis of applied force.

In a test with a perfectly hard application of force, there is no elastic energy feed-in from the restraints applied to the load-bearing faces of the cube. The elastic energy stored in the material is sufficient to fragment the cube into particles, and the extent of fracture will depend on the energy leve:. However, any additional feed-in of energy after initial fracture will also contribute to the total fracture.

In general, it appears that Impact fracture will produce many irregular particles, and the energy fed in from the descending tup will be used to produce additional fracture surface at stages following the initial fracture from stored energies. This energy efflciency is the basis of the surface-energy correlation obtalned by Piret, as discussed in the main body of this report. 


\section{APPENDIX C \\ LOGNORMAL PARTICLE STATISTICS}

In the physical process of br?ttle fracture, there results the random variation of the size and shape of particles, including random variations of the volume and surface area of the particles. The total surface area of fracture is the total surface area of these particles, and therefore the fracture surface is able to be characterized statistically, from measurements analyzed in terms of particle-size distribution. The appropriate conti unous mathematical function describing the result of very many and very small additive factors determining a physical size of a particle is the normal probability function [HERDAN], which has two forms, the frequency or probability density $p$ and the cumulative probability P. Mathematically, it is convenient to formulate these functions in terms of the standardized normal variate $u$, such that

$$
P(u)=\int_{-\infty}^{u} p(u) d u
$$

where $u$ is the random property defined in terms such that its mean value is zero and its standard deviation is unity. For different (but finite) values of the mean $(\mu)$ and the standard deviation $(\sigma)$, standardized variate $u$ is defined by the relation

$$
u=\frac{x-\mu}{\sigma}
$$

That is, $u$ is obtained from the normal variate $X$ in terms of the difference from the mean value $\mu$, in units of the standard deviation $\sigma$. This is the normal probability function, and it has a unique practical significance, due to the Central Limit Theorem of mathematical statistics, as it applies to all random sampling measurements. This theorem states that sample means follow normal distributions whatever the "true" probability distribution of the random population being sampled.

By convention, the value of $P(u)$ is normalized to unity; that is, $P(u) \rightarrow 1$ for all possible values of $u$, as $u+\infty$ in Eq. 1. This normalization gives a specific form to $p(u)$, namely

$$
p(u)=\frac{1}{2 \pi} e^{-u^{2} / 2}
$$

This mathematical form of the frequency distribution $p(u)$ of the random variate $u$ shows a definite pattern of variability of any physical process which is described mathematically by $p(u)$. That is, by differentiation, Eq. 3 becomes

$$
\frac{1}{p}\left(\frac{d p}{d u}\right)=\frac{d \ln p}{d u}=-u
$$


In Eq. 4, the frequency $p$ (of occurrence of the value u) decreases fractionally in direct proportion to the absolute value of $\mathrm{u}$, which as defined in Eq. 2 is the standard measure of differences from the mean value $\mu$.

The brittle-fracture process is one which proceeds by binary cleavage in multiple stages. In Appendix B, this is shown more concretely. In a single binary cleavage, a brittle body is broken in two. On the average, its original size $D_{0}$ is reduced to $D_{0} / 2$. In $n$ successive stages of binary $c$ eavage, the resulting size is

$$
\mathrm{D} / \mathrm{D}_{\mathrm{O}}=(1 / 2)^{\mathrm{n}}
$$

In brittle fracture, apparently, it is $\mathrm{n}$ that is a random variable following the normal probability law, described above. If we define the mean value of $\mathrm{n}$ as $\overline{\mathrm{n}}$, then random values of $\mathrm{D}$ can be expressed as

$$
\frac{D}{D_{g}}=\left(\frac{1}{2}\right)^{n-\bar{n}}
$$

Where $D_{g}$ is the size corresponding to $\bar{n}$. Equation 6 can be expressed in logarithmic form:

$$
\ln \frac{D}{D_{g}}=-(\ln 2)(n-\bar{n})
$$

Thus, when fracture particulates have size distributions which plot as straight lines on lognormal graphical coordinates, it is the ratios of random sizes $D$ to mean size that are distributed by the normal probability law, corresponding to the normal distribution of the differences of $\mathrm{n}$ from the mean. When sizes are so distributed, they are said to be distributed lognormally [HERDAN].

For the lognormal distribution of size, values of the probability functions are calculated for the standardized variate $u$ defined as

$$
u=\frac{\log \left(D / D_{g}\right)}{\log \sigma_{g}}=\frac{\log D}{\log \sigma_{g}}-\frac{\log D_{g}}{\log \sigma_{g}}
$$

Because the ratios of sizes are distributed normally, there are important properties of the lognormal size distribution that make analysis very convenient and practical. These are concerned with particle geometry. Every individual particle of linear size $D_{i}$ has a volume $V_{i}$ and a surface area $\mathrm{S}_{i}$. If the particle is spherical,

$$
\mathrm{V}_{\mathrm{i}}=\frac{\pi}{6} \mathrm{D}_{\mathrm{i}}^{3} \text { and } \mathrm{s}_{\mathrm{i}}=\pi \mathrm{D}_{\mathrm{i}}^{2}
$$

If the particle is not spherical, the geometry is described by shape factors $a_{v}$ and $a_{s}$ : 


$$
v_{i}=a_{v} D_{i}^{3} \text { and } s_{i}=a_{s} D_{i}^{2}
$$

The fracture particulate as a whole consists of some finite number of particles $N(D)$ for all particles less than size D. This cumulative number of particles can be expressed as the sum of the number of particles $N_{i}$ of each size $D_{i}$.

$$
N(D)=\sum^{D} N_{i}
$$

The corresponding cumulative surface areas and volume $V$ of the fracture particulate can be expressed as

$$
V(D)=\sum^{N(D)} a_{v} D_{i}^{3} ; s(D)=\sum^{N(D)} a_{s} D_{i}^{2}
$$

In sieve analysis of particle size, increments of particle mass are measured for increments of size. For a given density of material, the volume increments can be calculated from the mass increments obtained by weighing. By summing these volume increments up to size $D$, the physical value of $V(D)$ is obtained for the given sample of material used in the sieve analysis. In order to apply mathematical probability, these values of $V\left(D_{j}\right)$ for sieve sizes $D_{j}$ must be normalized, $1 . e$. , converted to cumulative fractions of mass and of volume. That is, the cumulative probability function for the distribution of particulate volume $V$ (or mass $M$ ), according to size $D$, is $P_{V}(D)$, and

$$
P_{v}(D)=\frac{V(D)}{V_{n}}=\frac{M(D)}{M_{n}}
$$

where $V_{n}$ is the normalization volume. Typically the value of $V_{n}$ is the total volume $V_{0}$ of the original specimen impacted or it is the volume (or mass) of all particles up to some large size (say, all particles passing through an $8-\mathrm{mm}$ sieve opening).

Mathematical analysis is now applied by using the standardized variate $\mathrm{u}$ defined by Eq. 2 for the size distribution of the particulate volume:

$$
\mathrm{P}_{\mathrm{v}}(\mathrm{D})=\mathrm{P}(\mathrm{u})
$$

In graphical analysis of size data obtained by sieving, the value of $u$ is defined by the empirical data according to the relations of Eqs. 2, 13, and 14. This is the probability size distribution by volume, 1.e., the particulate volume distribution. The values of the lognormal parameters $\mathrm{D}_{\mathrm{g}}$ and $\sigma_{g}$ are thus determined by the empirical data. When $D_{g}$ and $\sigma_{g}$ are known, the values of $P_{v}(D)$ can be calculated or graphed for any size $D$ ?not just those in the range measured by sieve size). That is, values of u are calculated for a given $D$ and values of $P(u)$ are found from mathematical tables or from computer programs. Mathematically, $u(P)$ is the inverse probability function corresponding to $\mathrm{P}(\mathrm{u})$. 
It is a mathematical property of the lognormal size distribution that the distribution by size of the surface areas of the particles and the distribution of the number of particles (according to size) can also be found in terms of the parameters $D_{g}$ and $\sigma_{g}$ derived from the volume distribution [HERDAN]. That is, for the volume distribution $P_{v}\left(D, D_{g}, \sigma_{g}\right), D_{g}$ is the size corresponding to volume median (or mass median) of the distribution. The surface-area median size is $D_{g s}$ and the number median size is $D_{g n}$. These are related to $\mathrm{D}_{\mathrm{g}}$ and $\sigma_{\mathrm{g}}$ as

$$
D_{g s}=D_{g} \sigma_{g}^{-1 n} \sigma_{g} ; D_{g n}=D_{g} \sigma_{g}^{-3} \ln \sigma_{g}
$$

The surface-area distribution and the particle-number distribution can be plotted by locating the calculated values of $D_{g s}$ and $D_{g n}$ on the graph and plotting a straight line with the same slope as the $\mathrm{P}_{\mathrm{v}}(\mathrm{D})$ line. (This is because the slope of all three distributions is determined by the value of $\sigma_{\mathrm{g}}$ alone. In fact, the slope is $\left(\log \sigma_{g}\right)^{-1}$. The $\log ($ base 10$)$ is used here because $\log \mathrm{D}$ is the graphical coordinate; otherwise $\ln$ (base e) is used.)

Alternatively, each of the three distributions can be plotted from a pair of calculated points. The median size has already been calculated above. One point of practical significance is the size which corresponds to $98 \%$ of the cumulative probability. If this size is specified as $D_{98 v}, D_{98 s}$, and D98n for the volume, surface, and number distributions, then

$$
\begin{aligned}
& D_{98 v}=D_{g} \sigma_{g}^{2} \\
& D_{98 s}=D_{g} \sigma_{g}^{2-1 n} \sigma_{g} \\
& D_{98 n}=D_{g} \sigma_{g}^{2-3} \ln \sigma_{g}
\end{aligned}
$$

Typically, values of $\mathrm{D}_{\mathrm{g}}$ and $\sigma_{\mathrm{g}}$ are determined by $\mathrm{P}_{\mathrm{v}}(\mathrm{D})$ data for a limited size range and only for upper-1imit sizes $\mathrm{D}_{\mathrm{L}} \sim \mathrm{D}_{\mathrm{g}}$. In this case, there is no actual physical representation of a complete lognormal distribution of particles (i.e., for $\mathrm{P}_{\mathrm{V}}=1$ ), and the normalization volume (or mass) used in calculating cumulative volume (or mass) fractions is somewhat arbitrary. The values of $\mathrm{D}_{\mathrm{g}}$ and $\sigma_{\mathrm{g}}$ will depend on the normalization volume used. This does not affect practical uses of them as statistical parameters.

Another lognormal property concerns the ratios of the normalization factors $\left(V_{n}, S_{n}, N_{n}\right)$ for the three distributions discussed above $\left(P_{v}, P_{s}, P_{n}\right)$ and the shape factors $\left(a_{v}, a_{s}\right)$ defined in Eq. 12. That is,

$$
\begin{aligned}
& \mathrm{V}(\mathrm{D})=\mathrm{P}_{\mathrm{v}}(D) \mathrm{V}_{\mathrm{n}}=\mathrm{P}(\mathrm{u}) \mathrm{V}_{\mathrm{n}} \\
& \mathrm{S}(\mathrm{D})=\mathrm{P}_{\mathrm{s}}(\text { D }) \mathrm{S}_{\mathrm{n}}=\mathrm{P}\left(\mathrm{u}+1 \mathrm{n} \sigma_{\mathrm{g}}\right) \mathrm{S}_{\mathrm{n}} \\
& \mathrm{N}(D)=\mathrm{P}_{\mathrm{n}}(D) \mathrm{N}_{\mathrm{n}}=\mathrm{P}\left(\mathrm{u}+31 \mathrm{n} \sigma_{\mathrm{g}}\right) \mathrm{N}_{\mathrm{n}}
\end{aligned}
$$




$$
\begin{aligned}
a_{v}\left(\frac{N_{n}}{V_{n}}\right) & =\frac{\sigma_{g}^{4.5} \ln \sigma_{g}}{D_{g}^{3}} \\
a_{s}\left(\frac{N_{n}}{S_{n}}\right) & =\frac{\sigma_{g}^{4}}{D_{g}^{3}} \ln \sigma_{g} \\
\left(\frac{a_{v}}{a_{s}}\right)\left(\frac{S_{n}}{V_{n}}\right) & =\frac{\sigma_{g}^{0.5}}{D_{g}}
\end{aligned}
$$

In Eq. 17, note the calculation of $P_{S}$ and $P_{n}$ in terms of the values of these standardized normal variates, when $u$ is defined by the volume distribution $P_{v}$. The shape factor $a_{V}$ and $a_{s}$ are mean values (constants) for the fracture particulate as a whole. The use of the normalization ratio $a_{s} / a_{v}$ is illustrated by the following relation derived from Eq. 18 for the ratio of total surface area to total volume of a lognormal particulate with an upper-limit size D.

$$
\frac{S(D)}{V(D)}=\left(\frac{a_{s}}{a_{v}}\right) \frac{P\left(u+1 n \sigma_{g}\right)}{P(u)}\left(\frac{S_{n}}{V_{n}}\right)=\left(\frac{a_{s}}{a_{v}}\right) \frac{P\left(u+1 n \sigma_{g}\right)}{P(u)}\left(\frac{\sigma_{g}^{0.5} \ln \sigma_{g}}{D_{g}}\right)
$$

An alternative form is

$$
\frac{D S(D)}{V(D)}=\frac{a_{S}}{a_{v}} \frac{P\left(u+\ln \sigma_{g}\right)}{P(u)} \sigma_{g}^{u+0.5} \text { ln } \sigma_{g}
$$

In order to show how this function behaves for various values of $u$ and $\sigma_{g}$, a parametric plot is shown in Fig. C-1. In the figure, $\alpha_{g}$ is defined as $a_{s} / a_{v}$ and a size-dependent shape factor $\alpha(D)$ is defined as

$$
\alpha(D)=\frac{D S(D)}{V(D)}
$$

A conputer program has been written to facilitate these calculations, to calculate the "best values" of the parameters $D_{g}$ and $\sigma_{g}$ by linear regression statistics, and to prepare straight-line lognormal graphs directly. The special lognormal coordinates required to linearize the probability function are based on the following linear equation, where $A=$ constant slope and $B=$ the intercept of a straight line:

$$
\mathrm{u}=\mathrm{AX}+\mathrm{B}
$$

where of course $u$ is the inverse probability function and $X=\log D$. Thus, when $u$ and $X$ are plotted as linear coordinates, the corresponding $P(u)$ and $D$ are scaled as nonlinear coordinates. This is the basis of standard lognormal graph paper.

The lognormal coordinates can also be plotted for $p(u)$, the frequency function, using the linear form of $U$ in Eq. 22. This is useful, as are histograms in general, for showing the mode (maximum frequency) of probability distributions. Single impacts do not show modes in the particle-size distribution. Nevertheless modal analysis provides assistance in analyzing complex distributions, e.g., bimodal distributions. 


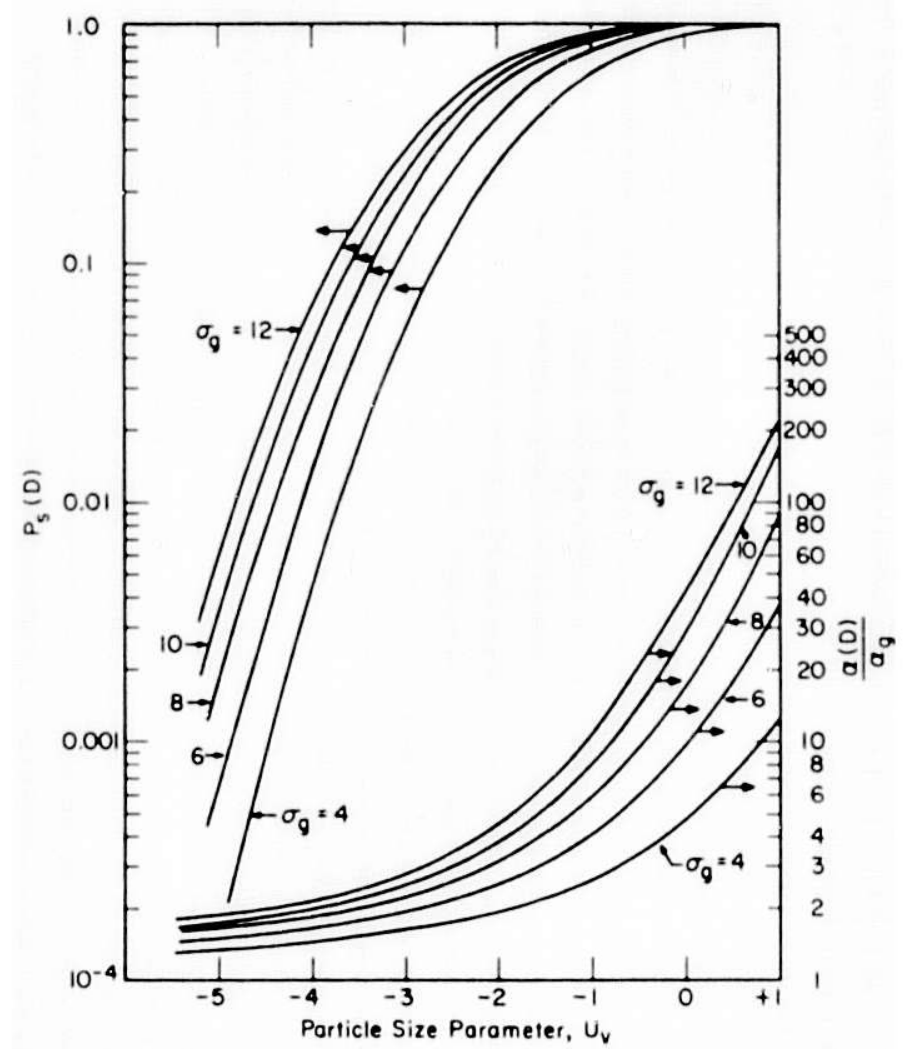

Fig. C-1. Lognormal Parameters for Fractional Surface Area $P_{S}(D)$ and Shape Factor $\alpha(D)$ as a Function of Particle-Size Parameter $u=\left(\ln D-\ln D_{g}\right) \div \ln \sigma_{g}$ 


\section{REFERENCES}

Bradt

R. C. Bradt et al., Eds., Fracture Mechanics in Ceramics, Vol. 1,

Plenum Press, New York (1973).

Doremus

R. H. Doremus, Glass Science, John Wiley and Sons, New York (1973).

Epstein

B. Epstein, The Mathematical Description of Certain Breakage Mechanisms Leading to the Logarithmic-Normal Distribution, J. Frankiln Institute V. 294 , p. 471 (1947).

Evans, A.

A. G. Evans, Fracture Mechanics Determinations, p. 17 in [BRADT]

Evans, I.

I. Evans and C. D. Pomeroy, The Strength of Coal in Uniaxial Compression, Mechanical Properties of Non-metallic Brittle Materials, W. H. Walton, Ed., Butterworths Scientific Publications, London (1958).

Hasselman

D. P. Hasselman et al., The Griffith Criterion and the Reversible and Irreversible Fracture of Brittle Materials, p. 749 in [BRADT].

Herdan

G. Herdan, Small Particle Statistics, 2nd Ed., Academic Press, New York (1960).

Hilliard

J. E. Hilliard, Metal Progress, 85(5), 99 (1964).

Lange

F. F. Lange, Origin and Use of Fracture Mechanics, p. 3 in [BRADT].

Langhaar

H. L. Langhaar, Dimensional Analysis and the Theory of Models, John

Wiley and Sons, Inc., New York (1961).

Marion

R. H. Marion and J. K. Johnstone, A Parametric Study of the Diametrical Compression Test for Ceramics, Sandia Laboratories Report SAND-75-0347 (1975).

Marscha11

C. W. Marschall and A. Rudnick, Conventional Strength Testing of

Materials, p. 69 in [BRADT]. 
Mecham-1979

W. J. Mecham, L. J. Jardine, and M. J. Steindler, "The Effect of Impact Energy in Solid-Waste Composites of Brittle and Ductile Materials," Proceedings of an International Symposium on Ceramics in Nuclear Waste Management, April 30-May 2, 1979, Cincinnati, Oh1o, CONF-790420, Technical Information Center, U.S. Department of Energy (1979), p. 327.

Mecham-1980

W. J. Mecham, L. J. Jardine, and M. J. Steindler, Characterization of Impact Fracture of Brittle Solid-Waste Forms, Scientific Basis for Nuclear Waste Management, Vol. 2, C. J. M. Northrup, Ed., Plenum Press, NY (1980), p. 307.

Piret -1950

J. W. Axelson and E. L. Piret, The Crushing of Single Particles of

Crystalline Quartz, Ind. Eng. Chem. 42, 665 (1950).

Piret -1961

W. J. Kenny and E. L. Piret, Slow Compression Crushing of Single

Particles of Glass, AIChE J. 7, 199 (1961).

Piret -1962

R. A. Zeleny and E. L. Piret, Description of Energy in Single-Particle Crushing, Ind. Eng. Chem. Process Des. Dev. 1, 34-41 (1962).

PNL-1975

T. H. Smith and W. A. Ross, Impact Testing of Vitreous Simulated HighLevel Waste in Canisters, Battelle Pacific Northwest Laboratory Report BNWL-1903 (1975).

PNL-1977

J. L. McElroy, Quarterly Progress Report Research and Development Activities Waste Fixation Program. October-December 1976, Pacific Northwest Laboratory Report PNL-2264 (1977).

PNL-1979A

J. M. Rusin et al., Multibarrier Waste Forms. Part II. Characterization, Pacific Northwest Laboratory Report PNL-2268-2 (1979).

PNL-1979B

C. C. Chapman et al., Vitrification of Hanford Wastes in a Joule-Heated Ceramic Melter and Evaluation, Pacific Northwest Laboratory Report PNL-2904 (1979).

PNL-1979C

L. R. Bunne11, Tests for Determining Impact Resistance and Strength of Glass For Nuclear Waste Disposal, Pacific Northwest Laboratory Report PNL-2954 (1979). 
PNL-1979D

W. A. Ross and J. E. Mendel, 1978 Annual Report on the Development and Characterization of Solidified Forms for High-Level Wastes, Pacific Northwest Laboratory Report PNL-3060 (1979)

Shappert

L. B Shappert et al., Cask Designers' Guide, Oak Ridge National Laboratory Report ORNL- NSIC-68 (1970).

SRL-1976

R. M. Wallace and J. A. Kelley, An Impact Test for Sol1d Waste Forms, Savannah River Laboratory Report, DP-1400 (1976). 